\title{
iRepositório - Repositório Interativo \\ de Conteúdos Digitais para cursos baseados na Internet
}

\author{
Mauricio Garcia Franco do Nascimento
}

\author{
DisSERTAÇÃO APRESENTADA \\ $\mathrm{AO}$ \\ Instituto DE MATEMÁticA E EstatísticA \\ DA \\ Universidade DE SÃo Paulo \\ PARA \\ OBTENÇÃO DO TÍTULO \\ $\mathrm{DE}$ \\ Mestre em CiÊnCIAS \\ Programa: Ciências da Computação \\ Orientador: Prof. Dr. Leônidas de Oliveira Brandão
}

São Paulo, maio de 2014 


\section{iRepositório - Repositório Interativo de Conteúdos Digitais para cursos baseados na Internet}

Esta versão da dissertação contém as correções e alterações sugeridas pela Comissão Julgadora durante a defesa da versão original do trabalho, realizada em 21/05/2014. Uma cópia da versão original está disponível no Instituto de Matemática e Estatística da Universidade de São Paulo.

Comissão Julgadora:

- Prof. Dr. Leônidas de Oliveira Brandão (Presidente) - IME-USP

- Prof. Dr. Flávio Soares Corrêa da Silva - IME-USP

- Prof ${ }^{a}$. Dr ${ }^{\mathrm{a}}$. Juliana Cristina Braga - UFABC 


\section{Agradecimentos}

Ao meu orientador Prof. Leônidas Brandão e a Profa. Anarosa, pela atenção, apoio constante e incondicional prestado durante todo o período do meu curso de mestrado.

Aos meus pais Virgílio e Gislene, sempre presentes. São certamente meus grandes incentivadores e inspiradores para esta minha empreitada.

A minha esposa Flávia, que confirmou durante todos estes meses a sua enorme paciência, carinho e compreensão comigo, durante todas essas noites e fins de semana da minha ausência. Devo muito a ela por este trabalho! Aos meus filhos Vinícius e Caroline, que coincidentemente vieram a marcar, respectivamente com as suas vindas, o início e a conclusão deste projeto.

Aos amigos do grupo de pesquisa LInE por todo o auxílio prestado, sugestões e críticas ao meu trabalho e com pensamento positivo para sua conclusão. Aos demais colegas que conheci e troquei experiências durante o cumprimento dos créditos das disciplinas ou ainda os que mantive contato de maneira mais informal, na sala do cafezinho ou durante o horário das refeições.

A todas as demais pessoas que não citei explicitamente, que direta ou indiretamente contribuíram para o desenvolvimento e conclusão deste projeto. Muito obrigado a todos! 


\section{Resumo}

NASCIMENTO, M. G. F. iRepositório - Repositório Interativo de Conteúdos Digitais para cursos baseados na Internet. 100 f. Dissertação - Instituto de Matemática e Estatística, Universidade de São Paulo, São Paulo, 2014.

A crescente demanda por cursos baseados na World Wide Web (Web) tem imposto uma série de desafios para a área da Tecnologia da Informação e da Comunicação (TIC), em particular quando se considera a Educação apoiada pela Web. Uma das necessidades emergentes da Educação via Web está relacionada com o uso de Objetos de Aprendizagem (OA) dentro de Sistemas Gerenciadores de Curso (SGC). Além de considerar a produção de OA com "qualidade", deve-se providenciar seu armazenamento e disseminação de modo eficaz. Entretanto, algumas dificuldades tem sido reportadas por professores envolvidos com cursos pela Web, tais como: o "custo elevado" para a autoria do OA; a falta de ferramentas para o compartilhamento desses materiais; e experiências práticas negativas no reúso desses conteúdos em um SGC. Uma primeira proposta para mitigar esses problemas tem sido o desenvolvimento de ferramentas de Repositório de Objetos de Aprendizagem (ROA), visando principalmente facilitar a disseminação dos OA. Apesar do progresso já alcançado, ainda existem várias barreiras para a sua adoção pelos professores, como falta de integração simples entre o SGC e o ROA. Em geral as integrações atuais mostram-se difíceis para um usuário típico. Neste cenário, o objetivo deste projeto é apresentar um ROA inovador, o Repositório Interativo de Conteúdo Digital - iRepositório, cujo modelo prevê uma integração simplificada com um particular SGC e ainda oferece vários recursos para melhorar os processos de ensino e de aprendizagem, como o registro da eficácia educacional do OA. Como contribuição prática os fundamentos do iRepositório foram implementados para um SGC específico, o Moodle. Além de compartilhar OA entre cursos e usuários, ele provê recursos a outro componente do Moodle, o Tarefa Interativa - iTarefa, para armazenamento, classificação e busca de OA ou ainda facilidades para a manipulação dos Módulos de Aprendizagem Interativa (iMA).

Palavras-chave: Repositório de Objetos de Aprendizagem, Sistemas Gerenciadores de Repositórios, OER Commons, iTarefa, iMA, repositório para o Moodle, federação de repositórios, recomendação, reputação, autoria, educação, aprendizagem. 


\section{Abstract}

NASCIMENTO, M. G. F. iRepository - Interactive Repository of Digital Contents for Internet based courses. 100 f. Dissertação - Instituto de Matemática e Estatística, Universidade de São Paulo, São Paulo, 2014.

The increasing demand for World Wide Web (Web) based courses has imposed some challenges in Information and Communications Technology (ICT) field, in particular when considering the education supported by the Web. One of the emerging needs of education supported by the Web is related to the Learning Objects (LO) usage inside Learning Management Systems (LMS). Besides production of "good quality" LO, it must be provided efficient methods concerning their storage and dissemination. However, some difficulties have been reported by teachers of Web based courses: "expensive costs" for LO authoring; lack of tools for sharing these materials; and negative practical experiences for reusing them in an LMS. Some proposals to mitigate these problems have been the development of Learning Object Repository (LOR) tools, mainly in order to facilitate the dissemination of LO. Despite the progress already achieved, there are still several barriers for their adoption by teachers such as lack of easy integration between LMS environment and LOR. In general, current integrations are not simple for typical users. In this context, the target of this project is to presents an innovative LOR, the Interactive Repository of Digital Contents - iRepository. Its model provides seamless integration with a particular LMS and offers several resources to help teaching and learning processes, such as registry of LO educational effectiveness. As a practical contribution, the fundamentals of iRepository model were implemented for an specific LMS, the Moodle system. Besides promoting LO sharing among courses and users, it provides resources to other Moodle component, the Interactive Assignment - iAssign, for storage, classification e searching of LO, or even ease management of Interactive Learning Module (iLM).

Keywords: Learning Object Repository, Repository Management System, OER Commons, iAssign, iLM, Moodle repository, repository federation, recommendation, reputation, authorship, education, learning. 


\section{Sumário}

$\begin{array}{ll}\text { Lista de Abreviaturas } & \text { ix }\end{array}$

Lista de Figuras $\quad$ xi

Lista de Tabelas $\quad$ xiii

1 Introdução $\quad 1$

1.1 Justificativas . . . . . . . . . . . . . . . . . . . . . . . . 2

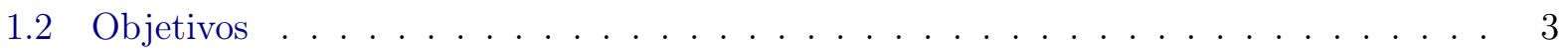

1.3 Principais contribuições . . . . . . . . . . . . . . . . . . . . 3

1.4 Organização do trabalho . . . . . . . . . . . . . . . . . . . 3

2 Fundamentação $\quad 5$

2.1 Objetos de Aprendizagem . . . . . . . . . . . . . . . . . . . . . . 5

2.2 Sistemas Gerenciadores de Curso . . . . . . . . . . . . . . . . . . . . 8

2.2 .1 O SGC Moodle . . . . . . . . . . . . . . . . . . . . . . . 9

2.3 Repositórios de Objetos de Aprendizagem . . . . . . . . . . . . . . . . . . . . 10

2.4 Sistemas Gerenciadores de Repositórios . . . . . . . . . . . . . . . . . . . . . . 12

2.5 O LInE e seus principais produtos . . . . . . . . . . . . . . . . . . . . . 13

2.5.1 Módulos de Aprendizagem Interativa . . . . . . . . . . . . . . . . . . . 14

2.5.2 Arcabouço para os $i M A \ldots \ldots \ldots \ldots \ldots \ldots$

2.5.3 Componente de tarefa interativa para o SGC Moodle . . . . . . . . . . . . 15

2.5.4 Prova de conceito de um repositório para OA . . . . . . . . . . . . 17

3 Revisão Bibliográfica dos Sistemas Gerenciadores de Repositórios $\quad 19$

3.1 Busca por repositórios públicos a partir de indexadores . . . . . . . . . . . . . 20

3.2 Análise dos repositórios candidatos . . . . . . . . . . . . . . . . . 23

3.3 Quantificação das citações dos repositórios . . . . . . . . . . . . . . . . . . . . . . . . . . . . . . . . . . . . . . . . . .

3.4 Análise dos resultados obtidos . . . . . . . . . . . . . . . . . . . . 27

4 Proposta conceitual do iRepositório $\quad 31$

4.1 Representação interna de um OA . . . . . . . . . . . . . . . . . . . . 31

4.1 .1 Registro único . . . . . . . . . . . . . . . . . . . . 31

4.1 .2 Propriedades internas . . . . . . . . . . . . . . . . . . 32

4.1 .3 Metadados . . . . . . . . . . . . . . . . . . . . . . 34

4.1 .4 Apontadores . . . . . . . . . . . . . . . . . . . 34 
4.1 .5 Trilhas de auditoria . . . . . . . . . . . . . . . . 36

4.1.6 Arquivos e referências externas . . . . . . . . . . . . . . . . 36

4.2 Coleta e armazenamento de dados históricos sobre a utilização do OA . . . . . . . . 37

4.3 Classificação e busca de materiais digitais . . . . . . . . . . . . . . . 38

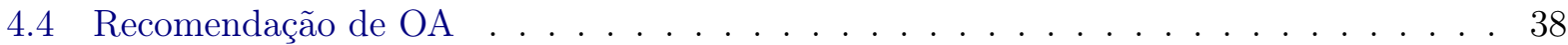

4.5 Reputação de OA e de autores de conteúdo . . . . . . . . . . . . . . . . 39

4.6 Não-duplicidade de arquivos e de OA . . . . . . . . . . . . . . . . . . . . . 39

4.7 Importação de instâncias de módulos do curso do SGC . . . . . . . . . . . . . . . . 40

5 Implementação do iRepositório no SGC Moodle 43

5.1 Principais características do projeto . . . . . . . . . . . . . . . . 43

5.2 Visão geral da interação com o Moodle . . . . . . . . . . . . . . . . . . . . . 46

5.3 Modelo Entidade-Relacionamento do banco de dados . . . . . . . . . . . . . . . . . . 47

5.4 Casos práticos de uso do iRepositório integrado ao Moodle . . . . . . . . . . . . . . 50

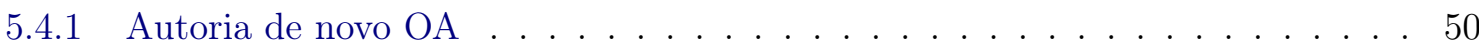

5.4 .2 Visualização dos detalhes de um OA . . . . . . . . . . . . . . . 52

5.4 .3 Busca e recuperação de OA armazenados no repositório . . . . . . . . . . . 52

5.4 .4 Armazenamento de OA do iTarefa . . . . . . . . . . . . . . . 53

5.4 .5 Recuperação de OA a partir do iTarefa . . . . . . . . . . . . . . . . 55

5.4 .6 Importação e exportação de materiais em lote . . . . . . . . . . . . . . . . 57

5.5 Resultados de experimentos . . . . . . . . . . . . . . . . . 58

5.5.1 Avaliação do iRepositório por professores do Ensino Médio . . . . . . . . . . . 58

6 Conclusões $\quad 61$

6.1 Sugestões para pesquisas futuras . . . . . . . . . . . . . . . . . . . 61

6.1 .1 Mineração de dados no repositório . . . . . . . . . . . . . . . . . . 62

6.1 .2 Teoria da Resposta ao Item . . . . . . . . . . . . . . . . . . . . . 62

6.1.3 Aperfeiçoamento dos algoritmos e sistemas de buscas dos OA . . . . . . . . 63

A Ambiente $A M P$ e possíveis configurações $\quad 65$

A.1 Pacotes AMP pré-configurados e parametrizados . . . . . . . . . . . . . 66

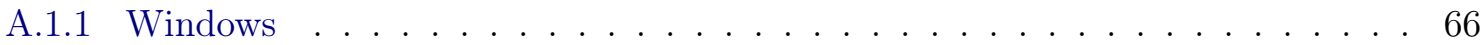

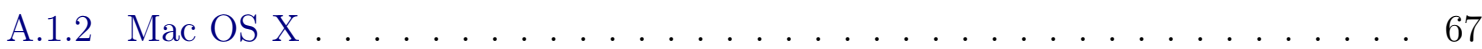

A.2 Configuração manual do AMP a partir de gerenciadores de pacotes pré-compilados . 67

A.2.1 Via utilitário $A P T$ do Linux . . . . . . . . . . . . . . . . 67

A.2.2 Via utilitário $Y U M$ do Linux . . . . . . . . . . . . . . . . . . 70

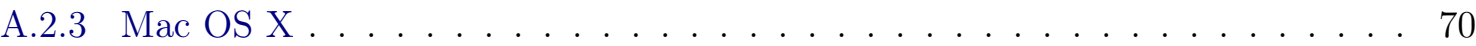

A.3 Compilação manual do PHP a partir do seu código-fonte . . . . . . . . . . . . . . . 71

B Instalação do ambiente Moodle $\quad 73$

$\begin{array}{lll}\text { C Pesquisa de avaliação do iRepositório } & 77\end{array}$

$\begin{array}{ll}\text { Referências Bibliográficas } & \mathbf{7 9}\end{array}$ 


\section{Lista de Abreviaturas}

ACM Association for Computing Machinery

ADL Advanced Distributed Learning

AMP Apache, MySQL e PHP

EaD Ensino a Distância (Distance Learning)

Enem Exame Nacional do Ensino Médio

Inep Instituto Nacional de Estudos e Pesquisas Educacionais

IEEE Institute of Electrical and Electronics Engineers

iMA Módulo de Aprendizagem Interativa

iRepositório Repositório de Conteúdos Digitais Interativos

iTarefa Tarefa Interativa

LInE Laboratório de Informática na Educação

LOM Learning Object Metadata

MEC Ministério da Educação

OA Objeto de Aprendizagem (Learning Object)

OER Open Educational Resources

OpenDOAR Directory of Open Access Repositories

RaaS Repository as a Service

ROA Repositório de Objetos de Aprendizagem (Learning Objects Repository)

ROAR Registry of Open Access Repositories

SaaS Software as a Service

SCORM Sharable Content Object Reference Model

SGC Sistema Gerenciador de Curso (Learning Management System)

SGR Sistema Gerenciador de Repositório (Repository Management System)

TIC Tecnologia da Informação e da Comunicação

(Information and Communications Technology)

TRI Teoria da Resposta ao Item (Item Response Theory) 


\section{Lista de Figuras}

2.1 O Quadrante de McGreal e os conteúdos educacionais . . . . . . . . . . . . . 6

2.2 Relação entre Contextualização e Reusabilidade de um OA . . . . . . . . . . . . . . . 7

2.3 Página principal do sítio do Moodle . . . . . . . . . . . . . . . . . . . . 9

2.4 Análise de popularidade dos nomes de alguns SGC livres . . . . . . . . . . . . . . 11

2.5 Exemplos de alguns módulos iMA . . . . . . . . . . . . . . . . . . . . . . 14

2.6 Exemplo de um iMA do tipo iGeom integrado ao iTarefa . . . . . . . . . . . . 16

2.7 Autoria de um OA no iRCD . . . . . . . . . . . . . . . . . . 18

3.1 Sítio do OpenDOAR, com destaque para o seu mecanismo de busca . . . . . . . . . 21

3.2 Sítio do ROAR, com destaque para o seu mecanismo de busca . . . . . . . . . . . . . 22

3.3 Sítios dos repositórios mais relevantes identificados na pesquisa . . . . . . . . . . . 27

3.4 Possíveis cenários para as interações do iRepositório . . . . . . . . . . . . . . . 28

4.1 A estrutura interna de um OA do iRepositório . . . . . . . . . . . . . . . 32

4.2 Representação do controle de versão de um OA do iRepositório ao longo do tempo e suas trilhas de auditoria . . . . . . . . . . . . . . . . . . 33

4.3 Diagrama de Estados de um OA do iRepositório . . . . . . . . . . . . . . . 34

4.4 O modelo de metadados IEEE LOM _ . . . . . . . . . . . . . . . . . 35

4.5 Estrutura hierárquica de OA através do uso de apontadores . . . . . . . . . . . . 35

4.6 Estrutura hierárquica de OA com múltipos sub-níveis e apontamentos . . . . . . . 36

4.7 Apontamentos de arquivos e OA idênticos por outros OA . . . . . . . . . . . . . . 40

5.1 Diagrama UML dos principais componentes colaboradores . . . . . . . . . . . . . 46

5.2 Modelo Entidade-Relacionamento do banco de dados do projeto . . . . . . . . . . . 48

5.3 Formulário para autoria de novo OA no iRepositório . . . . . . . . . . . . . 51

5.4 Visualização de detalhes de um OA do iRepositório . . . . . . . . . . . . . . . . 52

5.5 Formulário para localização de OA do iRepositório . . . . . . . . . . . . . . . . . 53

5.6 Resultado da busca de OA realizada no iRepositório . . . . . . . . . . . . . . 54

5.7 Detalhe das ações e informações associadas a um OA . . . . . . . . . . . . . . . . 54

5.8 Diagrama de Sequência UML para o armazenamento de OA e definição de Tarefa

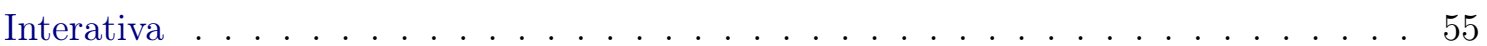

5.9 Diagrama de Sequência UML para a recuperação de OA e submissão de uma Tarefa

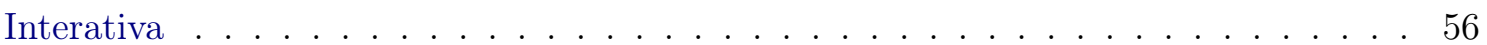

5.10 Interface para importação em lote de questões do banco para o repositório . . . . . . 57

A.1 Estrutura básica do pacote AMP e suas interações com os demais serviços . . . . . . 66 


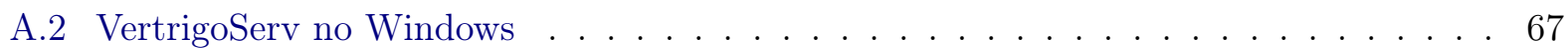

A.3 Tela inicial do navegador Web, a partir do VertrigoServ . . . . . . . . . . . . 68

A.4 Resultado parcial do comando phpinfo no servidor LAMP baseado no Ubuntu . . . . 69

A.5 Painel de administração do MySQL no Mac OS X . . . . . . . . . . . . . . 70

B.1 Assistente de instalação do Moodle . . . . . . . . . . . . . . . . . . . . . . 74

B.2 Parametrização para acesso ao banco de dados do Moodle . . . . . . . . . . . . . . 75

B.3 Avaliação das dependências do Moodle com as bibliotecas do PHP . . . . . . . . . . 75

B.4 Tela principal do ambiente Moodle recém-criado . . . . . . . . . . . . . . . 76 


\section{Lista de Tabelas}

2.1 Alguns exemplos de SGC para cursos baseados na Web . . . . . . . . . . . . . . 9

3.1 OpenDOAR: Repositórios com maior número de institutos . . . . . . . . . . . . 22

3.2 ROAR: Repositórios com maior número de institutos . . . . . . . . . . . . . . . 23

3.3 Indexadores acadêmicos na Web para quantificação dos repositórios . . . . . . . . . . 25

3.4 Quantidade de ocorrências dos termos dos repositórios buscados em cada indexador . 26

3.5 Pontuação obtida pelos repositórios analisados . . . . . . . . . . . . . . . . . 26

5.1 Principais bibliotecas do Moodle utilizadas no projeto do iRepositório. . . . . . . . . 44 


\section{Capítulo 1}

\section{Introdução}

A contínua e crescente demanda por cursos baseados na Web nos últimos anos, tanto no Brasil quanto no mundo, trouxe consigo um arranjo de novos paradigmas relacionados aos processos de Ensino e Aprendizagem e nas inter-relações entre professores e alunos. Um vasto leque de novos cenários, desafios, debates, frentes de trabalho e de pesquisas científicas tem tomado a atenção e despertado o interesse de especialistas em áreas multi-disciplinares, como as relacionadas à Educação e à Computação. O uso de computadores, aliado a ferramentas e tecnologias inerentes, pode contribuir de forma significativa para os processos de Ensino e Aprendizagem [Moran (2000)].

Em particular no Brasil, o advento da Educação a Distância (EaD) com a utilização da internet para apoio aos cursos tem recebido enfoque mais consistente desde 1996, ano no qual a oferta de cursos à distância foi regulamentada pelo Ministério da Educação (MEC) [Souza (1996)]. Segundo dados do Instituto Nacional de Estudos e Pesquisas Educacionais (Inep), no ano de 2010, os cursos de graduação presenciais tiveram um aumento de 12,5\% em suas turmas, enquanto que no mesmo período os de EaD avançaram mais de 30\% [Inep (2011)].

Uma das consequências diretas, analisada por especialistas sobre esses fatos, é que a demanda gerada para atividades relacionadas a produção, armazenamento e distribuição de conteúdos didáticos digitais também tem crescido seguindo uma proporção equivalente. A autoria e disseminação destes recursos, mais especificamente denominados por Objetos de Aprendizagem ${ }^{1}$ (OA), têm sido com frequência uma barreira considerável apontada pelos professores conteudistas para sua adoção sistemática na EaD [Fernandes e Ferreira (2011)]. Os autores ainda enumeram algumas dificuldades enfrentadas, como a tomada de decisão para a estrutura de organização de materiais digitais, a falta de um padrão consistente interoperável para o seu compartilhamento, aquisição e uso de ferramentas computacionais adequadas e formação de uma equipe multi-disciplinar que disponha de todas as competências e habilidades exigidas a esse trabalho [Barbosa et al. (2012)]. Metodologias e ferramentas também têm sido desenvolvidas com o propósito da melhoria e sistematização da produção e entrega de novos conteúdos digitais em um cenário de maior escala [Arimoto e Barbosa (2013)].

A fim de minimizar parte das dificuldades e deficiências supracitadas e pertinentes aos OA, diversos projetos têm sido apoiados por empresas, instituições e órgãos fomentadores nos últimos anos. Uma destas frentes de pesquisa está relacionada a sistemas computacionais especialistas, que possuem, dentre outras características, funções voltadas ao armazenamento, classificação, busca e compartilhamento de OA em um local centralizado e organizado, como num "armazém de materiais digitais". Tais sistemas foram nomeados como Repositórios de Objetos de Aprendizagem (ROA). Dentre centenas de opções atualmente disponíveis, poderiam ser citados como exemplo: Multimedia Educational Resource for Learning and Online Teaching (MERLOT), ARIADNE, Campus Alberta Repository of Educational Objects (CAREO), Edna, Portal do Professor, Banco Internacional de Objetos Educacionais, OER Commons e Repositório Científico de Acesso Aberto de Portugal (RCAAP).

\footnotetext{
${ }^{1}$ Definições e conceitos mais detalhados sobre os Objetos de Aprendizagem são apresentados mais adiante, no Capítulo 2 (Fundamentação) desta dissertação.
} 
Apesar do notável avanço alcançado, muitos fatores ainda inibem sua adoção em larga escala, principalmente pelos seus usuários-chave - os professores e tutores - que lecionam e compõem seus materiais em cursos apoiados na Web. Algumas deficiências são frequentemente reportadas, como a falta de integração com os Sistemas Gerenciadores de Curso $^{2}$ (SGC), alta curva de aprendizado exigida para os professores e dificuldade na definição de dependências lógicas e empacotamento de materiais digitais relacionados [Rosa e Brandão (2011)]. Além disso, a forma como os conteúdos são apresentados aos alunos nestes repositórios remetem a um padrão de aulas expositivas [Sartori et al. (2009)].

\section{$1.1 \quad$ Justificativas}

Conforme abordado, a área de aplicação da EaD tem crescido de forma incontestável no Brasil e no mundo. Apesar dos esforços já superados, essa ainda é carente de ferramentas computacionais que possibilitem um uso eficiente e racional para promoção de bons OA e cursos apoiados na Web. Além disso, a contratação de recursos humanos para apoio neste tipo de projeto é uma tarefa relativamente complexa, por abranger, na mesma equipe de trabalho, diferentes competências, habilidades, responsabilidades e exigências de treinamento e qualificação adequada aos mesmos [Eliasquevici et al. (2008)].

A literatura é rica no estudo exploratório de sistemas utilizados para ROA [Neven e Duval (2002); Sartori et al. (2009)], arcabouços para o seu desenvolvimento [Blat et al. (2006); Rocha et al. (2011)], além de análises qualitativas e quantitativas [Ochoa e Duval (2009)] a respeito da sua utilização e crescimento ao longo dos anos em termos do número de OA armazenados.

Apesar disso, seu uso ainda é de certa forma limitado segundo a visão dos professores. Dentro os fatores apontados, pode-se citar: $i$ ) aspectos técnicos (dificuldade do usuário para a sua operacionalização); ii) falta (ou insuficiência) de documentação técnica e operacional para a sua utilização efetiva; $i i i$ ) carência de funcionalidades do ambiente; $i v$ ) exigência por parte do fornecedor do ROA para aquisição de licença comercial de uso; $v$ ) a não possibilidade, tanto de personalização quanto para o acréscimo de novas funcionalidades devido ao seu código-fonte ser fechado; vi) exigência de equipe de profissionais especializados na área de computação para a sua instalação e parametrização e vii) falta de infra-estrutura (dentro do contexto da linguagem de programação, por exemplo) em empresas de hospedagens de sistemas na Web, principalmente em contratos com planos modestos, para a operacionalização do ROA.

Além das carências citadas, pode-se ainda destacar a falta de integração com os sistemas interrelacionados, como é um caso típico o SGC Moodle. Segundo Alves e Gomes (2007), sua base de usuários (incluindo autores conteudistas e professores) atinge centenas de milhares de participantes, sendo que o Brasil ocupa atualmente a terceira posição de sítios Moodle registrados [Moodle (2012)]. Ele ainda conta com diversos componentes acopláveis (plugins) que podem ser descarregados livremente a partir do seu sítio e instalados no seu ambiente. Apesar destas evidências, não existe um ROA disponível atualmente que seja totalmente compatível com o Moodle.

Como uma das consequências da integração com esse SGC, ele passará a dispor de interfaces ao professor para manipulação dos OA (como busca, classificação e armazenamento, por exemplo), através de componentes compatíveis, como é caso da Tarefa Interativa (iTarefa), que permite a inserção de Módulos de Aprendizagem Interativa (iMA) ao SGC [Rodrigues (2011)].

\footnotetext{
${ }^{2}$ A literatura também referencia esta classe de sistema com algumas outras nomenclaturas, como por exemplo: "Ambientes Virtuais de Aprendizagem" (AVA), "Ambiente Colaborativo", "Sistemas de Gerenciamento da Aprendizagem" (SGA), dentre outras variações [Haguenauer et al. (2009)]. Este trabalho considerou as definições destes autores para adotar o termo "SGC" como sendo o mais adequado para referenciar sistemas que promovam e facilitem o ensino-aprendizado, apoiado por ferramentas e ambientes computacionais. Geralmente os SGC oferecem personalização de ambiente e possuem contas individuais para os seus usuários - dentre eles alunos, professores e coordenadores.
} 


\subsection{Objetivos}

De acordo com o panorama apresentado da $\mathrm{EaD}$, as relações evidenciadas entre os OA e repositórios e suas limitações atuais, pode-se afirmar que o objetivo principal deste trabalho é a definição de um modelo arquitetural para um ROA, denominado por Repositório de Conteúdos Digitais Interativos (iRepositório).

Como objetivos específicos, ele contemplará as principais funcionalidades consolidadas de destaque nesta classe de sistemas, concomitantemente a promoção de características inovadoras, como: i) integração ao ambiente do curso do professor, em particular ao Moodle; ii) aprimoramento da sua experiência de uso pelos autores de conteúdo; iii) recursos para a coleta e disseminação de informações relevantes aos seus OA armazenados, relativos às suas qualidades e reputações e $i v$ ) registro de todas as avaliações realizadas e submetidas pelos alunos deste ambiente para cada OA das categorias de tarefas, exercícios ou equivalentes, que solicitem alguma forma de retorno das atividades executadas e submetidas pelos alunos.

\subsection{Principais contribuições}

As principais contribuições deste trabalho são o desenvolvimento da arquitetura geral do $i R e$ positório, bem como a entrega da implementação funcional de um protótipo, operável a partir do Moodle. Após a conclusão deste projeto, ele será disponibilizado gratuitamente a comunidade, sob a licença $G N U G P L$, a partir do sítio oficial daquele SGC. Por ter código-fonte aberto, ele poderá ser futuramente adaptado e aperfeiçoado de forma livre, segundo as necessidades particulares e contextos dos seus usuários e suas instituições apoiadoras.

O iRepositório beneficiará o professor na definição dos materiais do seu curso baseado na Web, bem como no aprimoramento dos seus OA, que poderão ser avaliados pelos pares ou ainda por uma comunidade mais abrangente. Como consequência direta, os alunos também terão estímulos adicionais, ao interagirem e serem avaliados com bons instrumentos pedagógicos.

\subsection{Organização do trabalho}

Os capítulos subsequentes deste trabalho estão organizados da seguinte maneira:

- Capítulo 2 - Fundamentação - realiza uma revisão bibliográfica e descreve alguns dos principais conceitos relacionados aos OA, ROA e finalmente aos SGC. O capítulo é encerrado com a exposição do grupo de pesquisa LInE e seus trabalhos relacionados a informática voltada a Educação;

- Capítulo 3 - Revisão Bibliográfica dos Sistemas Gerenciadores de Repositórios - descreve a pesquisa para prospecção de repositórios e seus sistemas gerenciadores disponíveis atualmente na internet. Seus recursos e características são observados e utilizados como subsídios para a análise das decisões acerca da adoção de um ROA para o iRepositório, ou ainda a definição de um novo sistema que possa agregar as características mais relevantes desses;

- Capítulo 4 - Proposta conceitual do iRepositório - apresenta as principais características adotadas no modelo do iRepositório. São também citados casos práticos da sua interação com o seu meio e com classes distintas de usuários;

- Capítulo 5 - Implementação do iRepositório no SGC Moodle - descreve a implementação de um protótipo funcional para o iRepositório, com base no modelo estrutural proposto no capítulo anterior;

- Capítulo 6 - Conclusões - encerra o trabalho com suas principais conclusões. Também são descritas sugestões para futuros trabalhos relacionados ao projeto do iRepositório; 
- Apêndices

- A - Ambiente AMP e possiveis configurações - apresenta conceitualmente a infra-estrutura computacional de apoio necessária ao Moodle e ao iRepositório. Ilustra sua instalação e configuração na prática em alguns sistemas operacionais (Linux, Mac OS X e Windows) comumente empregados para o seu uso;

- B - Instalação do ambiente Moodle - relata um caso prático e geral de instalação do SGC apoiado num ambiente $A M P$ preparado no Apêndice anterior;

- C - Pesquisa de avaliação do iRepositório - descreve o questionário e as respostas concedidas pelos participantes, durante a realização de um curso prático voltado a autoria de atividades interativas no ambiente Moodle. 


\section{Capítulo 2}

\section{Fundamentação}

Este capítulo tem por objetivo apresentar os principais tópicos e conceitos de fundamento relacionados ao projeto. Estes serão referenciados com frequência no decorrer deste capítulo e nos seus subsequentes. As próximas seções tratam a respeito dos Objetos de Aprendizagem, Sistemas Gerenciadores de Curso, Repositórios de Objetos de Aprendizagem e Sistemas Gerenciadores de Repositórios de Objetos de Aprendizagem. Ele é finalizado com a apresentação do Grupo de Pesquisa LInE e uma descrição do panorama geral acerca dos seus projetos e produtos, bem como suas intersecções e relacionamentos com o iRepositório.

\subsection{Objetos de Aprendizagem}

O termo "Objetos de Aprendizagem" (OA) originou-se a partir do novo paradigma consolidado no final do século XX, para os processos e práticas do Ensino e Aprendizagem assistidos pelas Tecnologias da Informação e da Comunicação (TIC).

Como confluência de ideias, essa expressão foi referenciada na época por diferentes nomenclaturas para designar conceitos semelhantes, como por exemplo: Componentes de Software Educacional; Conteúdos de Objetos Compartilháveis (Advanced Distributed Learning - ADL) e Objetos de Conhecimento [Merrill (2000)]. McGreal (2004) ainda enumera termos adicionais como: Recurso para Aprendizado, Objetos de Informação, Objetos Educacionais e Unidades de Ensino. Para efeito de simplificação e padronização de nomenclatura, esta dissertação adota o termo "Objetos de Aprendizagem" para estas entidades, em acordância com os princípios do Institute of Electrical and Electronics Engineers (IEEE) e de Wiley (2000), a serem expostos mais adiante nesta seção.

A literatura referencia o trabalho de Gerard (1967), como o pioneiro a abordar estes conceitos ${ }^{1}$. Segundo o autor, "unidades curriculares podem ser feitas de maneira reduzida, de modo que possam ser combinadas entre si, para a criação de uma grande variedade de programas personalizados para cada estudante. Repetições não-planejadas e perda de tempo (...) deveriam ser eliminadas, além dos conteúdos serem melhor direcionados e moldados aos objetivos de cada usuário".

Em 1992, época em que nomeou o grupo de trabalho Learning Architectures, APIs and Learning Objects, Wayne Hodgins cunhou o termo OA como "uma coleção de itens de conteúdo, itens de prática e itens de avaliação, que podem ser combinados entre si, com um objetivo de ensino único". O autor conclui afirmando que os OA "são como peças de um brinquedo Lego".

A literatura voltada às definições dos OA é vasta. Em termo gerais, ele é um material educacional voltado ao ensino. Outra definição concebida num dos padrões do IEEE, que autores tomam como embasamento, afirma que um OA é "uma entidade qualquer, digital ou não-digital, que pode ser utilizada, re-utilizada ou referenciada para o ensino, educação ou treinamento assistidos pela tecnologia (...), como sistemas de treinamentos baseados em computador, ambientes interativos de

\footnotetext{
${ }^{1}$ Apesar de ser apontado por autores mais contemporâneos como sendo o primeiro a descrever estes agrupamentos de objetos, ele não os referenciou com nenhuma nomenclatura em particular utilizada atualmente, como OA, por exemplo.
} 


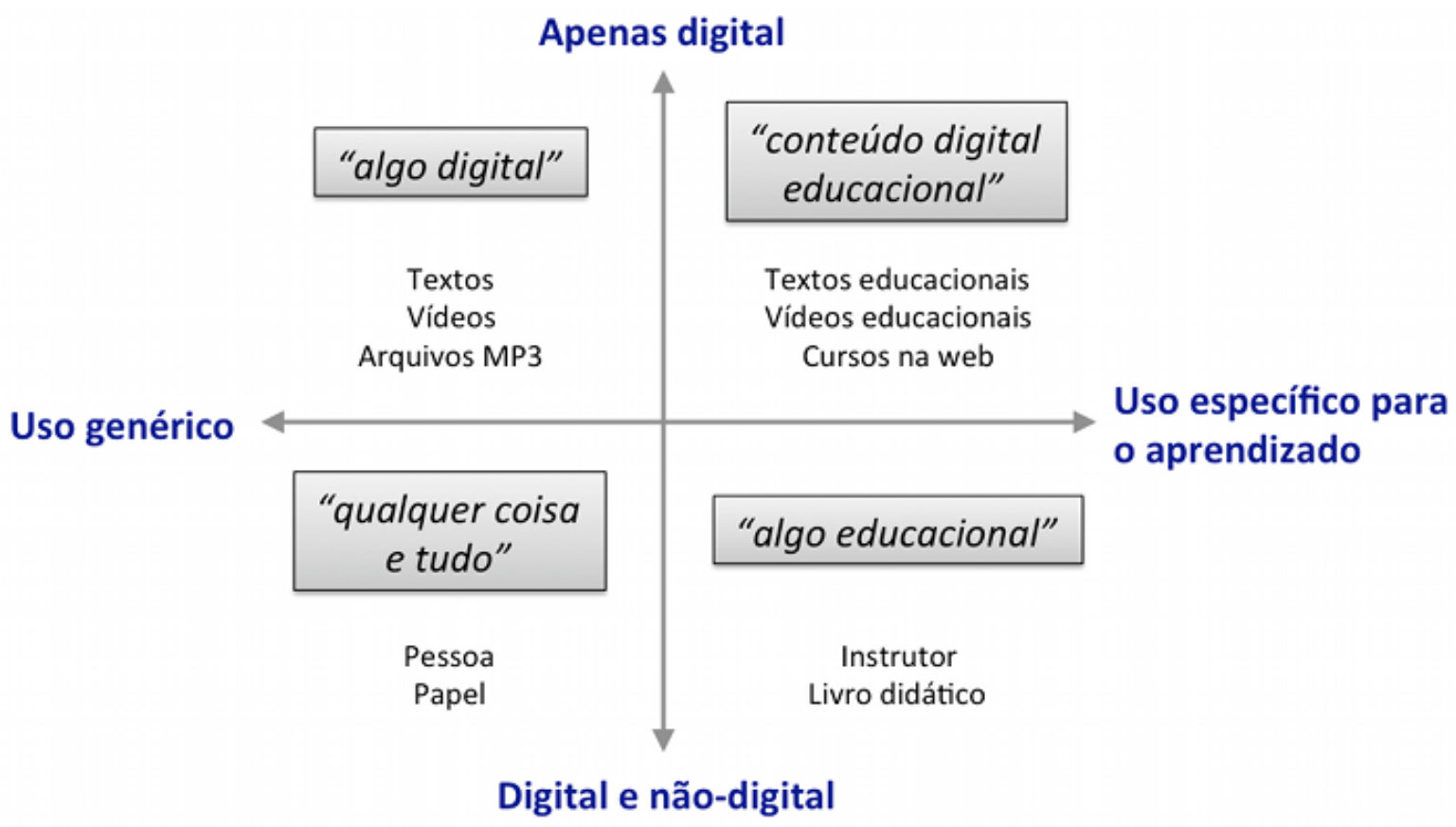

Figura 2.1: O Quadrante de McGreal e os conteúdos educacionais. Fonte: McGreal (2004)

aprendizado, sistemas inteligentes de auxílio guiados pelo computador, sistemas de EaD e ambientes colaborativos de ensino" [IEEE (2002)].

Merrill (2000) e McGreal (2004) criticam tal definição ao afirmarem ser demasiadamente genérica. O primeiro diz que "os OA podem ser tão pequenos como uma gota ou tão grandes como um oceano". Já o segundo aponta que "os OA são, a princípio, qualquer coisa e tudo". Este último propõe um quadrante para ilustrar o seu ponto de vista (Figura 2.1). Em seguida, sugere um critério para restrição dos objetos que devam ser de fato considerados como sendo de aprendizado ao concluir que "os OA são recursos digitais reutilizáveis, encapsulados em uma lição ou num conjunto destas, agrupados em unidades, módulos, cursos ou programas. Uma lição, por sua vez, é definida como um pedaço de instrução, que possui propósitos educacionais". De acordo com suas ideias, ele afirma que o quadrante superior direito da Figura 2.1 (denominado por ele como "conteúdo digital educacional") é o mais adequado para uma representação precisa dos OA.

Uma das referências mais citadas e contemporânea, é o trabalho de Wiley (2000), entitulado "Connecting learning objects to instructional design theory: a definition, a metaphor, and a taxonomy". O autor organizou e agregou as principais literaturas da época relacionadas ao tema e propôs a unificação de conceitos semelhantes ao termo "Objetos de Aprendizagem". De acordo com suas observações, "os OA são elementos de um novo tipo de instrução, baseados no paradigma orientado a objetos da computação, em que componentes (os objetos) podem ser reutilizados em diversos contextos. Os OA variam significativamente de tamanho e complexidade e podem ser compostos a partir de outros, o que garante grande flexibilidade para disposição de conteúdos pedagógicos". O autor acrescenta que, geralmente "os OA são entidades digitais e que podem, portanto, ser transmitidos pela Web de forma distribuída e acessados simultaneamente por um grande público, de uma maneira muito mais versátil em comparação à mídia tradicional, baseada em livros, documentos, video-tapes, dentre outros materiais disponibilizados em mídias físicas". Para concluir, Wiley critica a "metáfora do Lego" empregada anteriormente por Hodgins, ao afirmar que esta é demasiadamente superficial e que não representa de fato as principais características dos OA. Ele prefere denominálos por "átomos", pois segundo o autor: $i$ ) nem todo átomo pode ser combinado com outros átomos; ii) átomos precisam respeitar suas estruturas internas para serem combinados corretamente entre si e iii) é necessário treinamento prévio para a montagem de átomos.

Outros trabalhos considerados fundamentam os OA a partir de diferentes conceitos [Hodgins (2002); Polsani (2006)]. Alguns destes são enumerados a seguir: 


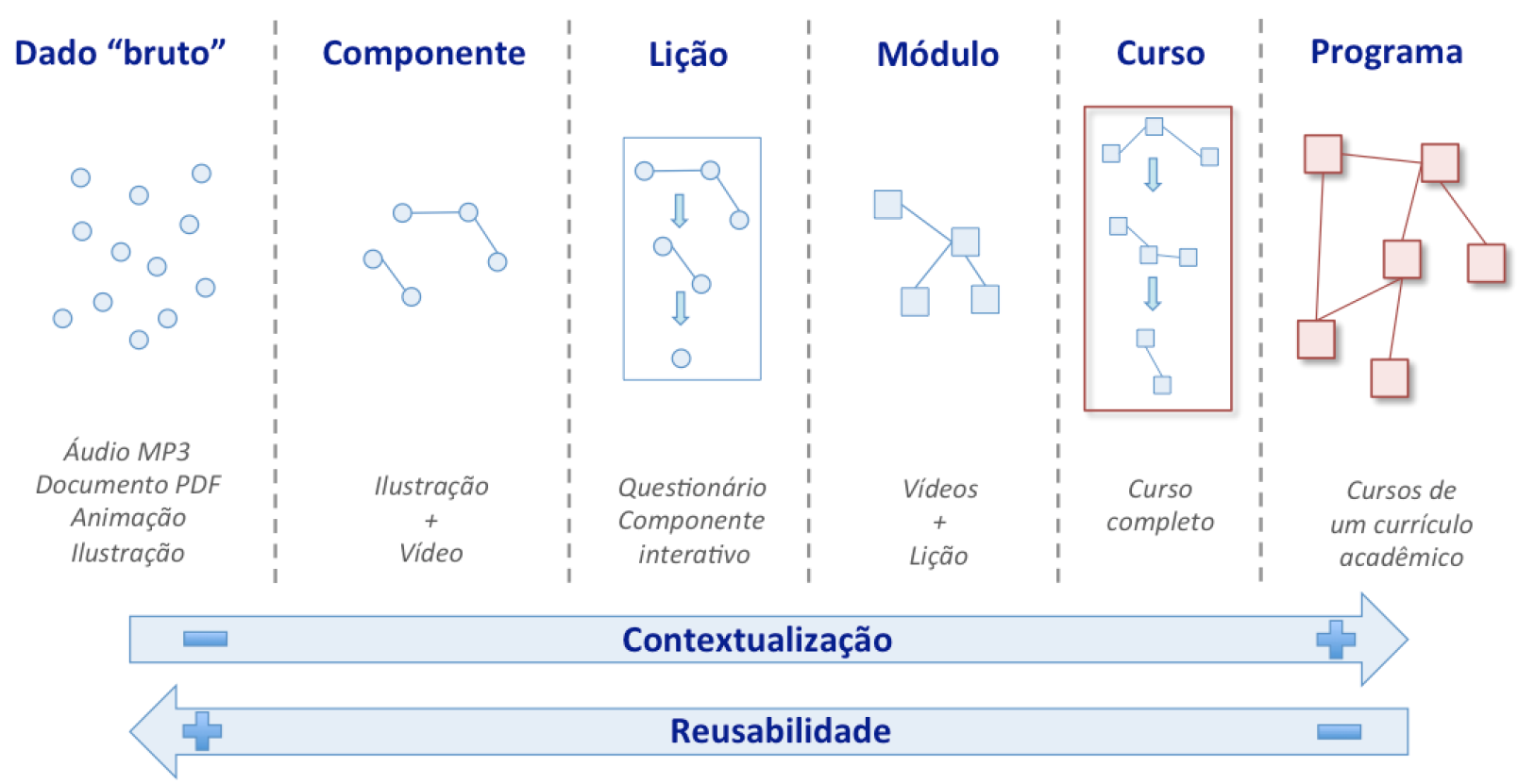

Figura 2.2: Relação entre Contextualização e Reusabilidade de um OA. Adaptado de Hodgins (2002); McGreal (2004)

- Aprendizado - possuir uma intenção de aprendizado, baseada numa forma e associação coerente com outros objetos relacionados;

- Reusabilidade - ser uma unidade independente de material educacional, adaptável o suficiente para ser reutilizada em diferentes contextos e por pessoas distintas;

- Composição - capacidade em se criar arranjos ordenados de materiais digitais pertinentes para criação de um objeto único, íntegro e coerente. A partir da composição, pode-se partir de materiais triviais e individuais, como um arquivo de áudio, um texto ou capítulo de livro, para a autoria de materiais mais complexos, compostos a partir da associação de múltiplos objetos. Tomando-se esta prática, um OA pode ser uma tarefa de avaliação para o aluno (composta por diversos sub-componentes individuais) ou até mesmo um curso ou programa curricular completo baseado na Web;

- Granularidade - derivado a partir da palavra "grão", é relativo a capacidade de sub-divisões do OA em partículas menores que preservem as características básicas dos OA, porém num contexto mais particular e específico que o seu OA original. Este conceito é comumente empregado em comparações de "menor"ou "maior" granularidade entre OA. Em geral, OA que possuam alto grau de granularidade são desejáveis, por permitirem um certo grau de possível particionamento em OA derivados;

- Contextualização - diz respeito a estratégia de desenvolvimento de um OA, para que seja completo para atender aos requisitos de conteúdo de um curso ao qual ele deva ser inserido e que ainda assim, disponha de informações auto-suficientes e concisas para que possa ser reutilizado em outros contextos. A Figura 2.2 ilustra a relação entre este conceito e o da Reusabilidade. Ele mostra 6 lacunas hipotéticas de organização dos OA, que vão desde "Dado bruto" até "Programa". OA das lacunas mais a esquerda estão em estados mais "brutos", menos contextualizados a um domínio específico, geralmente com baixa granularidade (são indivisíveis), porém com potencial de reusabilidade maior. Os voltados a direita tendem a ser mais sofisticados, devido a composição de coleções de elementos semelhantes ou inferires à sua lacuna. A medida que estes últimos são definidos e criados, mais contextualizados a um domínio eles serão, porém como consequência direta, sua reutilização em áreas distintas do conhecimento será reduzida; 
- Trabalho colaborativo - as competências e habilidades necessárias para criação de um OA geralmente envolvem áreas multi-disciplinas, como Programação (modelagem da arquitetura do componente e lógica de programação); Design gráfico (apresentação visual das interfaces do componente) e especialidades da área na qual o OA deva ser utilizado. Geralmente diversos profissionais precisam trabalhar de maneira colaborativa e integrada com a finalidade da autoria de $\mathrm{OA}$;

- Metadados - são descritores (também denominados por "dados sobre os dados") que relatam, dentre as diversas informações pertinentes aos OA, o nome, autor, data e local de criação, instituição fomentadora e direitos autorais. São utilizados para facilitar a classificação e busca destes materiais. Dentre diversos padrões públicos de descrição, destacam-se o Learning Object Metadata (LOM) [IEEE (2002)], Dublin Core [DCMI (2012)] e IMS Global Metadata [IMS (2006)].

\subsection{Sistemas Gerenciadores de Curso}

Os SGC facilitam os processos de Ensino e Aprendizagem e geralmente são disponibilizados aos seus usuários via Web. Em termos gerais, são flexíveis de modo que promovam um meio apropriado para diferentes modelos pedagógicos de cursos. Estes podem variar desde os totalmente voltados ao EaD, semi-presenciais ${ }^{2}$ e até os de apoio para aula presencial.

Um SGC típico oferece um ambiente colaborativo entre seus usuários (relações entre professores, tutores e alunos), de modo que esses possam interagir entre si para troca de informações, através de ferramentas específicas voltadas para estas práticas, como fóruns, salas de bate-papo, envio de mensagens em correio interno e vídeo-conferência.

Estes sistemas propiciam aos seus tutores um ambiente adequado para manutenção dos seus cursos baseados na Web, através de ferramentas interativas para autoria de conteúdo educacional, como editores de texto HTML, repositório e apontador de materiais digitais, apontadores para sítios externos pertinentes ao assunto da aula, além da representação de outros tipos de OA. Além disso, também contam com tarefas interativas voltadas aos alunos, como questionários, enquetes e avaliações.

A oferta atual de SGC é alta e eles podem ser classificados de acordo com critérios como: $i$ ) modelo de licenciamento: gratuitos ou licenciados comercialmente e ii) disponibilidade do códigofonte: abertos ou fechados. Com poucas exceções, SGC livres são gratuitos e possuem código-fonte aberto, descarregável a partir do seu sítio correspondente. Já os comerciais possuem um modelo de licenciamento comercial e pago, mantêm seu código-fonte fechado ou então disponibilizam seus aplicativos na forma de serviços $\mathrm{Web}^{3}$ a partir dos seus sítios. A Tabela 2.1 contém alguns SGC disponíveis atualmente para criação de cursos baseados na Web, agrupados de acordo com o seu modelo de licenciamento.

Além dos critérios supracitados, outros poderiam ser utilizados para classificação dos SGC, como a aderência ao negócio e aos modelos educacionais e pedagógicos, base de usuários, quantidade de participantes ativos nas comunidades envolvidas e os seus custos de implantação e manutenção (quando houver).

Os SGC têm um papel fundamental no presente projeto do iRepositório. São eles quem viabilizarão a comunicação entre as partes envolvidas (repositório e SGC) para permitir a apresentação, manipulação, empacotamento, busca, etc dos OA armazenados.

A escolha por um SGC ideal como base para o protótipo deste trabalho não é, a princípio, uma tarefa trivial, considerando-se as alternativas disponíveis atualmente e aos diversos critérios supracitados envolvidos. Pesquisa realizada pela IMS Global Learning Consortium confirma a falta de uma opinião unânime a respeito de um SGC mais adequado, pois "expectativas e cenários distintos de

\footnotetext{
${ }^{2}$ Também denominamos por "cursos híbridos", por fracionarem sua carga horária entre o EaD e o presencial.

${ }^{3}$ Também conhecidos como Software as a Service (SaaS), ou Aplicativo sob-demanda. É um modelo de distribuição onde tanto o sistema quanto os seus dados estão dispostos "na nuvem". Normalmente são acessados pelos seus usuários através de navegadores Web, apontados para o sítio do seu fornecedor ou em alguma localidade sob o domínio deste.
} 


\begin{tabular}{ll|ll}
\hline \multicolumn{2}{c}{ SGC gratuitos } & SGC comerciais \\
\hline Amadeus & http://migre.me/iWiD3 & ACS Learning & http://www.acslearningservices.com \\
ATutor & http://atutor.ca & BlackBoard & http://www.blackboard.com \\
Claroline & http://claroline.net & eCollege & $\mathrm{http://ecollege.com}$ \\
Moodle & http://moodle.org & JoomlaLMS & http://joomlalms.com \\
ROODA & https://ead.ufrgs.br/rooda & iLearning & http://ilearning.oracle.com \\
Sakai & http://sakaiproject.org & SharePointLMS & $\mathrm{http://sharepointlms.com}$ \\
SAW & http://milanesa.ime.usp.br/saw & webAula & $\mathrm{http://webaula.com.br}$ \\
TelEduc & http://teleduc.org.br & & \\
\hline
\end{tabular}

Tabela 2.1: Alguns exemplos de SGC para cursos baseados na Web

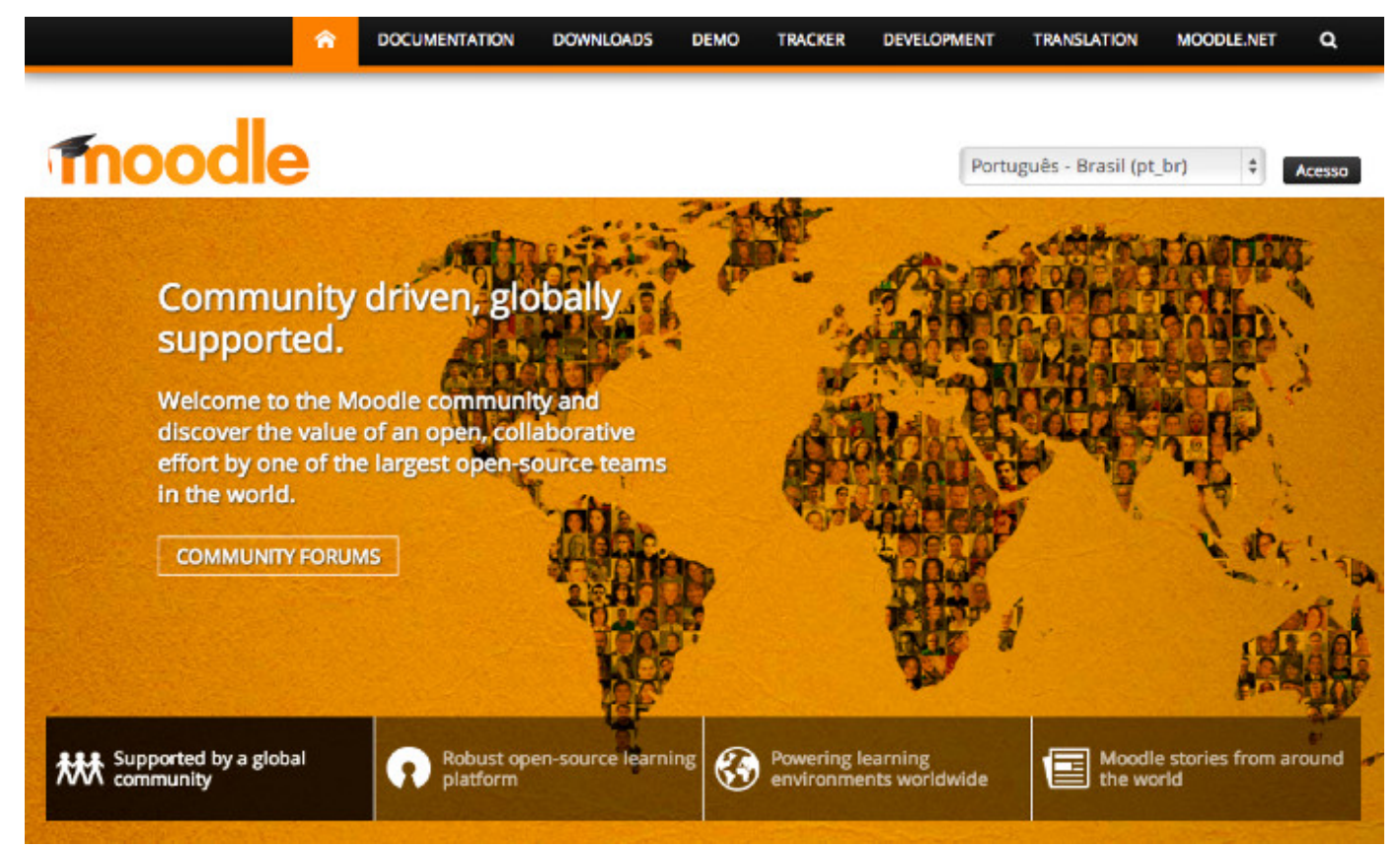

Figura 2.3: Página principal do sítio do Moodle

uma determinada instituição de ensino podem influenciar este julgamento" [IMS (2007)]. O SGC $M_{o o d l e}^{4}$ foi o escolhido como ferramenta de apoio para o projeto do iRepositório. A próxima seção apresenta suas principais características e as justificativas desta escolha.

\subsubsection{O SGC Moodle}

O desenvolvimento do Moodle iniciou-se em 1999 por Martin Dougiamas e sua primeira versão tornou-se pública em 2002 [Cole e Foster (2007)]. Desde então, ele vem sendo constantemente aprimorado, sendo que sua versão estável mais recente ${ }^{5}$ é a 2.6 , disponibilizada publicamente no final do segundo semestre de 2013. A Figura 2.3 exibe a página de entrada do seu sítio.

Algumas características foram decisivas para a tomada de decisão da escolha por este SGC e são descritas a seguir:

- Comunidade de apoio - sua base de usuários e profissionais envolvidos (programadores, professores e designers instrucionais) atinge atualmente centenas de milhares de participantes, o que potencializa as contribuições disponibilizadas para a comunidade e indiretamente ao próprio Moodle [Alves e Gomes (2007)];

- Modelo de licenciamento - possui código-fonte aberto e gratuito, licenciado sob o GNU Gene-

\footnotetext{
${ }^{4}$ Moodle é o acrônimo para Modular Object Oriented Learning Environment.

${ }^{5}$ Versão mais recente de acordo com a última pesquisa realizada em seu sítio e atualização desta dissertação.
} 
ral Public License ${ }^{6}$ (GNU GPL). Os demais sistemas envolvidos para sua operacionalização (Sistema Operacional, Servidor Web, Gerenciador de Banco de Dados) também têm modelos de licenciamento gratuitos semelhantes. Como exemplo, um ambiente típico ${ }^{7}$ é o composto por uma distribuição livre do Linux para o Sistema Operacional, o Servidor Web Apache e o Gerenciador de Banco de Dados MySQL;

- Linguagem de programação - é programado em PHP. Além de ser voltada principalmente para aplicações baseadas na Web, esta linguagem é interoperável entre Sistemas Operacionais distintos, o que lhe garante uma vantagem adicional em termos de flexibilidade. Considerada de rápido aprendizado e alta produtividade, possui uma extensa comunidade de entusiastas e profissionais ao redor do mundo [Melo e Nascimento (2007); Welling e Thomson (2008)]. Segundo o Índice $T I O B E^{8}$ de popularidade das linguagens de programação, ele ocupa a quarta posição dentre as linguagens avaliadas [TIOBE (2012)]. Além disso, o PHP é oferecido como linguagem padrão na maioria dos serviços de hospedagem de páginas de internet, o que garante uma grande oferta de serviços para sua instalação;

- Internacionalização - conta com tradução para aproximadamente 80 idiomas e é utilizado em mais de 220 países, o que o torna amplamente adotado e divulgado [Moodle (2012)]. O Brasil ocupa atualmente a terceira posição de sítios Moodle registrados, em um ranking liderado pelos Estados Unidos seguidos pela Espanha;

- Estudos de caso consolidados - é referenciado como caso de sucesso pela adoção em ambientes de larga escala, tanto no Brasil, pelo Consórcio CEDERJ, Universidade Aberta do Brasil (UAB) e Universidade Anhanguera, quanto em nível mundial pela Open University;

- Já adotado em outros projetos deste grupo de pesquisa - este SCG tem sido utilizado como base de pesquisa em outros projetos relacionados, para produção de componentes pedagógicos interativos e em cursos livres de extensão oferecidos pelo grupo. Seus membros componentes têm vivência suficiente para trocas de informações e experiências práticas, tanto em nível do seu uso como de programação interna;

- Referenciado - de acordo com o buscador Google Trends ${ }^{9}$, o termo "Moodle" é o mais popular dentre os SGC livres pesquisados. Como resultado de pesquisa realizada em 2012, a Figura 2.4(a) ilustra o resultado englobando os termos "aTutor", "Claroline", "Sakai" e "TelEduc", onde "Sakai" e "Claroline" tem maior destaque. Por outro lado, a Figura 2.4(b) confronta os termos anteriores com "Moodle". Nota-se uma diferença significativa deste em relação aos demais SGC analisados.

\subsection{Repositórios de Objetos de Aprendizagem}

A literatura é rica ao relatar as dificuldades e deficiências inerentes ao contexto dos OA, durante todo o seu ciclo de vida, e em particular às relacionadas, por exemplo, a sua autoria, reutilização e compartilhamento [Hodgins (2002); Nibon (2008)]. Fernandes e Ferreira (2011) afirmam que "a produção de conteúdos digitais é uma ciência e uma arte que requerem conhecimentos pedagógicos, grande experiência e acompanhamento dos progressos tecnológicos". Ainda segundo os autores, algumas das principais dificuldades apontadas em seu estudo são pertinentes a: $i$ ) demasiado tempo de desenvolvimento exigido pelos materiais; $i i)$ levantamento de informações quanto ao seu conteúdo;

\footnotetext{
${ }^{6}$ Esta licença garante que na prática, um sistema possa ser livremente distribuído, modificado e aperfeiçoado.

${ }^{7}$ Este ambiente é denominado pelo acrônimo $L A M P$, composto a partir das iniciais de Linux, Apache, MySQL e PHP. O Apêndice A descreve-o em maiores detalhes.

${ }^{8} \mathrm{O}$ Índice TIOBE é avaliado periodicamente, através de ferramentas de buscas na Web como o Google, Bing, Yahoo, Wikipedia, dentre outras. É baseado em estimativas mundiais do número de programadores, cursos e fornecedores de soluções.

${ }^{9}$ Disponível em http://www.google.com.br/trends.
} 

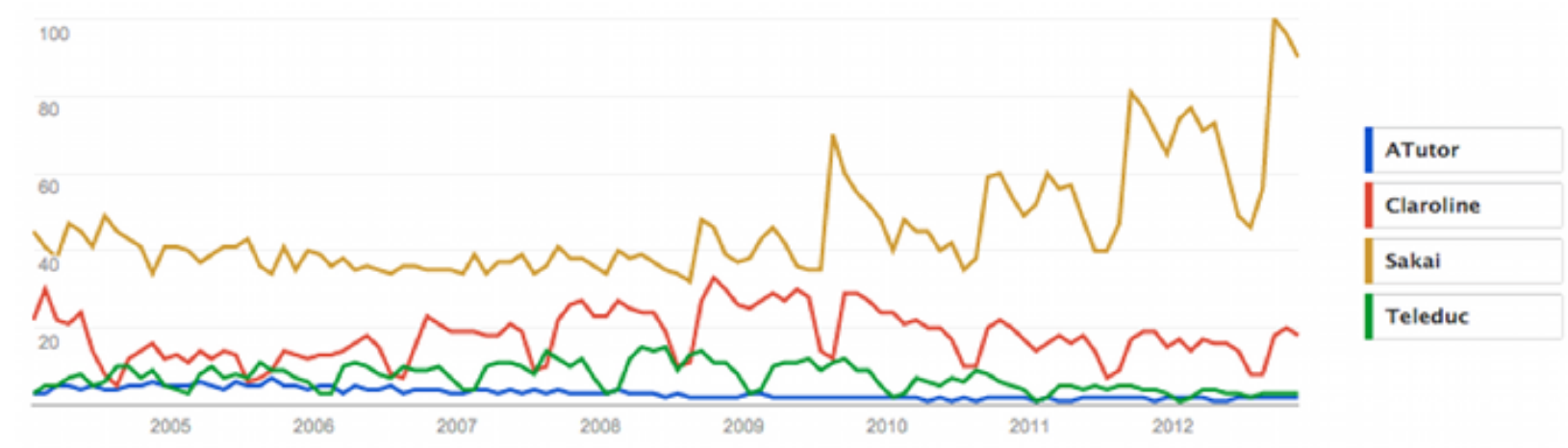

(a)

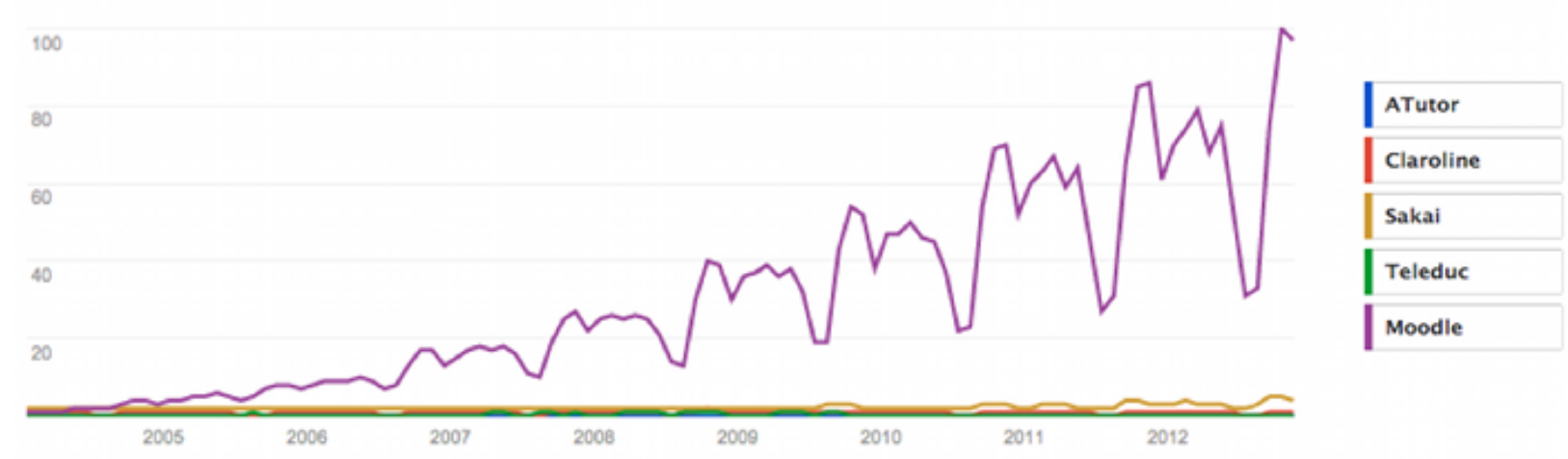

(b)

Figura 2.4: Análise de popularidade dos nomes de alguns SGC livres. Fonte: Google Trends

iii) geração de metadados; $i v$ ) projeto pedagógico; v) reutilização; vi) local de armazenamento e vii) formação e manutenção de equipe técnica capacitada para autoria de materiais. Em outras palavras, pode-se afirmar que os processos que envolvem a autoria de materiais didáticos digitais são dispendiosos - tanto em termos financeiros quanto de tempo necessário consumido durante este tipo de trabalho. Propostas inovadoras têm sido publicadas para a superação de parte destes esforços. Arimoto e Barbosa (2013) propõe um método sistemático de produção e entrega de OA. Para isto, tomam como base os métodos ágeis (em particular o Scrum e eXtreme Programming), geralmente empregados no desenvolvimento de sistemas de computacionais, para utilizá-los no contexto dos recursos digitais educacionais. Ainda assim, entretanto, os autores concluem que esta técnica ainda é incipiente e que não tem por objetivo abordar por completo as demais deficiências supracitadas acerca da autoria de OA.

Outro problema apontado por Retalis (2004) é a grande quantidade de recursos digitais educacionais dispersos pela Web e que não são localizáveis com precisão e eficiência pelos principais motores de busca da internet. Ainda segundo o autor, é necessária a adoção de mecanismos especialistas para o armazenamento e recuperação destes conteúdos.

South e Monson (2000) descreveram algumas das dificuldades enfrentadas e desafios na Universidade de Brigham Young de Utah, relacionadas aos seus cursos apoiados na Web. Dentre estas, destacam-se: o número crescente de alunos (total de 50.000 sendo 10.000 em cursos totalmente a distância); gestão de múltiplos ambientes de SGC de apoio a EaD; custos elevados para autoria de recursos digitais educacionais; métodos ineficientes para o compartilhamento destes recursos; e conteúdos com formatos sem um padrão unificado. Em seguida, os autores destacaram o projeto voltado ao desenvolvimento de um sistema unificado, que fosse capaz de agregar e disseminar esses materiais digitais produzidos na instituição. Assim como essa experiência vivenciada, outras universidades iniciaram projetos semelhantes para alcançar metas análogas.

Em seu artigo "Institutional Repositories: Essential Infrastructure for Scholarship in the Digi- 
tal Age", Lynch (2003) cita o termo "Repositório Institucional" para denominar esta nova classe emergente de sistema. Segundo seus relatos, estes ganharam destaque pela estratégia inovadora que permitia que centros universitários pudessem aprimorar seu conjunto de serviços relacionados a promoção destes OA, ao oferecer e difundir maneiras eficientes para a gestão destes materiais. O autor ainda cita o trabalho realizado pelo Instituto de Tecnologia de Massachusetts (MIT) para o desenvolvimento do repositório DSpace ${ }^{10}$, criado com a colaboração da Hewlett Packard Corporation e que foi utilizado como referência e estudo de caso para difusão deste sistema para outras universidades ao redor do mundo.

Muitas das deficiências supracitadas em consequência da crescente disseminação dos $\mathrm{OA}$ puderam ser, ao longo do tempo, minimizadas com o advento destes repositórios, que passaram a ser denominados com o passar dos anos pelo nome de "Repositórios de Objetos de Aprendizagem" (ROA).

Com o seu uso, os recursos didáticos produzidos por uma instituição poderiam ser armazenados (daí o emprego do termo "repositório" do seu nome) num local central, ou então serem visualizados como tal numa arquitetura de Sistemas Distribuídos, ao invés de manterem-se dispersos pelos seus campi, por institutos de um campus ou ainda em algum SGC departamental. Consequentemente, o custo total para a manutenção deste armazenamento central foi reduzido, em comparação ao modelo descentralizado, onde cada unidade era responsável pela sua própria gestão. Uma maior homogeneização dos padrões de formatos dos conteúdos digitais também ocorreu, em decorrência da necessidade da adequação estabelecida pelo repositório institucional para anotação dos metadados dos OA.

De maneira geral, devido aos ROA começarem a oferecer ferramentas exploratórias unificadas, os professores passaram a conhecer uma gama ampliada de possibilidades de materiais ofertados. Uma das consequências diretas deste fato foi a racionalização da demanda pela autoria de novos OA. A partir de então, estes materiais já produzidos anteriormente tornaram-se referenciados e reutilizados indefinidamente. Além disso, novos materiais sofisticados puderam ser compostos (e re-armazenados) a partir de outros OA pré-existentes.

Mais recentemente, alguns critérios para classificação de repositórios também têm sido propostos. McGreal (2007) cita um modelo relacionado ao local de armazenamento dos seus materiais: i) os que hospedam seus próprios conteúdos; ii) os "referenciais" ou "federados", que contêm apenas os metadados e um apontador para os respectivos conteúdos em repositórios externos e iii) os híbridos, que provêm ambos os modelos anteriores. O autor ainda oferece outras possibilidades de classificação, como a variedade de assuntos ou área de conhecimento cobertos pelos seus materiais digitais e os tipos de mídias oferecidos (vídeo, áudio, imagens, texto, materiais interativos ou uma composição indistinta destes).

Por promover os OA para além das fronteiras dos seus respectivos SGC, o uso de repositórios institucionais também acabou por estimular práticas que até então teriam um alcance pouco expressivo dentro desse contexto específico. Autores de conteúdos, dentre outros usuários, ganharam um papel mais "social" no ambiente do repositório. Alguns destes ROA passaram a oferecer serviços a serem utilizados entre seus pares como: $i$ ) avaliação e atribuição de conceitos (positivos ou negativos) aos $\mathrm{OA}$; ii) registro de comentários associadas a um determinado material e iii) indicação de OA entre seus pares [Lynch (2003)]. Uma das consequências é que estas informações puderam ser utilizadas posteriormente para análises estatísticas voltadas para classificação da sua relevância e apresentação de OA em resultados de busca. Alguns exemplos são: $i$ ) os mais visitados por usuários num determinado período; ii) os OA que mais receberam indicações entre pares ou ainda iii) os OA que receberam melhores avaliações.

\subsection{Sistemas Gerenciadores de Repositórios}

De acordo com o cenário descrito na seção anterior, um repositório institucional era desenvolvido, mantido e gerido por um instituto em particular, para suprir suas demandas específicas e ser

\footnotetext{
${ }^{10}$ Disponível em http://www.dspace.org.
} 
adequado a seu modelo e regras de negócio.

Com o passar do tempo, algumas soluções mais flexíveis de repositórios foram sendo disponibilizadas, tanto por instituições que já possuíam um sistema próprio, quanto por desenvolvedores independentes. Ao contrário dos repositórios institucionais locais, estas soluções apresentavam uma arquitetura mais genérica, de modo que pudessem ser utilizadas por um número maior de instituições que ainda não dispunham de um sistema próprio. Tais sistemas, denominados por "Gerenciadores de Repositórios" (SGR), permitiram que os seus usuários mantenedores fossem responsáveis pelas parametrizações destes ambientes, para que pudessem adaptar e personalizar a ferramenta de acordo com o seu cenário e necessidades.

Algumas destas soluções oferecem uma pilha completa de sub-sistemas para prover o repositório aos seus usuários, abrangendo desde o armazenamento interno dos documentos e artefatos, banco de dados, servidor de aplicação e as interfaces visuais do usuário. Alguns destes permitem personalizações da sua arquitetura interna, como a integração de outros repositórios a sua base ou a alteração de interfaces padrões do usuário. Sendo assim, eles podem ser encarados como um arcabouço para definição de um repositório institucional. Os projetos do DSpace (citado na seção anterior) e Fedora Commons, são dois exemplos práticos de SGR. Ambos são pacotes de sistemas que podem ser descarregados a partir dos seus sítios correspondentes, instalados pela sua instituição interessada e parametrizados para atender às suas necessidades específicas.

Outro modelo mais recente de negócio que tem recebido destaque e que promove um ambiente flexível para personalização do ROA é o oferecido "nas nuvens", através de fornecedores especializados. Desta maneira, instituições podem dispor de um repositório de OA sem a necessidade de aquisição e manutenção de um parque próprio de servidores e profissionais técnicos responsáveis diretamente por ele. Este tipo de serviço foi recentemente denominado por RaaS - Repository as a Service por Lewis et al. (2012), que fez uma analogia direta ao termo SaaS - Software as a Service. Neste paradigma, um sistema é encarado como um serviço virtual a ser entregue, em que detalhes da localização física dos seus servidores, infra-estrutura técnica ou armazenamento de dados são pouco relevantes aos seus usuários.

Os SGR ainda podem ser classificados de acordo com o seu modelo de licenciamento. Alguns destes são oferecidos a partir dos seus sítios para serem descarregados e instalados num servidor próprio do usuário ou instituição interessada, sendo que muitos destes possuem licença livre de uso. Por outro lado, os RaaS são oferecidos comercialmente e operam baseados na Web, através de instâncias dedicadas a partir do próprio sítio do seu fornecedor [Lewis et al. (2012)].

O Capítulo 3, relacionado a revisão bibliográfica dos SGR, faz um levantamento mais abrangente acerca dos sistemas existentes atualmente, bem como uma descrição mais detalhada das suas principais funcionalidades mais frequentemente oferecidas.

\subsection{O LInE e seus principais produtos}

O LInE (Laboratório de Informática na Educação) é um ambiente multidisciplinar que tem como objetivo colaborar para a redução de problemas educacionais utilizando técnicas de Computação (Interação Humano-Computador, Otimização, Engenharia de Software, Inteligência Artificial, etc). Além disso, estuda-se como as soluções propostas podem promover a inovação e a geração de melhoria nas mais diversas áreas da computação. Em particular, o LInE procura pesquisar e desenvolver protótipos e produtos (aplicativos) com potencial de melhorar a qualidade da educação em diferentes áreas do conhecimento [LInE (2012)]. Ele é apoiado por um grupo de pesquisadores da Universidade de São Paulo (USP), oriundos do Instituto de Matemática e Estatística (IME), Instituto de Ciências Matemáticas e de Computação (ICMC) e da Escola Politécnica.

O projeto do iRepositório também faz parte da linha de produtos desenvolvidos pelo grupo. No restante desta seção, são apresentados alguns dos aplicativos e pesquisas mantidos pelo grupo, que apresentam pontos de intersecção com o projeto desta dissertação. 


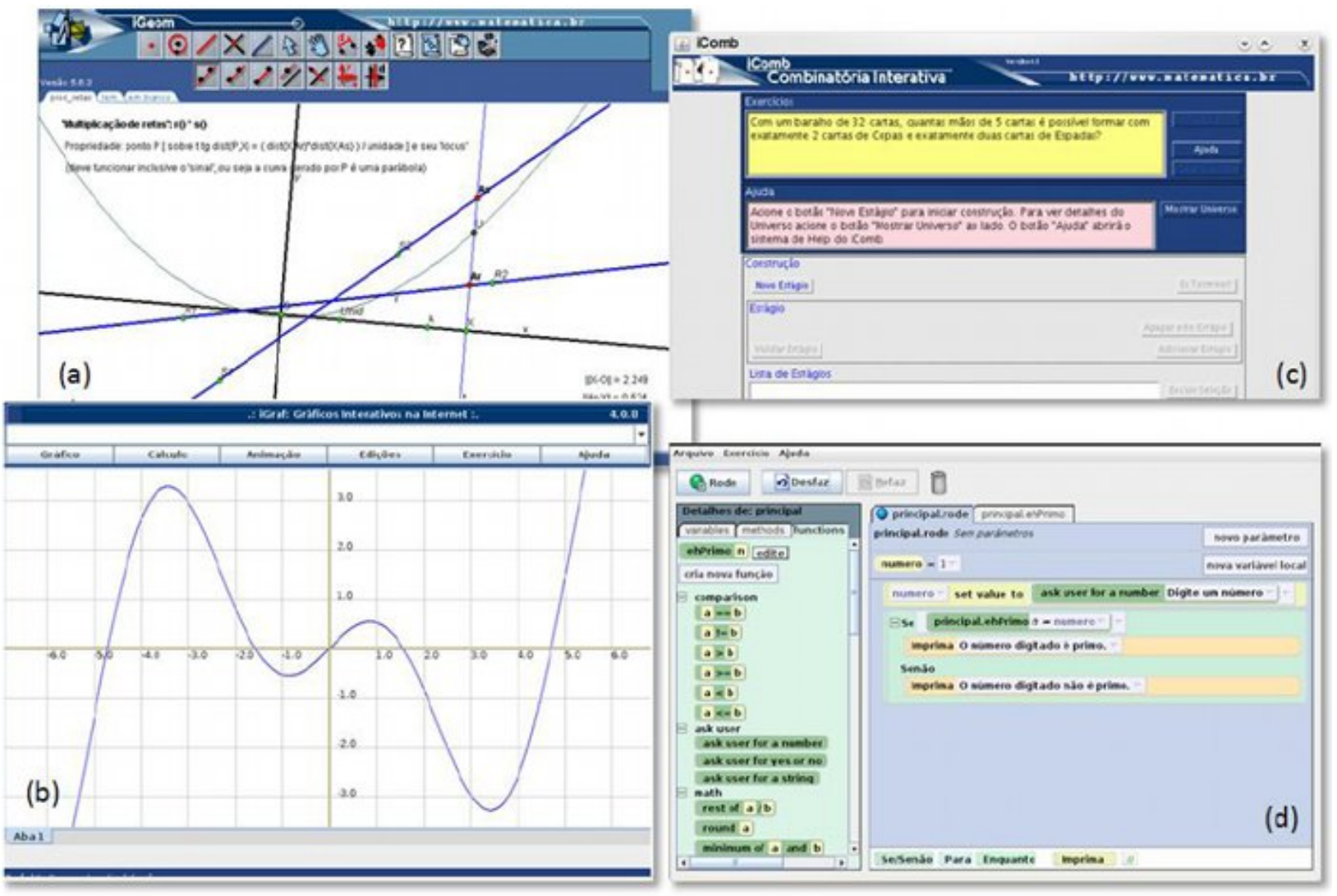

Figura 2.5: Exemplos de alguns módulos iMA: a) iGeom; b) iGraf; c) iComb e d) iVProg. Fonte: Dalmon (2012)

\subsubsection{Módulos de Aprendizagem Interativa}

Os chamados "Módulos de Aprendizagem Interativa" (iMA) são aplicativos educacionais que vêm sendo desenvolvidos desde o ano 2000 pelo grupo de pesquisa. Eles têm por objetivo minimizar algumas dificuldades dos alunos, principalmente em áreas introdutórias da Matemática e Computação [Isotani e Brandão (2003)].

Tais aplicativos apresentam características comuns entre si e têm por objetivo principal facilitar e aprimorar a qualidade do trabalho do professor durante suas aulas, através de componentes interativos e que provêm retroação (feedback) imediata ao seus usuários. Consequentemente, o ambiente de aprendizado torna-se mais interessante e motivador ao aluno [Dalmon et al. (2011)].

Os $i M A$ são oferecidos na forma de applet Java, o que garante interoperabilidade e independência da plataforma onde são executados. Protótipos mais recentes também têm sido propostos utilizando recursos do HTML 5, em substituição ao applet Java. Além de também garantir a independência da plataforma do seu usuário, esta nova tecnologia tem mostrado, até o momento, resultados interessantes e uma flexibilidade maior do que a tecnologia anterior. Independentemente do recurso utilizado para o seu ambiente, o professor pode disponibilizar, por exemplo, tais aplicativos a partir de navegadores Web aos seus alunos através de páginas HTML estáticas ou inseridos num material do SGC, como o Moodle.

A Figura 2.5 exibe telas de alguns dos aplicativos $i M A$ desenvolvidos pelo grupo LInE. Todos são disponibilizados gratuitamente nos seus respectivos sítios. São eles:

- $i$ Geom - Geometria Interativa na Internet ${ }^{11}$ - foi o primeiro $i M A$ produzido pelo grupo. Oferece recursos para autoria e atividades interativas aos alunos na área da Geometria [Isotani e Brandão (2003)]. Com o passar dos anos, novas funcionalidades foram agregadas ao aplicativo, que passou a dispor de scripts de recorrência para as atividades realizadas pelos alunos e avaliação

\footnotetext{
${ }^{11}$ Disponível em http://www.matematica.br/igeom.
} 
automática [Isotani (2005)];

- iGraph - Gráficos Interativos na Internet ${ }^{12}$ - uma alteranativa a sistemas proprietários para visualização de gráficos de funções matemáticas. Também dispõe de ferramentas de autoria para o professor e visualização de gráficos animados para os alunos, de acordo com os parâmetros fornecidos por eles [do Prado (2008)];

- iComb - Combinatória Interativa na Internet $^{13}$ - voltado ao ensino de Análise Combinatória [Eisenmann (2009)];

- iVProg - Programação Visual na Internet $^{14}$ - ambiente visual interativo para o aluno para facilitar a prática de programação de computadores [Kamiya (2010)].

\subsubsection{Arcabouço para os $i M A$}

A degradação do código-fonte dos aplicativos $i M A$ ao longo dos anos motivou esta frente de trabalho. Tais constatações foram observadas nos processos de desenvolvimento ad-hoc adotados até então, falta de padronização na codificação entre os $i M A$ e ao demasiado tempo de entrega exigido para a criação e entrega dos seus produtos. A fim de minimizar tais deficiências, foi proposta uma "Linha de Produtos de Software" voltada para o domínio de aplicativos educacionais e em particular para produção de $i M A$, composta por um arcabouço e manuais do seu funcionamento interno [Dalmon e Brandão (2013)].

Com a utilização deste conjunto de ferramentas, é esperado que o reúso de código seja feito de maneira eficiente, ao mesmo tempo em que a arquitetura dos aplicativos $i M A$ torne-se mais consolidada e simples de se manter.

No presente instante, o iVProg está em avançado estágio de refatoração com o emprego deste arcabouço. Em seguinda, outros $i M A$ serão também analisados, priorizados e trabalhados dentro desta mesma Linha de Produtos.

\subsubsection{Componente de tarefa interativa para o SGC Moodle}

Analisando-se isoladamente, um aplicativo educacional $i M A$ tem um modo de comportamento característico, conhecido por stand-alone, por ser independente ao meio em que está armazenado. Como já citado, estes podem ser embutidos em páginas dentro de um curso num SGC, porém sua interação com este meio é praticamente nula, dado que não há trocas de informações entre esses dois sistemas [Rodrigues et al. (2010)]. Em outras palavras, o componente não tem flexibilidade suficiente, por exemplo, para adaptar-se ao contexto do seu curso ou para retornar dados a este pertinentes às atividades realizadas e submetidas pelos alunos.

Além disso, é de conhecimento que os SGC (incluindo o Moodle) carecem de ferramentas flexíveis que possam proporcionar aos seus estudantes um aprendizado interativo e que permita a retroação imedidata.

Em vista desse cenário, Rodrigues (2011) desenvolveu um novo componente para este SGC, chamado iTarefa - Tarefa Interativa. Atuando como uma interface, este provê de maneira eficaz um canal bi-direcional para trocas de mensagens entre o Moodle e os aplicativos educacionais (em especial aos iMA). Algumas destas trocas de mensagens envolvem transferências de informações como: $i$ ) o envio do SGC ao $i M A$ da atividade a ser realizada, em conjunto com dados da sua configuração; ii) a disponibilização pelo $i M A$ ao SGC da resposta submetida pelo aluno e iii) o resultado da correção automática dessa resposta, calculada pelo iMA [Dalmon (2012)]. Outra vantagem desta solução é que pode superar as barreiras de comunicação apontadas anteriormente sem a necessidade de alteração do código-fonte daquele SGC ou de qualquer $i M A$ existente. A Figura 2.6 ilustra uma das suas telas integradas ao Moodle.

\footnotetext{
${ }^{12}$ Disponível em http://www.matematica.br/igraf.

${ }^{13}$ Disponível em http://www.matematica.br/icomb.

${ }^{14}$ Disponível em http://www.matematica.br/ivprog.
} 


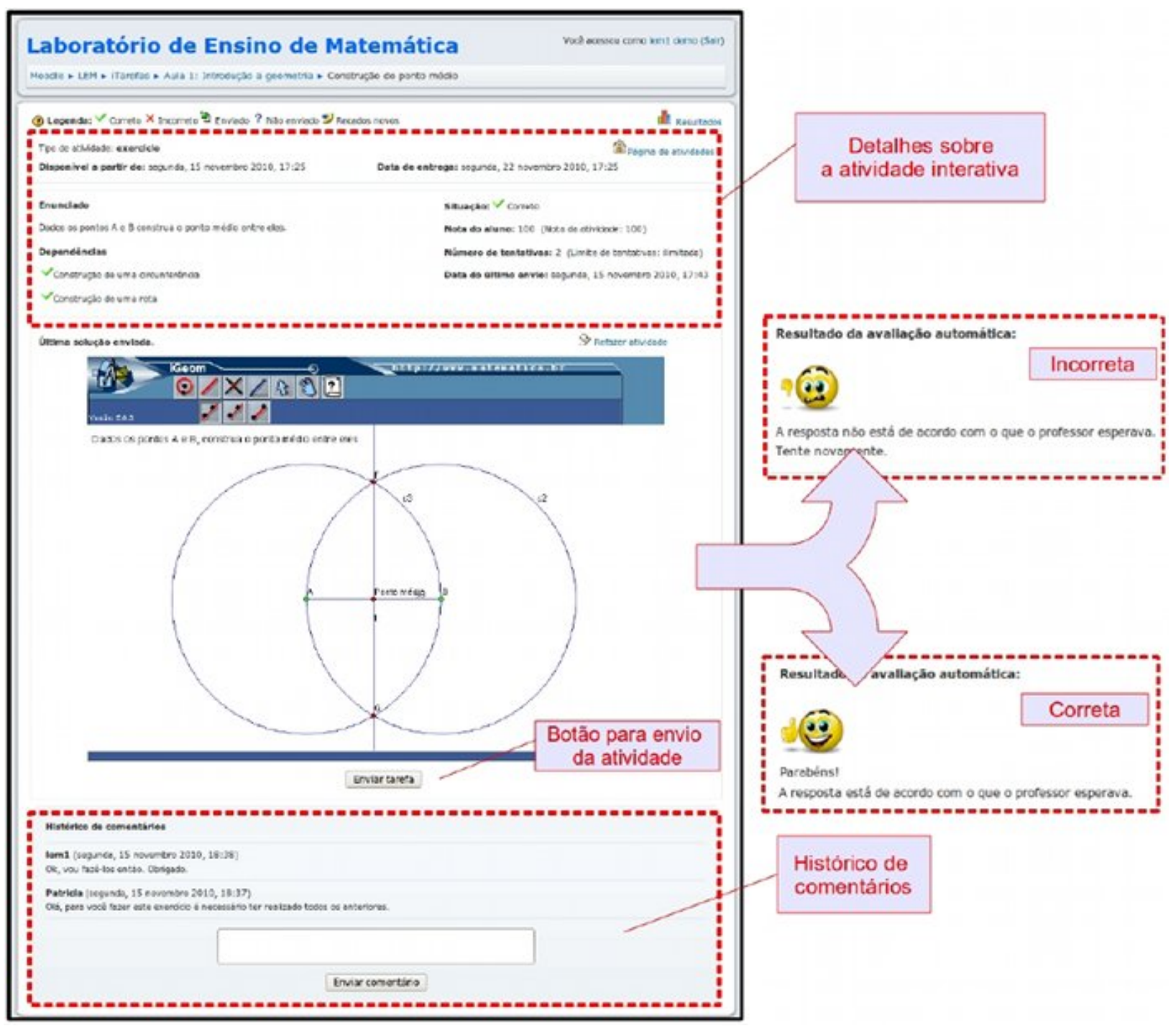

Figura 2.6: Exemplo de um iMA do tipo iGeom integrado ao iTarefa. Fonte: Rodrigues (2011) 
O módulo iTarefa está atualmente sendo refatorado para que seja compatível com a versão mais recente do Moodle. Novas funcionalidades também estão sendo analisadas, para que este possa, em breve, trabalhar de maneira integrada ao iRepositório, de modo que ofereça aplicativos $i M A$ de forma mais flexível, personalizada ao contexto de cada aluno, conforme o progresso mensurado nos históricos das suas avaliações.

\subsubsection{Prova de conceito de um repositório para OA}

Apesar do notável avanço alcançado com o advento dos ROA nos últimos anos, uma série de barreiras ainda são evidenciadas. Ainda são reportadas deficiências como falta de integração com os SGC, alta curva de aprendizado exigida para os professores e dificuldade na definição de vínculos ou associações lógicas e empacotamento de materiais digitais relacionados.

Tendo em vista estas dificuldades, o grupo de pesquisa iniciou em 2010 um novo projeto para o desenvolvimento de um repositório de OA. Seu objetivo principal foi o de disponibilizar um sistema integrado ao SGC Moodle, que compartilhasse os seus recursos (banco de dados, bibliotecas de funções, módulos do ambiente, controle de acesso, etc) e que fosse intuitivo para ser utilizado pelos professores. Ainda como seus requisitos, ele deveria ser integrado ao componente iTarefa, de modo que fornecesse a este conteúdos digitais na forma de $i M A$ ou outros tipos de materiais.

Uma prova de conceito deste repositório foi desenvolvida por Rosa e Brandão (2011) para a versão 1.9 do Moodle. Denominado por $i R C D$ - Repositório de Conteúdos Digitais Interativos, ele contava com funcionalidades elementares de repositório como: armazenamento, busca e recuperação de OA. A Figura 2.7 ilustra uma das suas telas, voltada ao armazenamento de OA e registro de alguns dos seus metadados pelo autor.

O presente projeto desta dissertação, denominado por iRepositório, é o sucessor do $i R C D$. Sua concepção inicial originou-se em meados de 2012, como sendo um aprimoramento daquele primeiro sistema. Conforme mencionado no Capítulo 1, este projeto tem por um dos seus objetivos as entregas tanto de um modelo arquitetural quanto de um protótipo funcional desenvolvido para o Moodle. Além disso, foi planejado pelo grupo LInE um conjunto de novos recursos em relação ao iRCD, apresentados mais adiante no Capítulo 4, com base no levantamento realizado no Capítulo 3. O iRepositório foi oficialmente divulgado pelo seus autores ao público no artigo entitulado "A Model

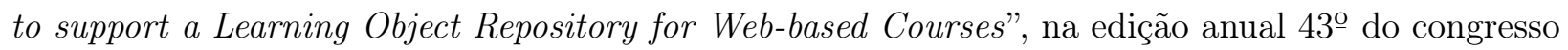
"Frontiers in Education" [Nascimento et al. (2013)].

O próximo capítulo descreve a metodologia utilizada para revisão bibliográfica dos ROA mais utilizados atualmente. Esta relação foi utilizada posteriormente como guia para nortear a elaboração de um conjunto de estratégias, recursos e funcionalidades para o projeto do iRepositório. 
Repositório de Conteúdos Digitais Interativos - Novo Arquivo

$$
\begin{gathered}
\text { Titulo: (?) * Polinômios } \\
\text { Descrição: (?) * }
\end{gathered}
$$

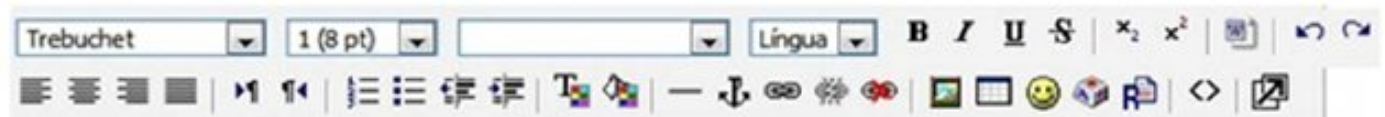

\section{Conceitos introdutórios}

Exercício 1: Construção de uma circunferência

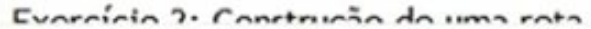

Caminho:

? 整国

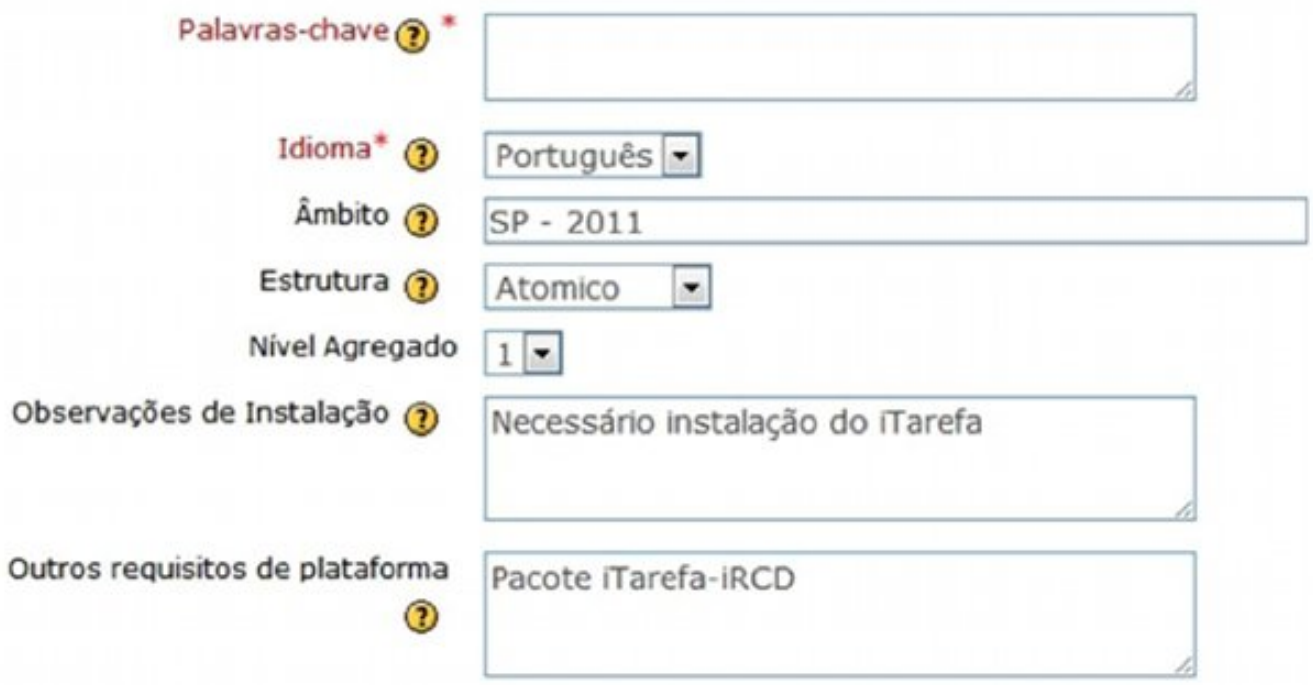

Figura 2.7: Autoria de um OA no iRCD. Fonte: Rosa e Brandão (2011) 


\section{Capítulo 3}

\section{Revisão Bibliográfica dos Sistemas Gerenciadores de Repositórios}

Um dos pontos de fundamento do projeto do iRepositório foi o levantamento dos principais repositórios existentes atualmente, seus modelos de licenciamento, formas de uso (descarregável para servidor próprio ou ser oferecido como serviço "nas nuvens") e suas funcionalidades mais frequentemente oferecidas, tanto aos seus usuários finais (professores, alunos e pesquisadores em geral) quanto aos seus administradores. Este projeto tem interesse direto nos resultados desta revisão, que foi viabilizada através de um processo sistemático de revisão bibliográfica dos SGR. Além de elencar os repositórios mais referenciados, seus recursos comuns e características técnicas, esta revisão também tem como objetivo responder a um questionamento pertinente, feito ainda durante as etapas iniciais de planejamento do iRepositório. Trata-se a respeito da decisão estratégica mais adequada a ser tomada, com consequências diretas nas fases posteriores do projeto: "a utilização de um repositório pronto, pré-existente, para compor sua base ou o desenvolvimento de um aplicativo próprio, personalizado às necessidades do projeto?". Caso a primeira proposta fosse adotada, o projeto contemplaria a implementação de um sistema integrador entre o SGC Moodle e o repositório pré-existente. Já a segunda proposta envolveria o desenvolvimento de um ROA por completo, de modo que pudesse ser acoplado aquele SGC.

Esta tomada de decisão é constantemente abordada na área da Computação, em particular a temas que envolvam o desenvolvimento de aplicativos. A oferta de produtos similares em um dado domínio geralmente é alta, independentemente do seu modelo de licenciamento ou da disponibilidade do seu código-fonte. Uma equipe composta por analistas, engenheiros de softwares e programadores com frequência realiza um estudo prévio deste cenário antes de tomar a decisão entre reutilizar um componente, módulo ou sistema pronto ou construir um novo, sob sua própria responsabilidade. Outras áreas do conhecimento também apresentam cenários análogos. Em particular, a da Administração, precisa lidar constantemente com processos de planejamento de aquisição (de um produto, recurso ou de um serviço, por exemplo). Neste caso, pode ocorrer um dilema acerca desta aquisição, a partir de um fornecedor externo, ou então desenvolvê-lo internamente pela sua equipe interna e com demais recursos próprios.

A oferta atual de ROA é vasta. Uma pesquisa informal realizada em Janeiro de 2014 no buscador público Google Acadêmico ${ }^{1}$ pela expressão "Learning Object Repository" apontou mais de 190.000 resultados. Estudos que realizaram levantamentos e categorizações de ROA podem ser encontrados na literatura, principalmente nos últimos 15 anos, com o advento e promoção desta classe de sistema. Um destes, entitulado "Reusable Learning Objects: a Survey of LOM-Based Repositories", foi apresentado por Neven e Duval (2002). Os autores classificaram alguns ROA baseados no padrão Learning Object Metadata $(\mathrm{LOM})^{2}$ de metadados, de acordo com critérios como o domínio de abordagem (área do conhecimento), quantidade de OA disponível, modo de armazenamento e

\footnotetext{
${ }^{1}$ Disponível em: http://scholar.google.com.

${ }^{2} \mathrm{O}$ padrão de anotação de metadados LOM é mantido pelo Institute of Electrical and Electronics Engineers (IEEE).
} 
organização destes. Outro trabalho semelhante é o de McGreal (2007). O autor norteou-se por alguns questionamentos, a fim de realizar seu estudo investigativo: "quais são os ROA disponíveis na internet?", ou ainda: "quais são os recursos mais comuns e o mais específicos para cada tipo de repositório?". Já Ochoa e Duval (2009) realizaram um estudo quantitativo a respeito de alguns ROA. Através de análises estatísticas feitas a partir de dados coletados em sua pesquisa, eles obtiveram informações relevantes como por exemplo, o número de objetos armazenados, tamanho médio requerido pelos OA e taxa de crescimentos destes ROA ao longo dos últimos anos. No Brasil, Rocha et al. (2011) publicou o artigo "Repositórios de Objetos de Aprendizagem - um estudo exploratório" com a temática principal voltada para a mesma linha de pesquisa dos estudos anteriores, ainda que baseada em um conjunto mais restrito de amostras de ROA.

Nas próximas seções deste capítulo são descritas as atividades realizadas durante o estudo exploratório acerca dos ROA oferecidos atualmente na internet. A fim de restringir este leque de opções para um conjunto reduzido de repositórios mais específicos e voltados aos propósitos deste estudo, este trabalho desenvolveu e aplicou uma metodologia para sistematizar sua prospeç̧ão. Esta partiu da análise de dados encontrados em dois indexadores da web para ROA públicos. Em seguida seus sistemas mais relevantes foram confrontados em alguns mecanismos de buscas em periódicos científicos, para identificação e ordenação dos mais referenciados. Os passos constituintes desta metodologia, bem como as estratégias adotadas e as saídas resultantes em cada uma delas são também descritos.

Este processo obteve como produto final um conjunto composto por 15 repositórios públicos, que serviu como principal insumo para o estudo das características chaves de cada um destes repositórios. A partir da análise destas informações, foi possível destacar os principais recursos que o iRepositório poderia compreender, bem como um norteador ao questionamento sobre a estratégia mais adequada a ser tomada em relação a utilização de um repositório pronto ou ao desenvolvimento de um novo, como parte das atividades deste projeto.

\subsection{Busca por repositórios públicos a partir de indexadores}

Esta etapa inicial teve por objetivo resgatar os repositórios mais referenciados atualmente, dentre uma vasta lista de candidatos. Para isto, foram consultados dois indexadores de repositórios repositórios: o OpenDOAR - Directory of Open Access Repositories ${ }^{3}$ e o ROAR - Registry of Open Access Repositories ${ }^{4}$. Ainda que não tragam uma relação completa de todos os repositórios existentes (dentre outros fatores, nem todos os repositórios são públicos ou são registrados pelas suas instituições), suas relações abrangem uma amostragem considerada significativa aos propósitos deste trabalho ${ }^{5}$.

Ambos os indexadores possuem mecanismos de buscas em seus respectivos sítios, para facilitar e refinar a localização de registros aos seus usuários, de acordo com parâmetros de entrada fornecidos. Dentre os filtros disponíveis, são relevantes ao trabalho: $i$ ) tipo de sistema gerenciador utilizado; ii) país ou continente da localização do repositório; iii) área de conhecimento coberta pelos seus materiais digitais e $i v$ ) data de criação do repositório.

O OpenDOAR é responsável pela indexação de repositórios acadêmicos públicos. É mantido pela organização inglesa $S H E R P A^{6}$ e é servido através da Universidade de Nottingham ${ }^{7}$ [SHERPA (2006)]. De acordo com sua política interna, toda nova solicitação de registro de repositório feita pela instituição responsável, é visitada, avaliada e aprovada manualmente pela equipe daquele indexador. Até a última atualização desta pesquisa, ele discriminava mais de 110 tipos de repositórios distintos, utilizados em mais de 2.200 institutos cadastrados. Sua ferramenta de busca para localização precisa destes registros está indicada em destaque na Figura 3.1.

\footnotetext{
${ }^{3}$ Disponível em: http://opendoar.org.

${ }^{4}$ Disponível em: http://roar.eprints.org.

${ }^{5}$ Última atualização dos resultados destas buscas nos indexadores foi realizada em Outubro de 2012.

${ }^{6}$ Disponível em: http://www.sherpa.ac.uk.

${ }^{7}$ Disponível em: http://www.nottingham.ac.uk.
} 


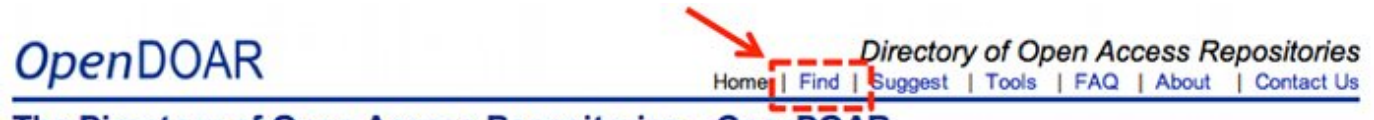

The Directory of Open Access Repositories - Open̄̄ōĀR

Search for repositories I Search repository contents I List of repositories I Repository Statistics

OpenDOAR is an authoritative directory of academic open access repositories. Each OpenDOAR repository has been visited by project staff to check the information that is recorded here. This in-depth approach does not rely on automated analysis and gives a quality-controlled list of repositories.
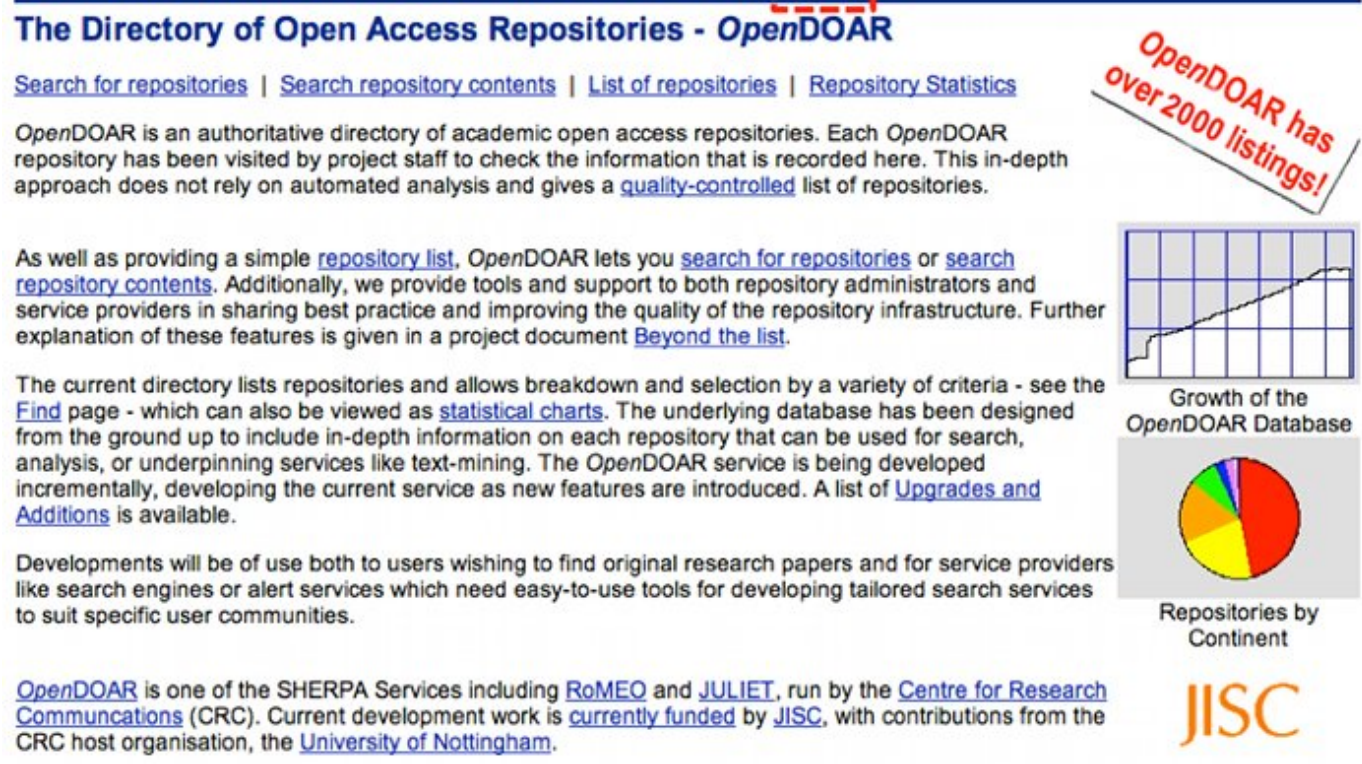
Communcetion (CRC). Current development work is currently funded by JISC, with contributions from the CRC host organisation, the University of Nottingham

OpenDOAR has also been identified as a key resource for the Open Access community (K.B.Oliver \& R.Swain, 2006 - PDF) and identified as the leader in repository directories in a study by Johns Hopkins University. OpenDOAR was one of the services which contributed to SHERPA being awarded the 2007 SPARC Europe Award for Outstanding Achievements in Scholarly Communications.

More information on the project is available on this site through the About page.

(ㄱ) 2006-2011, University of Nottingham, UK. Last updated: 11-Jul-2010

Figura 3.1: Sítio do OpenDOAR, com destaque para o seu mecanismo de busca

Assim como o OpenDOAR, o ROAR, é outra alternativa de indexador de repositórios abertos de conteúdos digitais. Ele é servido pela Universidade de Southampton ${ }^{8}$ e tem suporte da organização inglesa JISC - Joint Information Systems Committee ${ }^{9}$, uma entidade de incentivo a tecnologia digital voltada para pesquisa, ensino e aprendizado [JISC (2012)]. Até a última atualização desta pesquisa, ele contava com 31 repositórios, dispersos em mais de 2.500 institutos. Também possui uma poderosa ferramenta de busca (mais precisa que a do OpenDOAR, em relação ao oferecimento de filtros para o refinamento dos termos), apontada no destaque da Figura 3.2.

A partir das páginas de busca por repositórios de cada um destes dois sítios, foram realizadas pesquisas a fim de determinar quantos institutos utilizavam cada um daqueles repositórios. A lista resultante foi disposta de maneira ordenada de forma decrescente para a quantidade destes institutos. Desta forma, os repositórios com maior ocorrência estão no topo desta relação.

A fim da eliminação de resultados menos relevantes, foram considerados todos os sistemas, partindo-se da parte superior da lista, cuja distribuição acumulada de institutos representasse ao menos $75 \%$ (três-quartis) de todos os seus registros. As Tabelas 3.1 e 3.2 apresentam os resultados dos indexadores OpenDOAR e ROAR, respectivamente.

Ainda durante esta etapa, foi tomada a precaução em ignorar entradas irrelevantes retornadas pelas buscas. Foi ignorado no ROAR o item "Other softwares", retornado com 448 ocorrências. Já no OpenDOAR não foram contabilizados os itens retornados "Not specified" e "HTML", somando-se ao todo 317 entradas. Este último, em particular, é composto apenas por páginas Web estáticas para apresentação dos materiais digitais, o que não compreende de fato, um modelo esperado para um típico repositório, por não prover aos seus usuários ações interativas.

É possível notar através destes dados, uma considerável concentração de institutos que se utilizam destes repositórios listados. Dos mais de 110 tipos de repositórios apontados no OpenDOAR,

\footnotetext{
${ }^{8}$ Disponível em: http://www.soton.ac.uk.

${ }^{9}$ Disponível em: http://www.jisc.ac.uk.
} 


\section{Registry of Open Access Repositories}

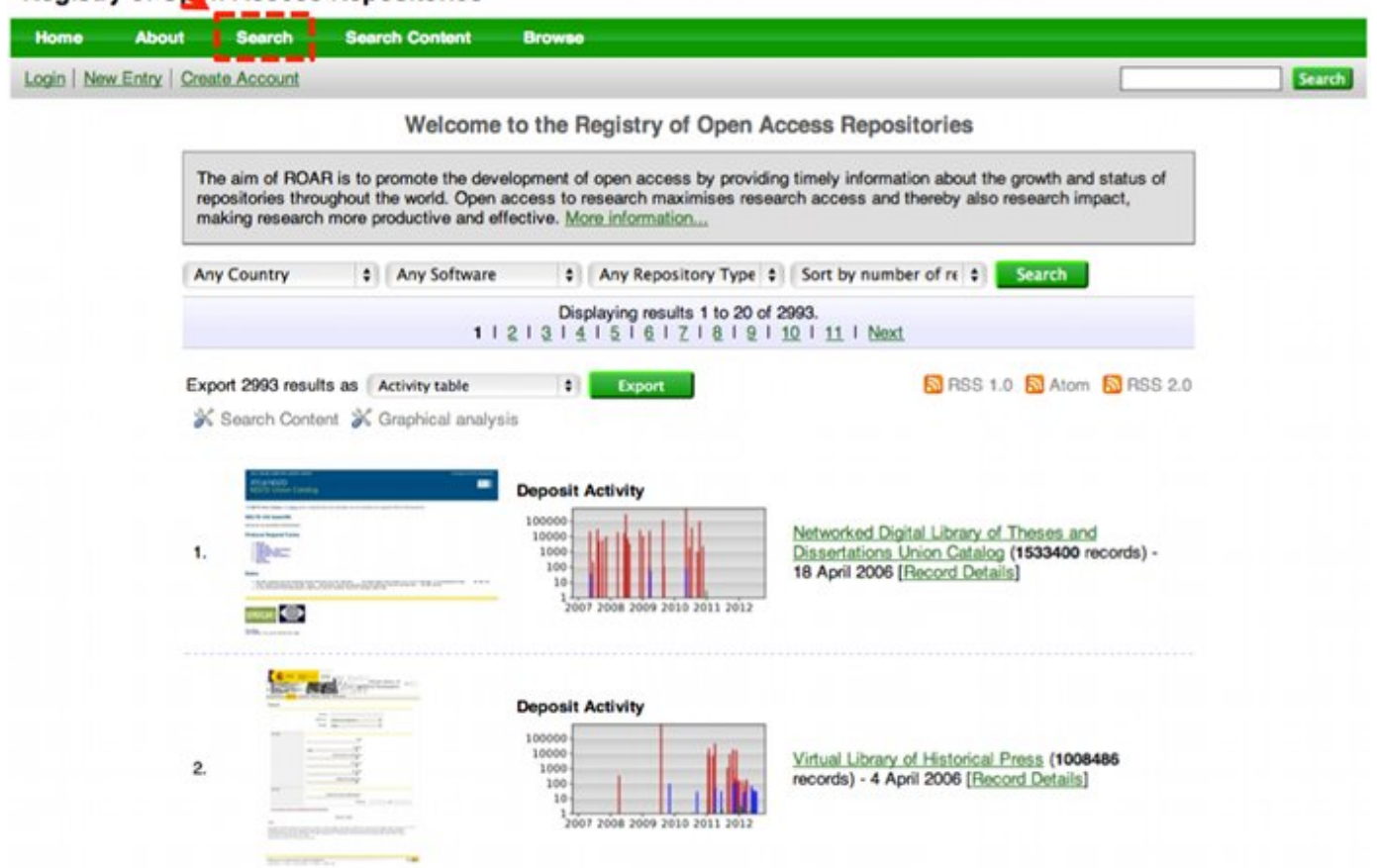

Figura 3.2: Sítio do ROAR, com destaque para o seu mecanismo de busca

\begin{tabular}{l|r|r|r}
\hline Repositório & Institutos & Distribuição & Distr. acumulada \\
\hline DSpace & 899 & $40.6 \%$ & $40.6 \%$ \\
EPrints & 314 & $14.2 \%$ & $54.8 \%$ \\
Digital Commons & 94 & $4.2 \%$ & $59.1 \%$ \\
OPUS & 74 & $3.3 \%$ & $62.4 \%$ \\
dLibra & 56 & $2.5 \%$ & $65.0 \%$ \\
Greenstone & 46 & $2.1 \%$ & $67.0 \%$ \\
CONTENTdm & 37 & $1.7 \%$ & $68.7 \%$ \\
DiVA & 32 & $1.4 \%$ & $70.2 \%$ \\
DigiTool & 19 & $0.9 \%$ & $71.0 \%$ \\
Fedora Commons & 19 & $0.9 \%$ & $71.9 \%$ \\
HAL & 19 & $0.9 \%$ & $72.7 \%$ \\
Open Repository & 19 & $0.9 \%$ & $73.6 \%$ \\
SciELO & 18 & $0.8 \%$ & $74.4 \%$ \\
Digibib & 16 & $0.7 \%$ & $75.1 \%$ \\
\hline Total & 1.662 & & \\
\hline
\end{tabular}

Tabela 3.1: OpenDOAR: Repositórios com maior número de institutos 


\begin{tabular}{l|r|r|r}
\hline Repositório & Institutos & Distribuição & Distr. acumulada \\
\hline DSpace & 1.182 & $46.2 \%$ & $46.2 \%$ \\
EPrints & 476 & $18.6 \%$ & $64.9 \%$ \\
Digital Commons & 137 & $5.4 \%$ & $70.2 \%$ \\
OPUS & 48 & $1.9 \%$ & $72.1 \%$ \\
Fedora Commons & 32 & $1.3 \%$ & $73.4 \%$ \\
ETD-db & 30 & $1.2 \%$ & $73.5 \%$ \\
DiVA & 25 & $1.0 \%$ & $75.5 \%$ \\
\hline Total & 1.930 & & \\
\hline
\end{tabular}

Tabela 3.2: ROAR: Repositórios com maior número de institutos

apenas 14 destes (13\% do total) são suficientes para cobrir ao menos $75 \%$ de todos os seus institutos. Valor semelhante também é verificado no ROAR, onde 7 destes sistemas ( $22 \%$ do total) são suficientes para cobrir semelhante proporção.

Estas duas relações foram unificadas e resultaram numa lista com 15 sistemas públicos distintos. Segundo estes dois indexadores, são os repositórios mais utilizados em institutos ao redor do mundo, Esta relação foi utilizada como entrada para a etapa a seguir, direcionada a uma análise preliminar destes candidatos.

\subsection{Análise dos repositórios candidatos}

Nesta etapa procurou-se conhecer um pouco a mais a respeito dos itens levantados na relação da fase anterior, através de uma análise qualitativa. Para isso, cada um dos seus itens passou por uma inspeção manual, de forma que algumas características chaves pudessem ser melhor compreendidas. As informações coletadas correspondem às avaliações do seguinte questionário:

Q1) O repositório possui sítio ativo na Web?

Há interesse particular em projetos e sistemas em atividade, que tenham uma comunidade, instituto ou empresa que os apóiem. Uma resposta negativa a este item seria um indício significativo para descarte do candidato;

Q2) Este sistema é um SGR ou é um repositório de instância única?

Normalmente um SGR atende múltiplas instâncias, de modo que cada uma destas sirva a um grupo de institutos em particular, de acordo com suas regras e parametrizações específicas. Por outro lado, um sistema com instância única serve a apenas um único conjunto de institutos ou clientes. Devido a isto, essa sub-classe de repositório não tem tanta flexibilidade para generalizações como a primeira;

Q3) Como é o seu modelo de operação? Ele pode ser descarregado a partir do seu sítio ou apenas opera como serviço "nas nuvens" (RaaS)? Se operar "nas nuvens", ele pode ser avaliado livremente?

Há maior interesse em sistemas que possam ser descarregados, em relação aos que sejam oferecidos apenas como RaaS;

Q4) Se puder ser descarregado, qual a data e a versão da última versão pública disponibilizada? Assim como a primeira pergunta, esta também pode indicar o nível de atividade do projeto do repositório. Sistemas com frequentes atualizações disponíveis recentes (ao menos de 2 anos atrás), indicam um potencial nível de atividades realizadas pelos seus responsáveis. Caso contrário, pode indicar inatividade dos seus apoiadores e ser um candidato para descarte;

Q5) Seu modelo de licenciamento é gratuito ou comercial?

Há maior interesse em sistemas gratuitos e que preferencialmente sejam disponibilizados com 
código-fonte aberto.

Todos os 15 candidatos responderam positivamente ao questionamento $Q 1$ (possuir sítio ativo) ${ }^{10}$. Já o questionamento Q3 eliminou alguns candidatos, por não serem descarregáveis (operam exclusivamente "nas nuvens"), nem possuírem versão de avaliação gratuita. São eles: DigiTool ${ }^{11}$ e $d$ Libra ${ }^{12}$. O questionamento $Q 4$ (possuir versão pública recente) também resultou na eliminação de mais um repositório, o $E T D-d b^{13}$, por apresentar sinais de descontinuidade no projeto. Segundo seu sítio, sua versão mais recente é a 1.8, datada em Março de 2004. Por último, foi também descartado o repositório Open Repository ${ }^{14}$. De acordo com a inspeção do seu sítio, foi constatado que ele é oferecido como um "Repositório como Serviço" comercial e que é apoiado sob o repositório DSpace. Devido a este fato, ele não apresenta um modelo que possa agregar alguma função inovadora e de relevância a esta revisão.

O 11 repositórios resultantes foram discriminados e agrupados de acordo com os seus modelos de operação (ser ou não descarregável) e de licenciamento (comercial ou gratuito). Cada uma das relações abaixo contém os respectivos repositórios, listados em ordem alfabética pelo seu nome e uma breve descrição das demais respostas aos questionamentos:

- Repositórios descarregáveis e com licença de uso livre:

- DSpace (http://www.dspace.org) - última versão 1.8.2 de Fevereiro de 2012;

- EPrints (http://www.eprints.org) - última versão 3.3.10 de Maio de 2012;

- Fedora Commons (http://www.fedora-commons.org) - última versão 3.6.1 de Setembro de 2012;

- Greenstone (http://www.greenstone.org) - última versão 2.85 de Novembro de 2011;

- OPUS (http://www.opus.cx) - última versão 2.29 de Março de 2010.

- Repositórios não-descarregáveis ou que possuam licença de uso comercial:

- CONTENTdm (http://www.contentdm.org) - é descarregável, entretanto depende de contrato comercial para utilizá-lo;

- Digibib (http://www.digibib.net/Digibib) - é um Portal "referenciador" de conteúdos digitais, ou seja, contém apenas os metadados sobre conteúdos institucionais depositados em outros repositórios. Não pode ser descarregado;

- Digital Commons (http://digitalcommons.bepress.com) - é um "Repositório como Serviço" comercial. Suas instâncias operam no próprio sítio do seu fornecedor;

- DiVA (http://www.diva-portal.org) - modelo semelhante ao Digibib, é um portal "referenciador";

- HAL (http://hal.archives-ouvertes.fr) - modelo semelhante ao Digibib, é um portal "referenciador";

- SciELO (http://www.scielo.org) - modelo semelhante ao Digibib, é um portal "referenciador".

Finalizada esta etapa, esta relação com 11 candidatos foi utilizada como base para a próxima e última fase do processo de revisão por repositórios públicos: a quantificação das suas citações e indexadores da Web.

\footnotetext{
${ }^{10}$ Os respectivos sítios de cada repositório candidato foram manualmente localizados, ao fornecimento do seu nome próprio, através de consultas triviais no buscador público Google Search na Web, disponível em http://google.com.

${ }^{11}$ Disponível em http://www.exlibrisgroup.com/category/DigiToolOverview.

${ }^{12}$ Disponível em http://dlibra.psnc.pl.

${ }^{13}$ Disponível em http://scholar.lib.vt.edu/ETD-db.

${ }^{14}$ Disponível em http://www.openrepository.com.
} 


\begin{tabular}{ll|l}
\hline & Buscador & Sítio \\
\hline \#1 & IEEEXplore Digital Library & http://ieeexplore.ieee.org \\
\#2 & Springer & http://www.springer.com \\
\#3 & Association for Computing Machinery & http://www.acm.org \\
$\# 4$ & ScienceDirect & http://www.sciencedirect.com \\
$\# 5$ & Microsoft Academic Search & http://academic.research.microsoft.com \\
\#6 & Publish or Perish & http://www.harzing.com/pop.htm \\
\hline
\end{tabular}

Tabela 3.3: Indexadores acadêmicos na Web para quantificação dos repositórios

\subsection{Quantificação das citações dos repositórios}

Nesta última etapa do estudo exploratório, foi realizado um levantamento quantitativo acerca das referências destes 12 repositórios candidatos em fontes abertas de indexadores de contextos acadêmicos da Web. A Tabela 3.3 relaciona estes meios e seus respectivos sítios.

O propósito desta etapa foi o de compreender o grau de relevância de um repositório em relação aos demais, através da quantificação de termos relacionados ao seu nome nos resultados de busca. Através desta análise, foi possível ao final deste processo, obter uma lista ordenada destes repositórios pela sua relevância relativa.

O critério para aplicação dos termos de busca para posterior coleta dos resultados seguiu os seguintes passos:

- Se indexador permitiu critérios compostos de termos de busca (caso do \#1 e \#4), foi inserida a expressão booleana (<repo> "digital repository") OR (<repo> "digital repositories"), onde <repo> é o nome do repositório a ser pesquisado; caso contrário (em \#2, \#3, \#5 e \#6), utilizou-se a expressão simples (<repo> "digital repository");

- Se indexador permitiu seleção do período da publicação (todos com exceção do \#3), foi optado pelos apontadores e artigos mais recentes, a partir de 2005, sendo que no caso de \#6 optou-se por retringir a busca para 2007 em diante, devido ao grande volume de ocorrências resultante. Em \#3 foram coletados registros de maneira independente a alguma data;

- Se indexador permitiu busca completa da expressão em todos os metadados do material digital (título, resumo, palavras-chave, etc) e no corpo do seu texto (caso de \#1 e \#4), optou-se por esta forma de busca; caso contrário (em \#2, \#3, \#5 e \#6) foi realizada a busca padrão, apenas nos metadados dos materiais.

A Tabela 3.4 foi diagramada com base na aplicação das regras citadas e coleta dos valores encontrados. Cada célula contém um par $\langle M, N\rangle$, onde $M$ indica o total de registros e artigos absolutos retornados pelo indexador correspondente, aplicado ao repositório em análise. Já o valor $N$ representa a normalização deste número dentre todos os demais resultados apresentados por aquele indexador, em uma escala de 0 a 100. Este último passo foi necessário para estabelecer um domínio comum (normalizado) para a comparação dos resultados obtidos pelos diferentes indexadores utilizados. De acordo com esta escala: $i$ ) 0 (zero) significa que o repositório não teve nenhuma ocorrência apontada; ii) 100 (cem) significa que o repositório obteve o maior número de citações para aquele indexador e iii) qualquer outro valor dentro deste intervalo indica um resultado intermediário.

A Tabela 3.5 finaliza este processo. Nesta são apresentadas as respectivas pontuações obtidas por cada repositório, calculada a partir da soma das ocorrências normalizadas da Tabela 3.4. Como foram utilizados 6 indexadores acadêmicos nesta análise e a nota máxima que um SGR poderia obter em cada um deles foi 100, conclui-se que a pontuação máxima que um SGR possa atingir nesta última análise seja 600. Os repositórios foram então ordenados em forma decrescente de pontuação, de modo que as linhas superiores exibam os repositórios mais citados entre os indexadores. 


\begin{tabular}{l|rrrrrr}
\hline Repositório & $\# 1$ & $\# 2$ & $\# 3$ & $\# 4$ & $\# 5$ & $\# 6$ \\
\hline CONTENTdm & $1, \mathbf{2}$ & $1, \mathbf{1}$ & $0, \mathbf{0}$ & $10, \mathbf{2 2}$ & $0, \mathbf{0}$ & $463, \mathbf{9}$ \\
Digibib & $0, \mathbf{0}$ & $0, \mathbf{0}$ & $0, \mathbf{0}$ & $0, \mathbf{0}$ & $0, \mathbf{0}$ & $11, \mathbf{0}$ \\
Digital Commons & $\mathbf{1 , 2}$ & $2, \mathbf{2}$ & $0, \mathbf{0}$ & $11, \mathbf{2 5}$ & $4, \mathbf{2 1}$ & $789, \mathbf{1 6}$ \\
DiVA & $0, \mathbf{0}$ & $2, \mathbf{2}$ & $3, \mathbf{5}$ & $0, \mathbf{0}$ & $0, \mathbf{0}$ & $109, \mathbf{2}$ \\
DSpace & $50, \mathbf{1 0 0}$ & $79, \mathbf{1 0 0}$ & $60, \mathbf{1 0 0}$ & $44, \mathbf{1 0 0}$ & $19, \mathbf{1 0 0}$ & $4783, \mathbf{1 0 0}$ \\
EPrints & $19, \mathbf{3 8}$ & $45, \mathbf{5 6}$ & $3, \mathbf{5}$ & $27, \mathbf{6 1}$ & $6, \mathbf{3 1}$ & $1638, \mathbf{3 4}$ \\
Fedora Commons & $48, \mathbf{9 6}$ & $67, \mathbf{8 4}$ & $46, \mathbf{7 6}$ & $26, \mathbf{5 9}$ & $14, \mathbf{7 3}$ & $2673, \mathbf{5 5}$ \\
Greenstone & $10, \mathbf{2 0}$ & $26, \mathbf{3 2}$ & $56, \mathbf{9 3}$ & $13, \mathbf{2 9}$ & $4, \mathbf{2 1}$ & $1256, \mathbf{2 6}$ \\
HAL & $4, \mathbf{8}$ & $6, \mathbf{7}$ & $2, \mathbf{3}$ & $1, \mathbf{2}$ & $0, \mathbf{0}$ & $329, \mathbf{6}$ \\
OPUS & $0, \mathbf{0}$ & $2, \mathbf{2}$ & $1, \mathbf{1}$ & $2, \mathbf{4}$ & $0, \mathbf{0}$ & $398, \mathbf{8}$ \\
SciELO & $0, \mathbf{0}$ & $0, \mathbf{0}$ & $0, \mathbf{0}$ & $2, \mathbf{4}$ & $0, \mathbf{0}$ & $203, \mathbf{4}$ \\
\hline
\end{tabular}

Tabela 3.4: Quantidade de ocorrências dos termos dos repositórios buscados em cada indexador

\begin{tabular}{l|r}
\hline Repositório & Pontuação \\
\hline DSpace & 600 \\
Fedora Commons & 446 \\
EPrints & 227 \\
Greenstone & 223 \\
Digital Commons & 67 \\
CONTENTdm & 35 \\
HAL & 28 \\
OPUS & 17 \\
DiVA & 9 \\
SciELO & 8 \\
Digibib & 0 \\
\hline
\end{tabular}

Tabela 3.5: Pontuação obtida pelos repositórios analisados 

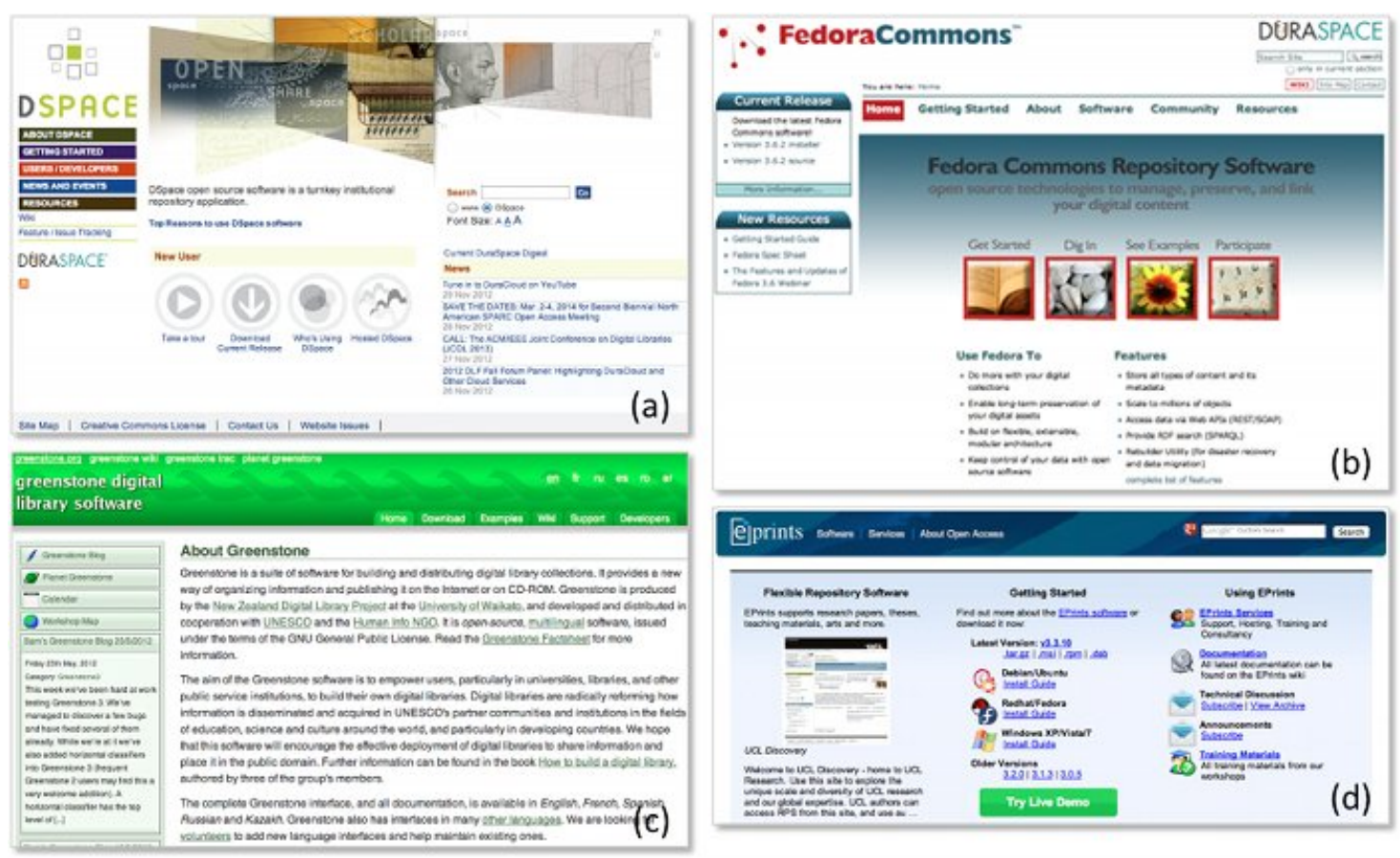

Figura 3.3: Sítios dos repositórios mais relevantes identificados na pesquisa: a) DSpace; b) Fedora Commons; c) Greenstone e d) EPrints

\subsection{Análise dos resultados obtidos}

Em particular aos propósitos deste projeto, consideram-se mais interessantes os modelos com código-fonte aberto, que possam ser descarregados a partir dos seus sítios, instalados e operados na própria máquina do usuário ou em outro servidor qualquer denominado por este. Sem dúvida, esses SGR podem ser mais facilmente inspecionados, testados e analisados. Em contrapartida, soluções comerciais que exigem estabelecimento de contratos de uso ou que são operados como serviço na Web $(R a a S)$ não são desejáveis. Estes ocultam o seu modo de funcionamento interno aos seus usuários, incluindo os desenvolvedores de potenciais soluções integradoras com os SGC.

A partir dos dados obtidos na seção anterior, conclui-se que os 4 primeiros repositórios da Tabela 3.5 (DSpace, Fedora Commons, EPrints e Greenstone) apresentam nítido destaque em comparação aos demais analisados, em relação às suas citações nos indexadores utilizados. A somatória das suas pontuações representa $90 \%$ do total da pontuação aferida ${ }^{15}$. As respectivas páginas dos seus sítios estão ilustradas na Figura 3.3. Além deste fato, esses 4 sistemas apresentam importantes características em comum e diferenciadas em relação aos demais candidatos. Estas foram determinantes para uma posterior análise de inspeção mais detalhada. São elas:

- Possuem licença gratuita de uso;

- Possuem código-fonte aberto;

- São descarregáveis a partir dos seus sítios, diretamente pelos seus códigos-fonte ou na forma de binários compilados para as principais plataformas (Windows, Linux e Mac OS);

- São Gerenciadores de Repositórios (SGR), o que significa que múltiplas instâncias de repositórios podem ser criadas e parametrizadas;

- Suportam a utilização de ao menos um Gerenciador de Banco de Dados gratuito, como o $M y S Q L$ ou PostgreSQL.

\footnotetext{
${ }^{15}$ Os 4 repositórios mais relevantes somaram 1.496 pontos, enquanto que a tabela possui ao todo 1.660 pontos.
} 

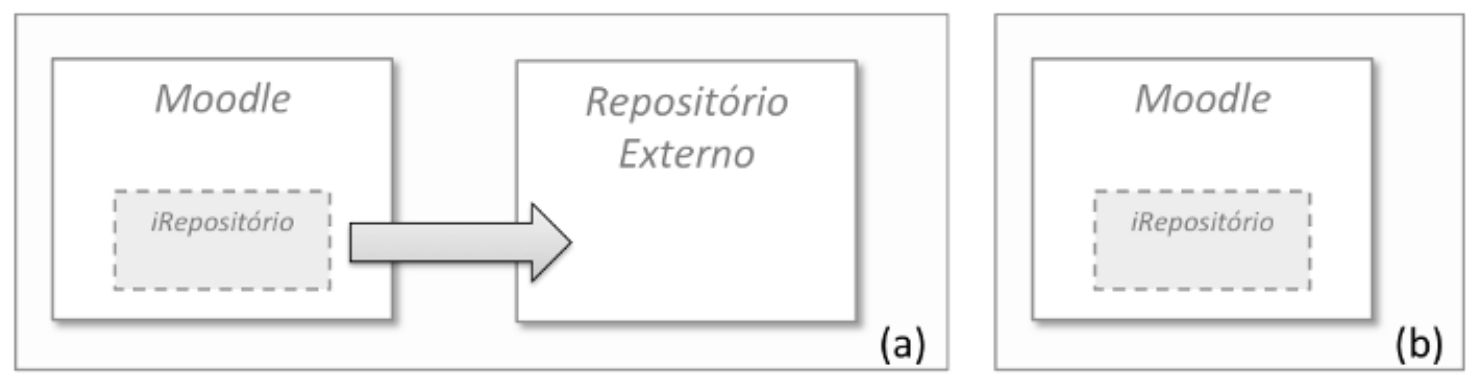

Figura 3.4: Possíveis cenários para as interações do iRepositório: a) o iRepositório visto como um integrador entre o $S G C$ e o repositório externo; b) o iRepositório servindo diretamente ao $S G C$.

Ainda que o cenário apresentado anteriormente seja otimista quanto à utilização de um destes repositórios, algumas deficiências são evidenciadas. Aschenbrenner et al. (2010) critica a falta de flexibilidade destes sistemas quanto ao seu reúso dos seus OA e sugere propostas para um novo arcabouço com funcionalidades comuns. Em outro artigo recente, Mikhail et al. (2012) relata um estudo de caso para o desenvolvimento de um repositório institucional para a Bibliotheca Alexandrina. Apesar de reconhecerem a existência de SGR disponíveis para o uso, os autores identificaram a necessidade em se construir um repositório próprio, ao considerarem que os já existentes eram, de acordo com suas palavras, "demasiadamente monolíticos", e que devido a este fato, "não proviam facilidade para criação de extensões ou para o seu reúso em outros projetos". Um sistema computacional "monolítico" tem uma arquitetura interna rígida, não-modular entre seus componentes, de modo que não existam "camadas" explícitas modulares responsáveis por tarefas específicas. Embora sejam comumente adotadas em plataformas do tipo mainframes, esta arquitetura impede que seus sistemas sejam facilmente adaptados, reutilizados ou extendidos ${ }^{16}$.

Ao contrário do Moodle (e por extensão todos os seus plugins), que é desenvolvido na linguagem PHP, estes 4 repositórios são programados em outras linguagens. Java é utilizado tanto no DSpace quanto no Fedora Commons. Já o EPrints é desenvolvido em Perl, enquanto que o Greenspace é em $C++$. Este fato é negativo quanto a estratégia em se utilizar um destes sistemas existentes para compor o repositório deste projeto.

Ainda assim, uma possível integração poderia viabilizar o projeto. Como já citado anteriormente, o projeto do iRepositório poderia ser encarado apenas como uma "ponte integradora" entre algum destes repositórios e o Moodle. Neste modelo, representado pela Figura 3.4 (a), o repositório externo adotado atenderia requisições vindas do iRepositório, que por sua vez foram solicitadas por ações do Moodle, vindas dos seus mecanismos internos ou por ações diretas dos usuários.

Neste cenário, é requisito fundamental que o repositório adotado exponha alguma forma de interface pública de comunicação com o seu meio externo. Os 4 repositórios analisados atendem a esta necessidade. Eles contam com recursos de leitura e extração de metadados dos seus OA armazenados, como é o caso, por exemplo, do protocolo $O A I-P M H^{17}$. Outros ainda oferecem recursos adicionais para manipulação dos seus objetos e inserção de novos conteúdos digitais (apesar de dependerem da instalação de plugins para o oferecerimento destas funcionalidades). Dos analisados, o que disponibiliza um conjunto mais flexível de comandos na sua interface pública é o Fedora Commons. Ele conta com uma ampla gama de recursos para gestão e manutenção do seu repositório e dos seus OA, através de uma interface via "serviços-web", utilizando os protocolos $S O A P^{18} \mathrm{e}$ $R E S T^{19}$, ambos baseados na Web para transferência de conteúdos digitais.

\footnotetext{
${ }^{16}$ Fonte: http://en.wikipedia.org/wiki/Monolithic_application. Acessado em 12/10/2013.

${ }^{17}$ OAI-PMH, ou ainda, Protocolo OAI, é o acrônimo de Open Archives Initiative Protocol for Metadata Harvesting. Estruturado em XML, é utilizado para coletar e arquivar metadados a partir de repositórios de conteúdos digitais. Fonte: http://en.wikipedia.org/wiki/OAI-PMH. Acessado em 25/01/2014.

${ }^{18}$ SOAP é o acrônimo de Simple Object Access Protocol. Sua primeira especificação foi desenvolvida em 1988 pela Microsoft e desde 2003 é mantido e recomendado pelo Consórcio W3C, como parte componente da Linguagem de Descrição de Serviços-Web (WSDL). Fonte: http://en.wikipedia.org/wiki/SOAP. Acessado em 25/01/2014.

${ }^{19}$ REST é o acrônimo de Representational State Transfer. Sua proposta foi apresenta em 2000 e é baseada na arquitetura existente da Web para representação e transferência de conteúdos. Fonte: http://en.wikipedia.org/wiki/
} 
Apesar da relativa facilidade de integração entre o repositório que oferece uma interface pública e um cliente externo (neste caso o iRepositório), este cenário ainda deve ser analisado com certas restrições, quanto a sua viabilidade prática.

Normalmente sistemas "clientes" de repositórios externos realizam requisições ad-hoc esporádicas nesses sistemas, como por exemplo, para arquivar um certo recurso digital ou realizar buscas de acordo com critérios especificados pelos seus usuários. Por outro lado, o modelo proposto pelo iRepositório exige uma série de requisições adicionais, que poderiam sobrecarregar o canal utilizado entre ambos para estas comunicações e trocas de conteúdos. O Capítulo 4 aborda mais adiante em detalhes alguns destes eventos. Alguns exemplos são: $i$ ) a coleta automática de avaliações submetidas por todos os alunos em uma determinada atividade e $i i$ ) durante o processo de mineração de dados do seu repositório para extração de informações pertinentes ao uso dos seus OA. Como consequência imediata destes cenários, prevê-se uma degradação considerável da performance geral do modelo, em vista do alto tempo de latência estimado, exigido entre as requisições deste cliente e a devolução dos dados.

Outro fato negativo à adoção de repositórios externos diz respeito a um dos requisitos fundamentais do projeto do iRepositório: o de promover a facilidade na instalação, parametrização e uso deste repositório no Moodle aos seus usuários mantenedores. Mesmo que algum destes 4 repositórios candidatos compartilhassem a mesma infra-estrutura deste SGC (o que não ocorre na prática por não serem desenvolvidos na linguagem de programação $P H P$ ), estes sistemas externos não ofereceriam as facilidades desejadas e descritas acima ao projeto. Seria necessário que os responsáveis pela instância do Moodle também fizessem a gestão e monitoramento de um sistema adicional (o repositório externo), além da sua infra-estrutura particular e requisitos de sistemas de apoio. Além disso, demandam um tempo considerável para a sua parametrização, definição de políticas de segurança, criação das contas de usuários, dentre outros aspectos técnicos [Lam e Chan (2007)]. Ao considerar este cenário, pode-se afirmar que estes exigem profissionais especializados para realizar sua instalação, manutenção e garantia da sua plena capacidade de operação.

Estes dois fatos anteriores contribuíram e reforçaram para a tomada final da decisão para a não adoção de algum repositório externo ao Moodle. A partir da análise desses cenários, concluiu-se que a estratégia mais adequada seria a de desenvolver um repositório compatível com esse SGC, na forma de um componente (plugin). Deste modo ele poderia ser descarregado a partir do seu sítio oficial e instalado na própria infra-estrutura do SGC, de maneira semelhante a outros componentes (módulos, blocos, filtros, etc) que oferecem esta funcionalidade. Nenhum pacote adicional ou dependência externa seria exigido neste cenário, ao contrário dos repositórios externos que solicitam com frequência estes recursos ou atualizações prévias de componentes do servidor.

Além das vantagens citadas, outro fator positivo para o desenvolvimento de um repositório na forma de um componente do próprio Moodle é o de poder compartilhar sua estrutura interna (arcabouço) existente. A Figura 3.4 (b) ilustra este caso. O SGC dispõe de diversas implementações de bibliotecas auxiliares de funções, classes de objetos, renderizadores das interfaces do usuário, regras de negócio pré-definidas (como contas de usuários e controle de autorização), etc. Isto traz um benefício considerável em termos de tempo demandado para desenvolvimento e testes do novo módulo, em comparação ao desenvolvimento de um sistema isolado, desde suas porções mais elementares e fundamentais.

O próximo capítulo descreve o modelo conceitual utilizado pelo iRepositório. Neste, não são considerados os detalhes acerca do SGG que será o adotado como sua base. Entretanto, já se prevê no seu modelo proposto uma arquitetura semelhante ao da Figura 3.4 (b), em que ele é o próprio servidor de repositório de OA e não apenas uma "ponte integradora" para um sistema especialista externo. Mais adiante, no Capítulo 5, são evidenciadas as estratégias e resultados da sua implementação de fato no SGC Moodle.

$\overline{\text { Representational_state_transfer. Acessado em }}$ 25/01/2014. 


\section{Capítulo 4}

\section{Proposta conceitual do iRepositório}

A revisão da literatura apresentada no Capítulo 2, tomada em conjunto com o estudo exploratório de repositórios do Capítulo 3, ofereceram subsídios para a definição das características e funcionalidades do projeto conceitual do iRepositório. Os principais modelos que foram utilizados como embasamento deste projeto foram os 4 SGC descritos no capítulo anterior, que mais se destacaram pelas suas características, similaridades e propostas para integração com sistemas terceiros (neste caso em particular com o SGC Moodle).

As próximas seções ilustram os principais pontos-chaves deste projeto, compilados a partir das observações dos repositórios supracitados. Por ser tratar da descrição de um modelo conceitual, ainda não há neste capítulo uma referência explícita a um SGC em específico. Sua implementação e integração serão descritas no capítulo seguinte.

\subsection{Representação interna de um OA}

A Figura 4.1 exibe a estrutura geral de representação interna de um OA armazenado no iRepositório. Este modelo foi desenvolvido com base numa adaptação dos adotados pelos repositórios DSpace e Fedora Commons. Em termos gerais, é composto por duas seções distintas: a primeira que representa suas informações a respeito de características e controle interno e a segunda com uma possível lista de arquivos, que contêm, por sua vez, os seus materiais e conteúdos auxiliares propriamente ditos. A seguir uma breve descrição sobre cada um deles.

\subsubsection{Registro único}

Sua função é identificar, de forma precisa e inequívoca, cada OA armazenado no repositório. É um atributo que exige um valor único e exclusivo para cada um desses. Qualquer outro item do repositório que estabeleça alguma forma de associação com o OA (como por exemplo avaliações de usuários, rastreadores de versões, relacionamentos entre objetos, etc) devem referenciá-lo utilizando o valor contido neste campo.

Por representar uma informação vital para o controle interno do OA, nenhum outro componente, ou qualquer usuário do ambiente, têm permissão para definí-lo, além do próprio repositório. Ele é gerado automaticamente pelo sistema, sempre que um novo conteúdo é criado ou importado e permanece imutável, independente de qualquer outra ação que venha a ocorrer no futuro. Isso é válido durante todo o seu ciclo de vida, até mesmo numa possível ação de descarte pelo seu autor. Em outras palavras, mesmo que o OA já tenha sido removido, ele ainda preservará seu valor único e inalterado.

Como o valor do registro único tem relevância apenas para o controle do próprio objeto pelo repositório, ele geralmente permanece oculto aos seus usuários finais. Na grande maioria dos casos, estes desconhecem seu valor ou até mesmo sua própria existência. 


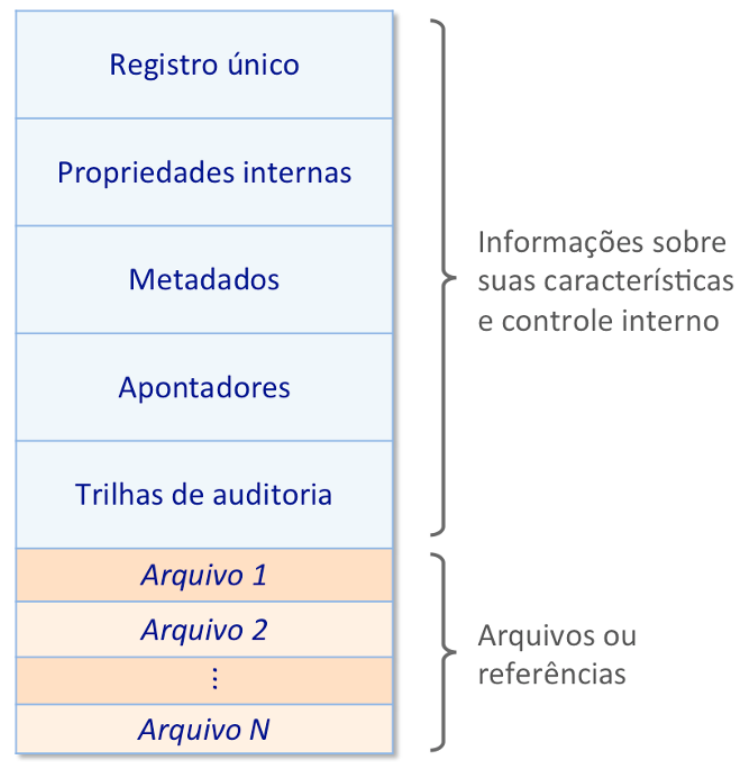

Figura 4.1: A estrutura interna de um $O A$ do iRepositório.

\subsubsection{Propriedades internas}

Propriedades internas são conjuntos de tuplas do tipo "chave/valor" que podem qualificar, caracterizar e servir de base para o controle de cada OA no repositório. O conjunto de chaves é pré-determinado no modelo do repositório e independe do tipo de anotação de metadado adotado pelo repositório. Um objeto pode conter no máximo uma ocorrência de cada par "chave/valor". De acordo com a chave, o próprio autor do conteúdo deve fornecer seu conteúdo. Caso contrário, o repositório contempla as regras necessárias para o seu cálculo e registro interno. As seguintes chaves são previstas no modelo do iRepositório:

- Rótulo - valor fornecido pelo autor durante a autoria do OA. O repositório não impõe regra rígida quanto ao seu preenchimento. Representa o nome deste objeto, geralmente escrito em formato "legível" ou "humano", com uma cadeia limitada de caracteres, que seja representativo e de fácil memorização. É uma das primeiras informações a serem exibidas ao público em geral que estiver visitando-o, seja através de um resultado de uma busca ou lista de objetos recomendados;

- Descrição - chave análoga à do rótulo. Seu conteúdo distingue-se da anterior por não impor um limite de caracteres para o seu conteúdo. É possível a inserção de textos em formato HTML. Assim como o rótulo, a descrição pode ser exibida aos usuários que estiverem visitando o objeto, seja numa tela com informações gerais sobre ele ou ainda numa janela do tipo pop-up, que exibe informações complementares;

- Identificador - valor fornecido pelo autor durante a autoria do OA ou indicado automaticamente por alguma ferramenta de importação em lote destes objetos. Quando o autor utiliza um novo valor para a chave identificador (algum valor ainda não utilizado anteriormente), ele passa a deter aquele nome consigo. Em outras palavras, seu valor não poderá mais ser utilizado por nenhum outro usuário no futuro para qualificar o identificador dos seus objetos. Não há necessidade que o valor do identificador seja "legível" aos usuários (como é o caso do rótulo). Ele pode ser composto por uma sequência de caracteres do alfabeto, números ou símbolos. Internamente, ele é utilizado para o controle interno da "família de OA" ao qual ele pertença. Uma "família" contém um ou mais objetos semelhantes, que vão sendo criados ao longo do tempo pelo repositório, a cada atualização realizada pelo seu autor;

- Versão - usuário não manipula seu valor. Esta chave é utilizada pelo repositório sempre em conjunto com o indentificador. Cada objeto que sofre atualização é internamente clonado 


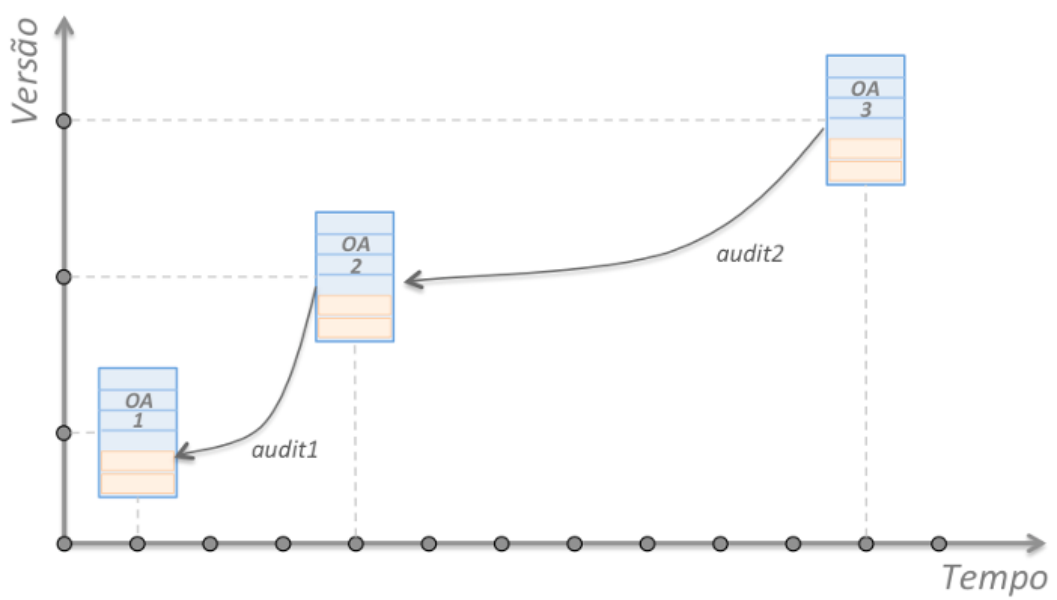

Figura 4.2: Representação do controle de versão de um objeto da família "OA" do iRepositório ao longo do tempo e suas trilhas de auditoria.

pelo repositório. Sua chave identificadora permanece com o mesmo valor (são OA pertences a mesma "família"), porém o número da sua versão é atualizado, de forma automática e transparente ao usuário. Desta forma, um par de chaves "identificador/versão" é único para todo objeto do iRepositório. A Figura 4.2 ilustra um caso hipotético de versionamento de um objeto da família denominada por "OA". A cada atualização daquele conteúdo, sua versão parte do valor 1 para 2 , em seguida para 3 e assim por diante;

- Tipo - utilizado internamente pelo iRepositório, registra o tipo de conteúdo relativo ao objeto armazenado, como por exemplo, uma questão de avaliação, um $i M A$ ou uma atividade do $i T a-$ refa. Ferramentas que fazem operação de importação e exportação de objetos em lote, podem utilizar o valor desta chave durante estas ações. De forma semelhante, esta informação pode ser consultada pelo iRepositório para determinar quais deles pertencem a um determinado tipo requisitado, durante um processo de discriminação e agrupamento de objetos;

- Proprietário - chave preenchida automaticamente pelo sistema, registra o valor correspondente ao usuário que criou o objeto. O valor desta chave representa, a princípio, o seu próprio autor. Num instante mais adiante, ele poderá ser transferido ou concedido a outro proprietário (outro usuário ou instituição, por exemplo). Seu valor é utilizado pelo iRepositório, para determinar o tipo de acesso que um usuário assumirá sobre ele. Usuários em geral podem realizar buscas por objetos ou ainda utilizar este valor para localizar conteúdos de um determinado proprietário. Já o proprietário do objeto tem direitos adicionais, como a edição e remoção do mesmo;

- Licença - valor indicado pelo autor do objeto. Representa o seu tipo de licença autoral, como por exemplo, de "domínio púbico", "todos os direitos reservados" ou ainda qualquer derivação da Creative Commons;

- Estado - utilizado internamente pelo iRepositório. Um objeto sempre tem um valor para o seu estado, independente do instante no tempo. Este pode variar entre as seguintes situações: $i$ ) "inativo" para os que estiverem em processo de autoria (portanto ainda não disponíveis ao uso público geral); ii) "ativo" para representar um objeto com potencial pleno de disponibilidade; iii) "removido" para marcar os descartados pelos seus autores; iv) "bloqueado" para indicar objetos temporariamente inacessíveis ao público (por estarem em processo de atualização pelos seus autores, por exemplo) e v) "obsoleto", indicados pelos seus autores como ainda válidos para serem referenciados por outros usuários, porém com conteúdo defasado em relação à outras versões mais recentes e atuais da sua família. A Figura 4.3 representa o Diagrama de Estados de um objeto no iRepositório. Cada um dos vértices representa um dos 5 possíveis estados descritos anteriormente e as arestas as transições permitidas entre eles. O vértice do 


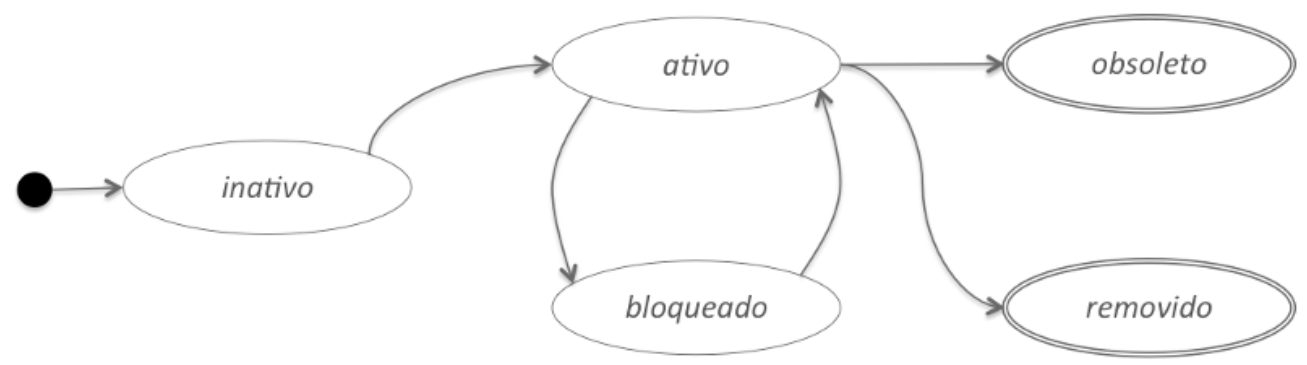

Figura 4.3: Diagrama de Estados de um OA do iRepositório.

estado "inativo" é o caminho inicial para as demais transições. Já os vértices indicados com linhas duplas (estados "obsoleto" e "removido") são terminais, ou seja, não é possível retornar a outro estado após atingir estes destinos;

- Assinatura - utilizado internamente pelo iRepositório. Contém uma sequência de 32 dígitos em formato hexadecimal, que identificam unicamente um determinado OA dos demais. Ela é calculada e registrada automaticamente, sempre que um novo objeto é criado ou alterado pelo seu autor. Alguns dos valores dos atributos internos do OA (rótulo, descrição, identificador, versão, tipo, licença, etc), metadados e apontadores são utilizados por uma função de hashing para o cálculo desta cadeia. Este valor é futuramente consultado pelo iRepositório sempre que uma nova solicitação de armazenamento de OA for requisitada. Antes da criação efetiva de um novo material, sua assinatura é confrontada com as demais já existentes no repositório, para avaliar se esse representa de fato um novo contéudo.

\subsubsection{Metadados}

O iRepositório contempla o armazenamento e recuperação de coleção de metadados para cada um dos seus objetos. Estes são registrados pelo seu próprio autor, num local apropriado nas estruturas internas do objeto. Isto ocorre durante o processo da sua criação ou num momento posterior, quando houver necessidade da sua atualização pelo seu autor. Neste último caso em particular, o objeto é internamente clonado pelo repositório e uma nova versão é gerada de acordo com suas informações mais recentes. A versão anterior é marcada com o estado "obsoleto".

O modelo do repositório é flexível o suficiente para trabalhar com uma coleção de metadados mais apropriada ao modelo do seu negócio, indicada pelo seu administrador. É previsto que futuramente outras coleções de metadados poderão ser agregadas, caso necessário. Inicialmente, há a possibilidade de escolha entre dois padrões abertos internacionais, amplamente utilizados para representação de OA e de outros conteúdos em geral, disponibilizados na forma digital ou tradicional em recursos físicos (mídia impressa, $\mathrm{CD}$, etc):

- IEEE LOM - especificação 1484.12.1, de Julho de $2002^{1}$, é um padrão de anotação descritor de OA, promovido pelo Comitê de Padrões de Objetos de Aprendizagem do Institute of Electrical and Electronics Engineers (IEEE). Seu modelo, representado pela Figura 4.4, é estruturado numa forma hierárquica de grupos de atributos semelhantes.

- Dublin Core - especificação 1.1, de Junho de $2012^{2}$, é um padrão de anotação geral de itens (incluindo-se também os OA) promovido pela Iniciativa de Metadados Dublin Core. Sua especificação simplificada contém 15 elementos descritores do seu vocabulário.

\subsubsection{Apontadores}

Um OA pode ser estruturado a partir da composição de um ou mais OA distintos. A Figura 4.5 ilustra um caso prático. O objeto identificado por "quest", do tipo "Questionário", agrega uma coleção

\footnotetext{
${ }^{1}$ Disponível em http://ltsc.ieee.org/wg12/files/LOM_1484_12_1_v1_Final_Draft.pdf.

${ }^{2}$ Disponível em http://dublincore.org/documents/dces/.
} 


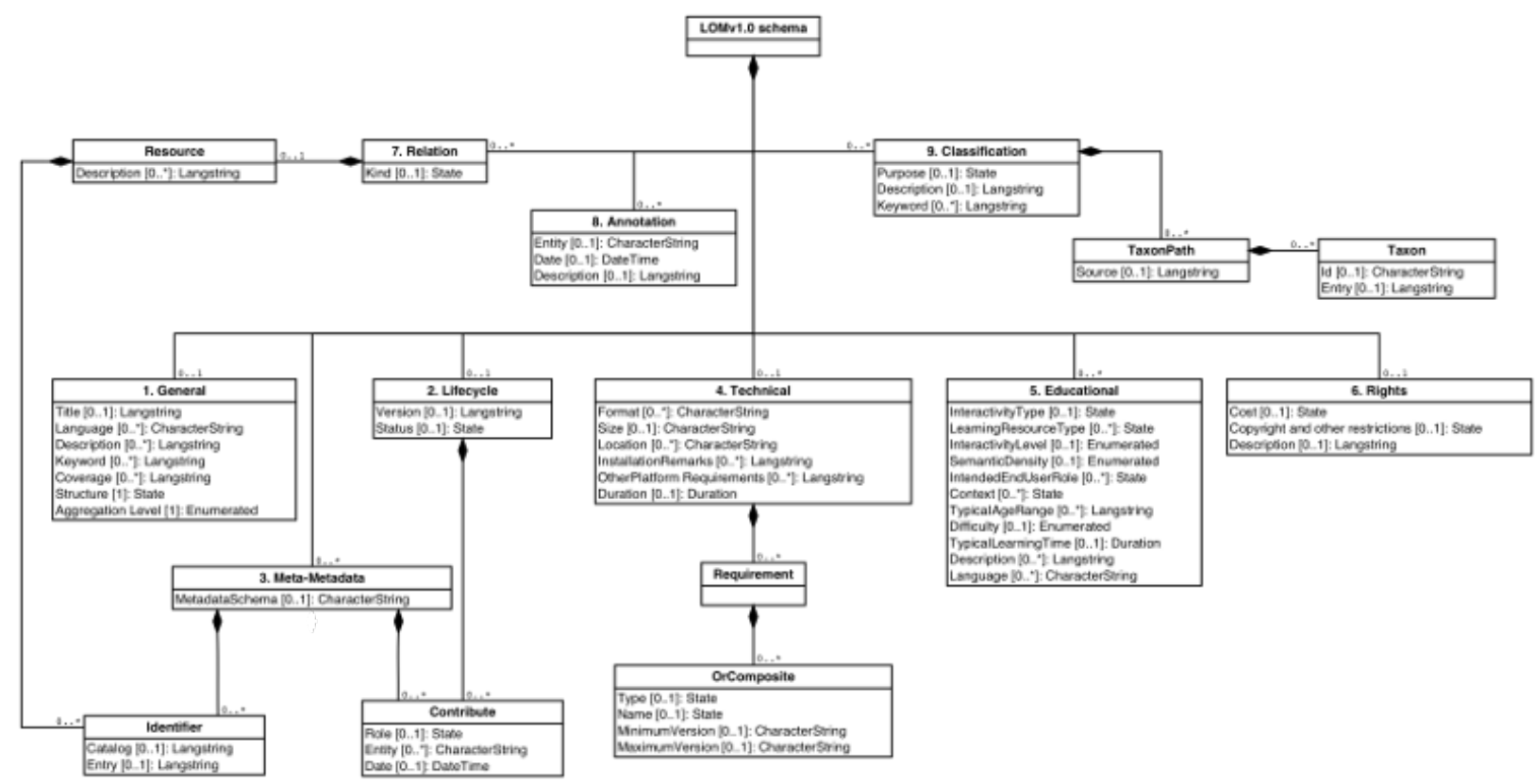

Figura 4.4: O modelo de metadados IEEE LOM. Fonte: IEEE LOM, especificação 1484.12.1-2002.

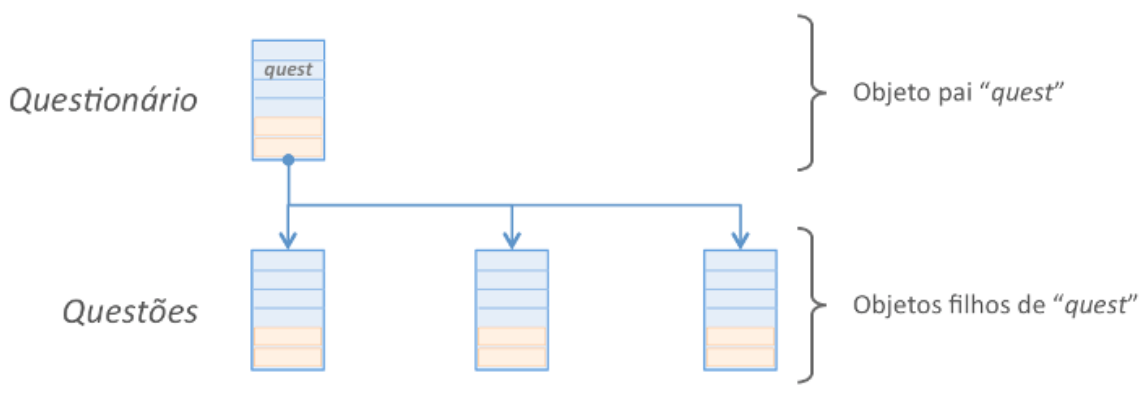

Figura 4.5: Estrutura hierárquica de $O A$ através do uso de apontadores.

de vários outros objetos do tipo "Questão". O primeiro, que detém o vínculo lógico, é denominado por objeto "pai", ou "OA superior". Já os demais, referenciados por esse, são os seus "filhos", ou "OA inferiores". A interpretação do significado do apontador é "contém" e parte do OA superior e alcança os OA inferiores.

Este vínculo é possível graças ao registro interno dos apontadores de OA. Estes registram e referenciam um coleção de um ou mais objetos "filhos". Não há obrigatoriedade de que todos os "filhos" de um determinado "pai" sejam de um tipo comum de objeto. Em outras palavras, um objeto do tipo "Questionário" pode ser estruturado a partir da composição de objetos do tipo "Questão" e outros objetos com conteúdo estático em PDF, por exemplo. Nota-se também que não existe uma dependência entre os OA inferiores em relação ao seu superior. Cada um dos OA do tipo "Questão" do exemplo anterior, pode ter autonomia própria e ser utilizado por um determinado usuário de maneira livre ao OA que o referencia.

Não há limite para o número de objetos apontados por um "pai". De maneira similar, também não existe um limite para o número de objetos distintos que apontam um mesmo "filho". Além disso, também é possível deduzir a representação de estruturas hierárquicas mais complexas, com 2 ou mais sub-níveis. Um determinado OA, que é "pai" de algum "filho", pode por sua vez ser um "filho" de outro OA superior e assim sucessivamente. Tomando-se outro exemplo, representado pela Figura 4.6, que parte de uma construção semelhante a anterior, pode-se imaginar um objeto superior, do tipo "Aula", que contém uma coleção de "Tarefas", que por sua vez contêm outros OA mais simples. Sendo assim, um autor de conteúdo pode publicar objetos com alto grau de granularidade, formados por diversos outros OA mais elementares e triviais do que ele. 


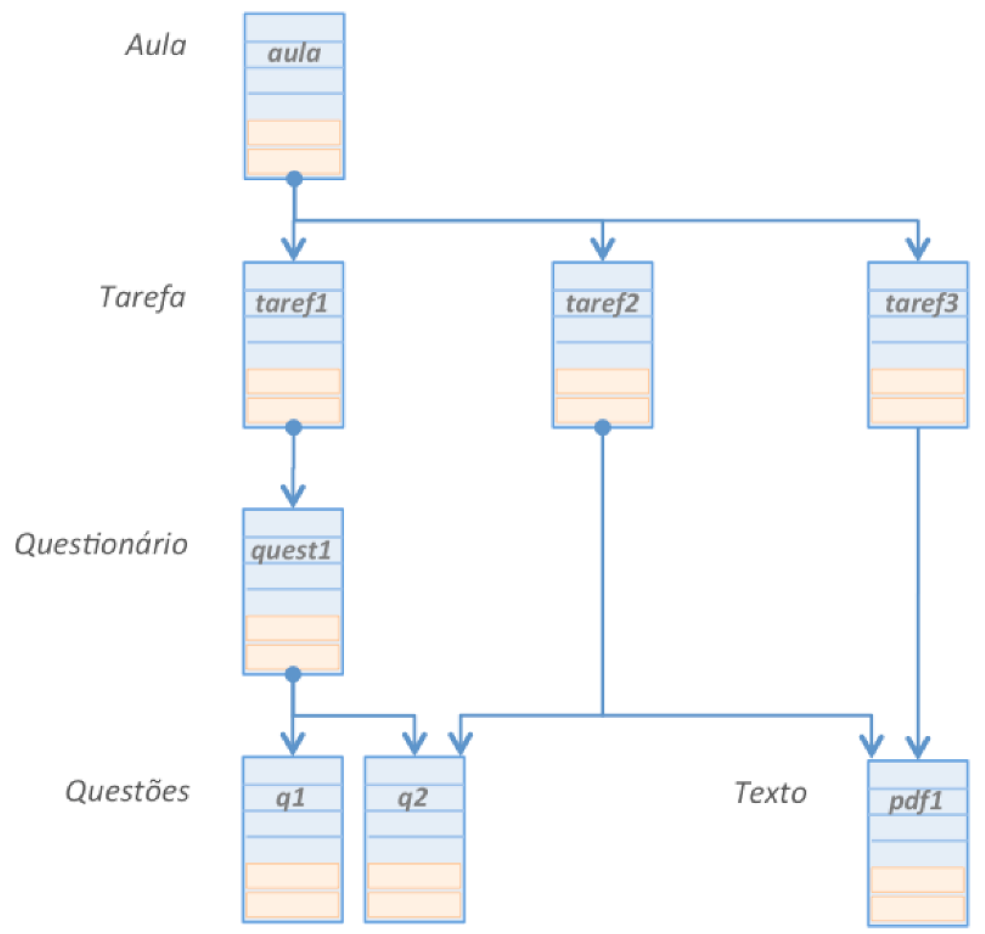

Figura 4.6: Estrutura hierárquica de $O A$ com múltipos sub-níveis e apontamentos.

\subsubsection{Trilhas de auditoria}

Armazenam, de maneira automática e transparente aos usuários e aos autores de conteúdo, todas as alterações (em propriedades internas, metadados, apontadores, etc) já sofridas pelo OA ao longo do seu ciclo de vida. É de certa forma análoga a um controle de versionamento de códigofonte, utilizada em ambientes de desenvolvimento de sistemas. Um usuário pode, por exemplo, realizar buscas por dados históricos em um determinado OA, comparar a evolução dos valores em seus registros internos ao longo das versões da sua "família" ou ainda recuperar qualquer uma das versões anteriores de um OA, que estejam atualmente em estado "obsoleto", para recriá-las em estado "ativo".

Internamente, as trilhas de auditoria são mantidas pelo modelo do iRepositório a partir de recursos semelhantes aos registros dos apontadores de OA. Cada ação de clonagem de um objeto, a partir de eventos de alteração dos seus registros, acaba por gerar um novo material com estado "ativo", que faz referência automática ao seu antecessor, agora em estado "obsoleto". Desta maneira, as ações descritas de rastreamento das alterações de um OA ao longo do tempo são viáveis graças a esta "cadeia" de apontamentos que um objeto mais recente mantém com o seu antecessor direto. A Figura 4.2 exibe estas referências entre versões distintas de objetos da mesma "família".

\subsubsection{Arquivos e referências externas}

Cada OA do iRepositório pode conter uma coleção de arquivos digitais estáticos. Alguns destes são utilizados diretamente pelo seu autor e em conteúdos da sua aula. Alguns exemplos são OA do tipo "leitura de texto", que contêm diversos arquivos PDF, ou ainda materiais de áudio, formados por arquivos do tipo mp3. O autor utiliza a tupla "identificador/versão/nome do arquivo" para referenciar um arquivo que é especificado pelo seu nome e que seja localizável através do identificador e versão do seu objeto referenciador.

Já em outros tipos de objetos, arquivos são utilizados internamente para armazenamento de informações próprias ao seu controle (sem o uso direto pelos seus usuários em conteúdos do seu curso, por exemplo). Um caso típico é o objeto do tipo "questão". Um dos seus arquivos, tratado diretamente pelo módulo compatível com este tipo, contém a sua estrutura interna empacotada em 
formato XML. Através desta, o OA preserva suas informações básicas acerca de como ele deve ser extraído e desempacotado em uma ferramenta compatível no SGC.

Esta coleção de conteúdos mantida pelo OA pode conter tanto arquivos próprios, armazenados internamente quanto apenas suas referências públicas para sítios externos. Neste último caso, o seu autor deve referenciá-lo com o uso de uma $U R L$ válida para o mesmo, de modo que este seja descarregado e lido pelo iRepositório quando necessário.

Assim como as demais propriedades do OA do iRepositório supracitadas, qualquer alteração nos seus arquivos, seja para inclusão ou remoção, gera uma ação consequente semelhante: o repositório cria automaticamente um novo objeto da mesma família, com estado "ativo" e versão mais recente e ao mesmo tempo marca o anterior com o estado "obsoleto". Entretanto, algumas exceções podem ocorrer. Existe um determinada classe de arquivo referenciada pelos objetos, cuja ação de inclusão ou remoção não aciona o evento descrito anteriormente, ou seja, o objeto preserva suas características, versão e estado atual. O Capítulo 5 trata com maiores detalhes a respeito desta classe de arquivos e quando estes são utilizados pelos objetos e repositório.

\subsection{Coleta e armazenamento de dados históricos sobre a utilização do OA}

Num SGC típico, como é o caso do Moodle, seus próprios componentes de atividades interativas são os responsáveis pelo armazenamento e recuperação dos dados pertinentes ao conteúdo específico de cada uma das suas instâncias. Para ilustrar um caso prático, podemos tomar como exemplo o seu módulo de questionário. O autor de uma atividade deste tipo prepara o seu conteúdo - neste caso composto por uma ou mais questões - e o armazena nos registros internos do SGC. Num segundo instante, o aluno requisitará este material a partir do seu ambiente. O Moodle deverá solicitar ao módulo responsável (o questionário) a extração de todas as suas questões componentes, a partir da sua base de dados. Após a submissão desta atividade pelo aluno, o SGC solicita novamente ações adicionais daquele componente, para que avalie este material e armazene internamente seus resultados.

A proposta do iRepositório dentro deste cenário é a de atuar como um componente central, mediador destes processos. Os componentes do SGC responsáveis até então pelo armazenamento e recuperação dos conteúdos digitais das suas instâncias poderão delegar estas tarefas ao repositório. Este último passará a registrar tais conteúdos na forma de OA, com as anotações previstas na sua estrutura interna.

Uma série de possibilidade interessantes podem ser evidenciadas neste novo modelo. Uma delas segue da própria definição do OA no contexto do repositório, como por exemplo as anotações previstas nos seus metadados e o controle de versão do seu conteúdo. Além disso, sendo um elemento central entre os componentes de atividades e seus respectivos conteúdos (os OA), o iRepositório é capaz de monitorar em tempo real e de forma transparente ao módulo, um conjunto de eventos pertinentes aos seus interesses. Alguns destes são os dados sobre a requisição destes conteúdos por parte dos alunos (quando e quem solicitou o OA) e sobre as suas avaliações (qual nota foi atribuída ao aluno para uma certa atividade, ou ainda quais atividades os alunos receberam avaliações mais relevantes).

O registro dessas informações acadêmicas de um determinado OA pelo repositório ainda abre algumas possibilidades a serem exploradas futuramente. Uma das frentes de destaque de pesquisa e que possui interesse imediato nestes dados é o da Mineração dos Dados Educacionais. Ela trata a respeito do estudo e desenvolvimento de metodologias para a exploração de dados provenientes a partir de contextos educacionais [Romero e Ventura (2010)]. Segundo estes autores, dentre os possíveis processamentos relevantes a serem realizados, poderiam ser citados as observações de padrões em avaliações dos alunos e identificação de OA com qualidade produzidos pelos professores. 


\subsection{Classificação e busca de materiais digitais}

Um mecanismo adequado de classificação dos metadados de OA é crucial para a sua posterior busca e localização, para que possa ser consultado ou ainda reutilizado pelos professores [Duval (2001)]. Entretanto, uma série de barreiras ainda são evidenciadas para a sua adoção efetiva.

Existem atualmente alguns padrões de metadados voltados aos OA, como por exemplo o IEEE $L O M$ e Dublin Core, mas a interoperabilidade entre eles não é plena. Alguns estudos apontam para estas dificuldades e algumas propostas já foram sugeridas. A especificação IMS Digital Repository Interoperability ${ }^{3}$, propôs uma anotação para garantia da troca de dados entre padrões pré-existentes. Outra estratégia abordada é a adoção de modelos descentralizados (ponto-a-ponto) de repositórios, que utilizam protocolo especializados para o intercâmbio de dados e OA entre as suas distintas instâncias [Retalis (2004); de Santiago e Raabe (2011)]. Apesar dos esforços e êxitos alcançados, esta questão ainda apresenta lacunas abertas [Blat et al. (2006)].

Outra deficiência frequentemente identificada é com relação ao tempo demandado pelo autor do OA para classificá-lo de forma adequada, consistente e coerente, justificado pela considerável quantidade de informações a serem registradas em cada um destes durante o seu processo de autoria.

O iRepositório não tem como pretensão entregar uma solução definitiva para estes problemas, mas irá colaborar e contribuir com alguns benefícios na área de anotações de metadados de OA. Como já citado anteriormente a respeito das estruturas internas do OA no repositório, o projeto contemplará dois dos principais padrões de anotação de metadados discriminados desde Duval (2001), para conteúdos didáticos: o IEEE LOM e o Dublin Core. Como consequência direta, buscas realizadas pelos usuários serão mais sofisticadas e precisas do que as oferecidas pelos módulos de atividades padrões do SGC. Além disso, por contarem com padrões internacionais de anotação de metadados, amplamente utilizados para conteúdos digitais em geral, os OA do iRepositório poderão ser indexados, se necessário, em repositórios externos que ofereçam compatibilidade com estes padrões.

\subsection{Recomendação de OA}

O modelo do iRepositório conta com mecanismos para recomendação de OA aos autores de conteúdo. Esta ação pode ocorrer através de dois modos distintos:

- Ação ativa de autores, que podem recomendar de forma manual objetos do repositório aos seus pares. Uma recomendação é feita para um ou mais objetos e há a possibilidade de inserção de comentários pertinentes durante esta ação. Tanto a lista de OA recomendados quanto os comentários, serão disponibilizados aos autores destinatários desta comunicação;

- Recomendação feita a partir do próprio repositório, através de avaliação periódica sob o conjunto de OA recentemente visitados e descarregados pelos autores do repositório. A partir desta análise, o repositório atualiza uma estrutura contendo conjuntos de autores que guardam entre si certa semelhança de utilização do repositório, de acordo com OA similares visualizados e descarregados. De posse destes grupos, ele passa a recomendar objetos aos autores pertencentes a estes grupos, sempre que um dos autores gerar um destes eventos monitorados (visualizar ou descarregar conteúdos).

O sistema de recomendação não compreende apenas a notificação em si feita aos interessados. Todo evento deste tipo é monitorado pelo repositório, que registra tanto os objetos recomendados quanto os usuários envolvidos. De posse destes dados, o iRepositório pode avaliar OA com boa reputação, ao considerar os que sejam recomendados por múltiplos autores distintos num certo intervalo de tempo. O sistema de reputação de OA é descrito na seção seguinte com maiores detalhes.

As recomendações de objetos aos autores de conteúdo e demais usuários interessados são feitas a partir de notificações. Assim como outros possíveis comunicados do iRepositório aos seus usuários,

\footnotetext{
${ }^{3}$ Disponível em http://www.imsglobal.org/digitalrepositories/driv1p0/imsdri_infov1p0.html.
} 
este sistema é responsável apenas pela geração do seu conteúdo (o texto em si do comunicado), o seu emissor e lista de destinatários. Já os meios de transmissão são delegados ao SGC e não fazem parte, portanto, do seu modelo. Desta maneira, cabe ao SGC a definição de regras e políticas para definição do meio de transmissão e divulgação destes, seja via correio eletrônico, painel informativo, canal $R S S$, dentre outros. De forma semelhante, também caberá ao mesmo sistema as regras de notificação aos destinatários, bloqueios de destinatários ou de emissores.

\subsection{Reputação de OA e de autores de conteúdo}

A literatura descreve algumas técnicas para mensuração da reputação e qualidade geral de OA. Uma das características chaves para estimativa da qualidade destes materiais é o número de avaliações positivas que eles recebem por outros autores ao longo da sua utilização em cursos nos ambientes dos SGC. O trabalho de Cruz et al. (2008) descreve um modelo de reputação baseado num contexto de "Comunidade de Prática", que em termos gerais, avalia um determinado conteúdo de acordo com o grau de concordância entre seus membros em avaliações de materiais compartilhados. Como consequência, as evidências da qualidade podem ser consideradas para o processo de priorização e ranqueamento dos resultados de buscas de OA realizadas pelos usuários no repositório.

De maneira análoga, autores de conteúdo também podem ser classificados segundo sua reputação, que pode variar de acordo com os seus objetos considerados com boa qualidade e que estejam publicados no repositório. Objetos de autores que possuam boa reputação terão consequentemente maior destaque em resultados de busca.

O iRepositório utiliza um conjunto destas métricas para mensurar e qualificar seus OA. Uma delas é o número de acessos que o OA possui recentemente (nos últimos 2 anos, por exemplo) e é calculada com base na proposta de monitoria e coleta de dados históricos sobre a sua utilização, evidenciados na seção anterior. Outro critério é o da avaliação de OA diretamente pelos autores de conteúdo, através de uma escala linear de notas, que variam de 0 a 10, sendo esta última a mais positiva para indicar boa qualidade do material.

\subsection{Não-duplicidade de arquivos e de OA}

Em alguns casos práticos, podem ocorrer duplicidades e redundâncias desnecessárias em materiais digitais em repositórios de conteúdos. Em geral, os mais comuns, representados na Figura 4.7 (a), são:

- Arquivos digitais idênticos referenciados pelos OA - quando dois ou mais OA apontam para arquivos digitais idênticos, que estão replicados fisicamente no sistema de arquivos, sendo cada uma das cópias referenciadas por um OA em específico;

- OA idênticos referenciados por outros $O A$ - quando dois ou mais OA apontam para outros OA idênticos, que estão replicados no repositório, sendo cada uma das cópias referenciadas por um OA em específico. Isto pode ocorrer em processos de importação em lote de materiais para o repositório. Conteúdos que já haviam sido armazenados na forma de OA, podem tornar-se duplicados após um segundo processo de importação, pelo mesmo autor ou por outros.

O iRepositório conta com mecanismos internos que evitam ambos os cenários descritos. Deste modo, materiais adicionais não são instanciados e armazenados de forma desnecessária. Internamente, o repositório realiza este controle, tanto para os arquivos referenciados pelos OA quanto pelos próprios OA, através do controle de assinatura dos mesmos. Estas estão representados na Figura 4.7, abaixo de cada recurso referenciado pelo objeto - com um cadeia hipotética simplificada de caracteres, para efeito de ilustração.

Cada arquivo referenciado por um OA possui uma assinatura interna, calculada pela função de hashing MD5. Antes que qualquer outro arquivo digital seja referenciado por algum OA do repositório, seu conteúdo é primeira analisado por aquela função. Caso a sua assinatura seja a 
OA / arquivo
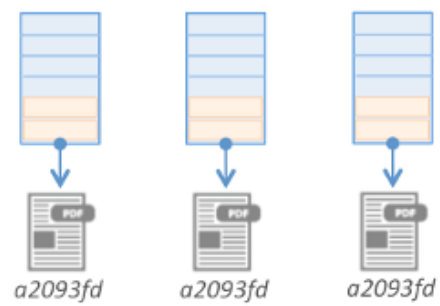

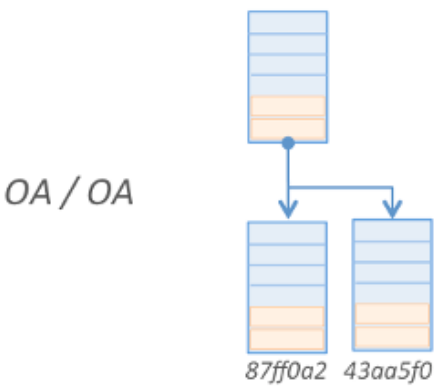

$O A / O A$

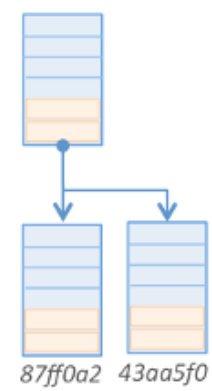

(a)
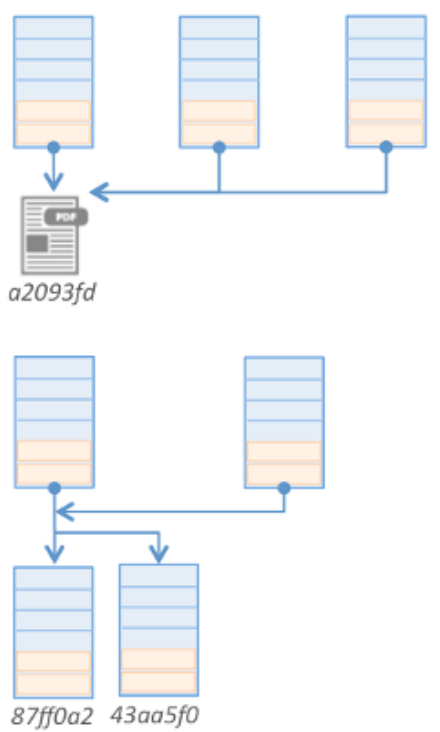

(b)

Figura 4.7: Apontamentos de arquivos e OA idênticos por outros OA: a) cenário onde estes são desnecessariamente replicados; b) cenário de não-duplicidade destes recursos.

mesma de outro arquivo já existente, o repositório conclui que não é necessário o armazenamento deste arquivo e apenas cria o apontamento do OA para aquele arquivo.

De maneira análoga, toda nova requisição para criação de objeto no repositório gera uma ação de comparação do hashing deste OA com os demais já armazenados. Se sua assinatura for localizada, apenas um apontamento é feito. Isto é particularmente útil em processos de importação em lote de objetos, como no caso de um banco de questões. Diversos OA, que representam cada uma das questões individuais, podem já existir no repositório previamente a importação. Neste caso, o OA "pai", que coordena as associações entre as questões "filhas" e que agrega todas elas, gera um apontamento para o OA pré-existente, ao invés de criar um novo conteúdo.

Para tornar a gestão de objetos íntegra e consistente, também é necessário um controle adicional do repositório para remoção destas referências lógicas entre arquivos e OA e entre OA distintos. O iRepositório controla quando um arquivo referenciado pode, de fato, ser removido quando ele deixa de ser referenciado por um OA. Caso este apontamento seja único, o arquivo pode ser descartado pelo repositório. Caso contrário, se outros OA mantiverem dependência com este arquivo, apenas o apontamento do OA em questão é descartado. Os demais OA, apontamentos e o próprio arquivo permanecem ativos no repositório.

\subsection{Importação de instâncias de módulos do curso do SGC}

Além da autoria de itens individuais de objetos pelos autores, o iRepositório oferece a possibilidade de criação de conteúdos digitais a partir da importação de objetos pré-existentes do SGC. Para que isto seja possível, o SGC deve contar com funções de empacotamento (utilizadas geralmente em processos de backups) dos seus conteúdos. Desta forma, estes podem ser enviados ao repositório para o seu armazenamento interno. De forma análoga, processos de extração de objetos a partir de pacotes recuperam seu conteúdo armazenado e utilizam processos de restauração providos pelo SGC, para que retornem a forma nativa, compatível com este sistema.

Em termos gerais, os processos de importação de conteúdos pré-existente do SGC e o de criação tradicional de novo conteúdo são semelhantes. Ambos compartilham o mesmo formulário para preenchimento dos atributos do objeto e dos seus metadados e acabam por gerar objetos com as mesmas estruturas. A exceção, entretanto, é que os objetos importados a partir de conteúdos do SGC têm algumas referências adicionais para arquivos que armazenam os dados oriundos do seu processo de empacotamento.

Como os OA do iRepositório contam com o recurso de apontamento para outros AO (os seus OA 
"filhos"), deduz-se que objetos mais complexos podem ser definidos a partir da importação em lote de módulos do SGC. É possível ao autor indicar a importação de objetos de um mesmo módulo do curso (exemplo: todas as atividades de "tarefa") e agregá-los em um único objeto resultante. Neste caso, ele é composto por um único objeto ("pai", o agregador), que aponta para diversos outros OA ("filhos"), sendo cada um destes para cada conteúdo individual.

De maneira semelhante, também é possível a definição de objetos que contenham não apenas um único tipo de componente do curso do SGC, mas um conjunto distinto destes. Esta ideia pode ser levada até o nível do curso completo do professor, onde todos os seus componentes são importados na forma de OA ao repositório e agregados em um único objeto "pai", neste caso, o curso completo do professor.

Independente do nível de abrangência da importação em lote de componentes, o iRepositório realiza uma estratégia bottom-up, ao importar primeiramente os componentes mais elementares (folhas) destes conteúdos. Em seguida, ele cria objetos superiores, a partir da composição destas folhas. Este processo segue adiante, de forma recursiva, até que o importador crie um único objeto (raiz, ou o "pai" principal) que agrega todos os conteúdos previamente importados.

Além dos meios mencionados para importação de objetos, interfaces auxiliares de importação em lote podem ser definidas, para o caso de objetos que estejam contidos num nível superior ao do curso do professor. O SGC Moodle, em particular, pode armazenar um banco de questões em um nível global do seu ambiente, de forma que esteja disponível a todos os cursos de uma determinada categoria, ou ainda para qualquer curso do seu ambiente. Estas interfaces podem identificar tais classes de objetos e oferecer ao autor de conteúdo a possibilidade da sua importação em lote, de forma semelhante a executada no contexto mais restrito do seu curso. 


\section{Capítulo 5}

\section{Implementação do iRepositório no SGC Moodle}

Este capítulo tem por objetivo a apresentação da implementação do modelo conceitual proposto no capítulo 4 do iRepositório no SGC Moodle. Concomitantemente a esta implementação, são exemplificados casos práticos da sua utilização e interações entre o SGC, seus respectivos módulos de atividades e usuários (autores de conteúdos e alunos). Neste capítulo, presupõe-se uma exposição mais explícita da utilização do Moodle, tanto para as interações com o repositório quanto para o apoio ao seu arcabouço e compartilhamento de recursos.

Como já exposto no Capítulo 3, a proposta do iRepositório é a de implementá-lo apoiado no arcabouço do SGC Moodle. Desta forma, não há a necessidade de manutenção de um local externo, ou a preparo de aplicativos específicos, uma vez que toda a infra-estrutura disponibilizada ao referido SGC é também utilizada e compartilhada com o repositório. Além disso, operações como instalação, parametrização e atualização do repositório são executadas dentro desse ambiente, de forma facilita aos seus usuários administradores.

Outras vantagens ainda podem ser citadas. Por ser desenvolvido na mesma linguagem de programação PHP, pode-se re-utilizar o conjunto das suas bibliotecas de funções auxiliares de propósitos diversos, o seu arcabouço, além dos sistemas de apoio, como o Servidor Web e o gerenciador do Banco de Dados. Uma série de benefícios adicionais imediatos ainda são evidenciados como: $i$ ) redução do prazo necessário para o desenvolvimento do iRepositório; ii) uso do sistema de arquivos do Moodle para armazenar e recuperar o conteúdo de arquivos referenciados dos OA; iii) compartilhamento das contas de usuários do SGC e suas respectivas permissões de acesso para autorização do uso do repositório; iv) utilização da rotina de backup e recuperação deste SGC para os conteúdos do repositório e $v$ ) curva de aprendizado suave para os usuários, principalmente para professores e autores de OA, que poderão manipular este módulo a partir de telas padronizadas, com identidade visual familiar a empregada no SGC e utilização de componentes e interfaces próprias do Moodle.

Devido a esses fatos, pode-se prever que o grau de compatibilidade entre os ambientes é alto, independente do Sistema Operacional utilizado para o SGC (que é multi-plataforma). Sendo um módulo (ou plugin, em termos mais técnicos pelas definições do próprio Moodle), o repositório poderá ser oferecido futuramente, no sítio oficial desse $\mathrm{SGC}^{1}$, para que os usuários interessados possam descarregá-lo e instalá-lo no seu próprio ambiente. Os Apêndices A e B tratam a respeito da preparação de um local denominado frequentemente pelo acrônimo $A M P$, que é propício para operação, tanto do Moodle quanto do iRepositório.

\subsection{Principais características do projeto}

O projeto do iRepositório é implementado na mesma Linguagem de Programação PHP empregada pelo Moodle. Esse é encarado pelo SGC como sendo um dos seus plugins, que podem ser

\footnotetext{
${ }^{1}$ Módulos do Moodle são descarregados a partir da página Moodle Plugins do seu sítio, disponível em https: $/ /$ moodle.org/plugins.
} 


\begin{tabular}{l|l|l}
\hline Biblioteca & Propósito & Documentação (http://docs.moodle.org/dev/) \\
\hline Access & autorização de acesso & Access_API \\
Data manipulation & interface com o banco de dados & Data_manipulation_API \\
Events & integração entre componentes & Events_API \\
File & gestão dos arquivos & File_API \\
Form & definição de formulários & Form_API \\
Logging & controle dos logs & Logging_API \\
Page & páginas dos usuários & PAGE_API \\
Navigation & menus dos usuários & Navigation_API \\
\hline
\end{tabular}

Tabela 5.1: Principais bibliotecas do Moodle utilizadas no projeto do iRepositório.

descarregados a partir da internet e instalados internamente nas suas estruturas. Por estar embutido e integrado ao arcabouço desse SGC, ele tem como vantagem a utilização de uma série de bibliotecas e interfaces públicas. Além da obtenção de agilidade no desenvolvimento deste projeto, garante-se que o seu código-fonte seja padronizado em relação a codificação empregada no Moodle. Desta forma, facilita-se o trabalho futuro para sua extensão. A Tabela 5.1 relaciona as principais bibliotecas utilizadas e sua respectiva página de documentação, a partir do sítio oficial do SGC.

Em particular, este projeto é compatível com a versão 2.4 ou superior do Moodle ${ }^{2}$. Seu códigofonte está adaptado ao idioma inglês para facilitar sua promoção e colaboração futura em nível mundial. Ele contém nome de variáveis, nome de arquivos do seu código-fonte, descrição dos comentários do código-fonte e Modelo ER traduzidos para esse idioma.

Ele é residente no seu sub-diretório de plugins, denominado por local. Cabe aqui uma breve explicação a respeito do propósito deste diretório, em relação às possibilidades de sub-diretórios oferecidos pelo Moodle para utilização de plugins. Segundo Moodle (2014b), algumas das opções, a partir do seu diretório raiz, são descritas abaixo:

- mod - utilizado para os módulos de atividades do SGC, como o Fórum, Tarefa, Chat ou ainda recursos estáticos como páginas HTML, diretório de arquivos ou rótulos. São conteúdos a serem acrescentados na página do curso do professor ou ainda na página principal da instância do Moodle;

- blocks - representam diversos componentes auxiliares, dispostos visualmente na forma de pequenos blocos laterais ao conteúdo do curso do professor ou da página principal da instância Moodle. Geralmente contém informações a respeito do curso, usuários ativos, últimas atividades realizadas pelos usuários, calendário de eventos, dentre outros ${ }^{3}$;

- theme - contêm definições de temas visuais para apresentação do conteúdo geral aos seus usuários. O Moodle traz uma série destes no seu pacote padrão;

- lang - são pacotes de termos e frases utilizados pelo ambiente de forma geral, em diversos idiomas. O Moodle traz por padrão apenas o inglês, mas outros podem ser descarregados conforme a necessidade;

- course/format - definem a estrutura de apresentação do curso aos seus usuários (professores e alunos), bem como a disposição de elementos de atividades. Alguns exemplo são: em "tópicos por semana", em "tópicos sequenciais", "único fórum", etc;

\footnotetext{
${ }^{2} \mathrm{O}$ primeiro lançamento da versão 2.4 do Moodle foi disponibilizado em Dezembro de 2012. Fonte: http://docs. moodle.org/dev/Releases\#Moodle_2.4.

${ }^{3}$ A prova de conceito do $i R C D$ - Repositório de Conteúdos Digitais Interativos, desenvolvido por Rosa e Brandão (2011) utilizava este tipo de plugin para a sua operação.
} 
- auth - descrevem as regras para políticas de identificação e autenticação de usuários no ambiente, seja por base de dados local (método padrão), baseado em correio eletrônico, em serviços na Web, banco de dados externo ao Moodle, protocolo LDAP, dentre outros;

- enrol - descrevem as regras para vínculo de usuários (professores, alunos, etc) nos seus respectivos cursos. Alguns exemplos são: base de dados local (método padrão), baseado em arquivo estático de texto, via autorização de ferramentas externas como o PayPal, protocolo LDAP, dentre outros;

- repository - contém interfaces para diversos repositórios de arquivos estáticos na Web, como Dropbox, Flickr, GoogleDocs, Amazon S3, Youtube, dentre outros. Uma vez que algum destes repositórios esteja ativo no Moodle, eles passam a localizar e servir arquivos estáticos dentro do curso do professor. Apesar do nome semelhante ao projeto do iRepositório, este diretório não deve ter seu propósito principal confundido. O projeto atual prevê uma gama mais ampla de funcionalidades a serem oferecidas do que os repositórios aqui controlados;

- local - diretório para armazenamento de plugins que não se enquadram em propósitos mais específicos aos demais plugins tradicionais [Moodle (2014a)]. Este local é oferecido desde a versão 2.0 do Moodle e apresenta um meio propício para extensão do Moodle, como por exemplo para disponibilizar: $i$ ) eventos que se comunicam com sistemas externos; $i i$ ) definições personalizadas de serviços na Web que consomem ou servem a recursos externos; iii) aplicações que ampliam a capacidade e os recursos deste SGC em um nível global, dentre outros.

É neste último item que enquadra-se o armazenamento do código-fonte do iRepositório: um sistema global no nível do SGC, que conta com uma série de recursos aos seus usuários e está disponível a partir dos seus menus globais de navegação. Em outras palavras, não está restrito apenas a um curso específico do professor, mas em qualquer uma das suas telas, incluindo a página principal do ambiente. Os principais sub-diretórios e arquivos do seu pacote, contidos a partir do diretório local, são:

- irepository/ - arquivos principais do projeto, como de busca, criação e edição de OA, bem como outros de uso recomendado pelo Moodle, como o da extensão do menu do usuário, de acordo o com o seu papel (lib.php), menu e parametrizações do usuário administrador (settings.php) e controle da versão atual (version.php);

- irepository/admin/ - scripts PHP voltados às parametrizações do ambiente restritas a usuários administradores, como as de escolha do padrão de metadados ativo (std.php e std_setting.class.php);

- irepository/db/ - de uso obrigatório pelo Moodle, contêm o grupo de privilégios a serem definidos para o projeto (access.php), regras para sua instalação e configuração inicial (install.php), descritor da base de dados (install.xml) e regras para atualização a partir de versões anteriores (upgrade.php);

- irepository/filters/ - contêm classes que tratam a respeito de diversos critérios específicos de busca de OA do repositório, não encontrados nos filtros convencionais deste SCG. Exemplos: OA da última versão disponibilizada, determinados valores de metadados dos OA, OA de propriedade do usuário ativo, dentre outros;

- irepository/interface/ - conjunto de "sub-plugins", compatíveis com o iRepositório para apoio a interfaces de ferramentas e módulos externos. Exemplos são os importadores do iTarefa e do banco de questões do Moodle, para a forma de OA do repositório. Outros módulos poderão ser desenvolvidos e adaptados neste sub-diretório, conforme a necessidade futura;

- irepository/lang/ - de uso obrigatório do Moodle, contêm pacotes de idiomas de tradução para as interfaces do usuário, de acordo com o seu perfil de preferência. Atualmente ele conta com pacotes para Português (Brasil) e Inglês, respectivamente sob os códigos " $p t_{-} b r$ " e "en" do Moodle. Outros pacotes de idiomas poderão ser acrescentados, conforme a necessidade futura; 

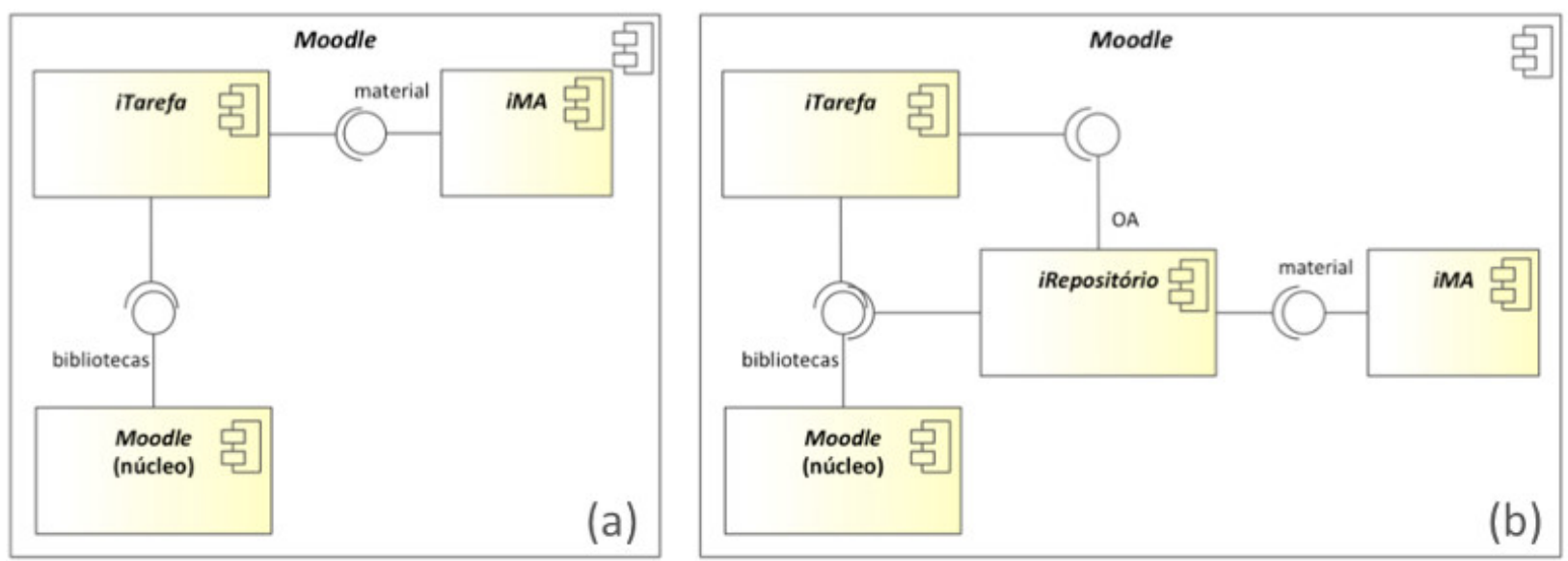

Figura 5.1: Diagrama UML dos principais componentes colaboradores: a) caso atual onde o iTarefa consome um recurso do tipo iMA e b) proposta com a inclusão do iRepositório.

- irepository/lib/ - contêm as definições das principais classes utilizados no projeto, como a dos OA (item.class.php), de referências dos OA (item_ref.class.php) ou de metadados (md.class.php);

- irepository/pix/ - de uso obrigatório do Moodle, contém arquivos de ícones visuais utilizados pelo projeto, como por exemplo, o ícone principal (icon.gif), que é exibido em telas gerais de parametrização do iRepositório.

\subsection{Visão geral da interação com o Moodle}

Uma descrição a respeito dos componentes do ambiente do SGC Moodle que podem interagir com o iRepositório é pertinente a compreensão do projeto. A Figura 5.1 exibe um comparativo de cenários reais de uso, entre a estrutura atual do SGC e a proposta com a colaboração do repositório. A Figura 5.1(a) mostra as interações atuais entre 3 classes distintas de componentes. São eles:

- Núcleo do Moodle - composto pelo arcabouço e por bibliotecas de funções auxiliares com propósitos diversos. As camadas "superiores" do SGC, (como por exemplo: gerenciadores dos módulos, dos blocos, páginas personalizadas, dentre outras) fazem uso e consomem recursos deste núcleo, através da requisição de funções das suas bibliotecas ou de instâncias das suas classes disponíveis;

- Módulos de atividade do Moodle - são apoiados pelo núcleo do sistema. Nativamente, o Moodle conta com módulos de Tarefa, Fórum, Chat, Questionário, Página HTML, dentre outros. Em particular no diagrama exposto, o módulo está sendo representado pelo iTarefa, desenvolvido pelo grupo de pesquisa LInE. Esse componente apresenta ao usuário (um professor, autor de OA ou aluno) uma atividade de avaliação interativa. Esta atividade exige com frequência a interação com componentes externos (um Módulo Interativo - iMA). O iTarefa realiza requisições para que esses módulos sejam recuperados, instanciados e exibidos dentro do seu conteúdo original definido pelo autor. Após a execução e submissão da atividade pelo aluno, o $i M A$ realiza sua avaliação e informa o resultado final de volta aos registros do SGC;

- Módulo interativo (iMA) de uma atividade do Moodle - se requisitado por algum dos módulos do Moodle, ele é carregado no ambiente e parametrizado de acordo com os dados definidos pelo autor para a atividade específica. Sua instância é então retornada ao seu módulo requisitante.

Já o cenário do diagrama da Figura 5.1(b) apresenta um modelo mais sofisticado de colaboração entre os componentes, com o acréscimo do iRepositório. Nota-se que não existe mais um relacionamento direto entre o módulo do iTarefa do Moodle e a atividade interativa ( $i M A$ ). Tais interações 
passam a ser gerenciadas pelo repositório, que atua como um mediador do processo. Sendo assim, ao processar o conteúdo da atividade a ser apresentada ao aluno, o iTarefa solicita ao repositório todos os seus OA pertinentes. Este por sua vez carrega seus conteúdos, instancia e parametriza cada um dos $i M A$ correspondentes e os retorna ao módulo requisitante.

Esta segunda abordagem traz benefícios em relação ao primeiro cenário. Com o uso do repositório, não existe mais a necessidade do módulo do Moodle conhecer todas as informações, local de armazenamento e parâmetros pertinentes a cada módulo interativo pertencente ao seu conteúdo. Todos estes dados ficam registrados num OA, sendo que sua localização física é de conhecido apenas pelo iRepositório. O OA pode estar no próprio repositório ou ser referenciado, através da sua URL, a partir de um repositório externo.

\subsection{Modelo Entidade-Relacionamento do banco de dados}

Um Modelo Entidade-Relacionamento (Modelo ER) simplificado, com as principais tabelas pertinentes ao iRepositório, está ilustrado na Figura 5.2. A região demarcada com fundo azul contém tabelas nativas do Moodle ${ }^{4}$. São elas: $i$ ) user, que registra cada usuário do ambiente (alunos, professores, autores de conteúdo, etc) e ii) files, que registra dados e referências dos arquivos armazenados no sistema de arquivos, originados a partir de diversas fontes (carregamento pelo próprio usuário, resultado do processo de backup de um curso, submissão de uma tarefa pelo aluno, etc). Apesar destas tabelas não pertencerem ao projeto do repositório, elas são citadas no diagrama por apresentarem um papel de destaque na integração com o restante do modelo.

Já as demais tabelas representadas pertencem ao projeto do iRepositório. Como descrito anteriormente, faz-se necessário definir novas tabelas apenas para as entidades estritamente relacionadas ao modelo do repositório. Como este projeto está embutido no arcabouço do Moodle, todas as demais tabelas "marginais" ao negócio (usuários, autenticação, autorização, componentes de tarefas, cursos, arquivos, logging, etc) podem ser utilizadas a partir das fornecidas e gerenciadas pelo próprio SGC.

Algumas padronização são sugeridas pela documentação do Moodle para organização da estrutura geral das tabelas ${ }^{5}$. Todas as entidades de uma certa classe ou de um determinado plugin devem ter o seu nome prefixado com uma cadeia de caracteres em minúsculo, a fim de facilitar sua identificação dentre as demais do SGC. No caso particular do iRepositório, o prefixo é "local", seguido de "irepository", em razão, respectivamente, da classe de componentes residentes no sub-diretório de mesma nomenclatura e pelo nome adotado ao projeto (traduzido para o idioma inglês). Além disso, sugere-se que as tabelas possuam o campo denominado $i d$, de domínio numérico, com capacidade de auto-incremento e que seja utilizado para a sua chave primária. Por fim, recomenda-se que as tabelas possuam os campos timecreated e opcionalmente timemodified para representar, respectivamente, a data de criação do registro e a data da sua atualização mais recente. Ambos têm domínio numérico, e representam a data no formato Tempo Unix ${ }^{6}$.

A tabela local_irepository_item tem um papel fundamental na arquitetura do projeto. Ela representa cada conteúdo (OA) armazenado no repositório, de forma independente ao seu estado atual, versão ou tipo. Os seus campos descritos a seguir estão relacionados à seção "propriedades internas" do OA do Capítulo 4. São eles: i) identifier e version, definidos diretamente a partir de ações dos autores destes conteúdos, representam o par utilizado para sua identificação única; ii) label e description são valores livres fornecidos pelo autor, respectivamente para o seu rótulo e descrição; iii) type indica aos módulos clientes do iRepositório do Moodle os OA compatíveis com o

\footnotetext{
${ }^{4}$ As tabelas nativas do Moodle apresentadas no modelo da Figura 5.2 contém diversos outros campos além dos destacados. Estes foram suprimidos por não serem essenciais à descrição do Modelo ER do repositório.

${ }^{5}$ Disponível em http://docs.moodle.org/dev/Database.

${ }^{6} \mathrm{O}$ formato Tempo Unix, também denominado por Tempo POSIX ou Tempo Epoch, utiliza uma notação numérica para representar uma data, de acordo com o tempo decorrido em segundos, desde 01/01/1970 00:00:00 até a data propriamente dita. Exemplo prático: o número 1.387.929.600 representa a data 25/12/2013 00:00:00 em formato Tempo Unix. A função time do PHP retorna a data corrente do sistema na notação Tempo Unix. Fonte: http: //en.wikipedia.org/wiki/Unix_epoch.
} 


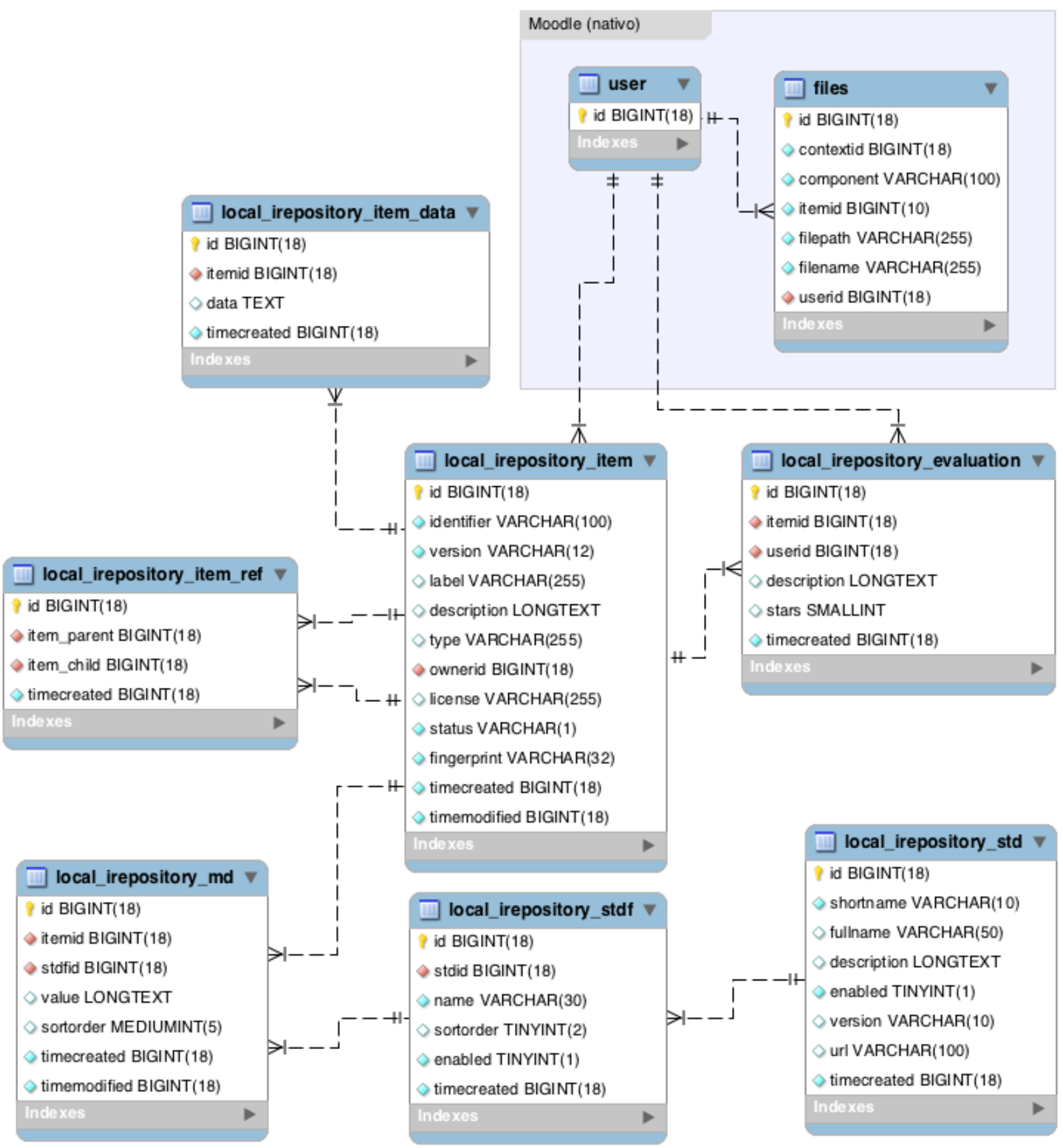

Figura 5.2: Modelo Entidade-Relacionamento do banco de dados do projeto. 
seu tipo (ex: um OA de $i M A$ do tipo $i G e o m$ ou um OA do tipo "questão"); iv) ownerid aponta para o proprietário daquele conteúdo e faz referência à tabela nativa user do Moodle; v) license indica a licença do OA, dentre as previstas no $M_{o o d l e}{ }^{7}$, ou ainda outra que venha a ser disponibilizada em versões futuras; vi) status indica o estado atual do OA (inativo, ativo, bloqueado, obsoleto ou removido $)^{8}$ e vii) fingerprint é a assinatura única do objeto, utilizada para evitar duplicidade no armazenamento físico de conteúdos digitais idênticos.

Cada arquivo que um OA faz referência (descrito na seção "Arquivos e referências externas" do Capítulo 4) mantém uma relação estreita com a tabela nativa files do Moodle. O Modelo ER não representa este vínculo graficamente, porque em termos estruturais do banco de dados, não existe uma chave estrangeira da tabela local_irepository_item para a files. Na realidade, esta última tem um propósito mais geral. Ela representa qualquer arquivo necessário ao ambiente Moodle, seja ele por exemplo, um conteúdo estruturado em $X M L$ de um OA ou uma atividade submetida por um aluno através de um módulo apropriado. Internamente, o iRepositório faz uso da interface pública de arquivos (File API) do Moodle para manipular estes recursos (para criar novo arquivo, recuperar o seu conteúdo, analisar seus metadados específicos, etc). Em particular, ele utiliza os seguintes valores para representar um arquivo do seu contexto: $i$ ) contextid para indicar o contexto do repositório, que é global a instância Moodle e que em termos práticos, possui o valor constante "1"; ii) component com o valor constante "local_irepository_item" para indicar que este registro é de propriedade do iRepositório (e não de outro módulo do Moodle, como a Tarefa); iii) itemid para indicação do identificador do OA que referencia o arquivo; iv) filepath e filename que indicam, respectivamente, o caminho e nome "virtual" deste arquivo no sistema e v) userid que mantém referência com o usuário proprietário deste recurso (no caso do repositório, armazena o responsável pela criação do mesmo).

As 3 tabelas local_irepository_std, local_irepository_stdf e local_irepository_md são utilizadas, respectivamente, para representação de cada padrão de anotação de metadados ("standards"), seus campos correspondentes ("fields") e finalmente os valores associados entre cada um destes e o OA ("metadata"). Estas tabelas estão relacionadas à seção "Metadados" do OA do Capítulo 4. A primeira delas possui atualmente 2 registros, para cada um dos padrões IEEE LOM e Dublin Core. Seus campos são: $i$ ) shortname, fullname, version e description para sua nomenclatura e breve descrição; ii) enabled para indicar se é um padrão ativo a ser disponibilizado pelo iRepositório e iii) url para o apontamento ao seu sítio oficial, caso o usuário deseje consultar sua documentação mais detalhada. Já a tabela local_irepository_stdf possui os seguintes campos: i) stdid para referência ao padrão de anotação; ii) name e sortorder para o nome do campo e a ordem da sua apresentação ao usuário e iii) enabled para indicar se é um campo ativo daquele padrão de anotação, a ser disponibilizado pelo iRepositório. Finalmente a tabela local_irepository_md contém os campos: i) itemid e stdfid que são referências, respectivamente, ao OA e ao campo de anotação, para um determinado valor contido no campo value e ii) sortorder para a ordem da apresentação destes valores ao usuário, no caso de múltiplos campos semelhantes de anotação em um certo OA.

A tabela local_irepository_item_ref controla o apontamento (associação) entre OA. Cada um dos seus registros indica uma relação do tipo "pai" e "filho" entre eles. Esta tabela está relacionada à seção "Apontadores" do OA do Capítulo 4. Seus dois campos de maior destaque são item_parent e item_child. Eles indicam os dois OA que participam da associação. Nota-se pela estrutura desta tabela, que é possível que um OA "pai" possua múltiplos "filhos" ou ainda que, um OA "filho" possua múltiplos "pais" distintos.

A tabela local_irepository_evaluation registra as avaliações concedidas aos AO pelos autores. Mais adiante, essas serão úteis para o cálculo da reputação dos materiais. Esta tabela está relacionada à seção "Reputação dos OA" do Capítulo 4. Seus campos são os seguintes: $i$ ) itemid e userid

\footnotetext{
${ }^{7} \mathrm{O}$ Moodle conta atualmente com as seguintes licenças: All rights reserved, Public domain, Creative Commons, Creative Commons - NoDerivs, Creative Commons - No Commercial NoDerivs, Creative Commons - No Commercial, Creative Commons - No Commercial ShareAlike e Creative Commons - ShareAlike.

${ }^{8} \mathrm{O}$ seguinte mapeamento é utilizado para fornecer o caractere de representação do estado do OA: "I" para "inativo" ("inactive"), "A" para "ativo" ("active"), "L" para "bloqueado" ("locked"), "D" para "obsoleto" ("deprecated")e "R" para "removido" ("removed").
} 
referenciam, respectivamente o OA avaliado e o usuário responsável por esta ação e ii) description e stars são referentes aos valores atribuídos por ele, seja num relato textual, a ser publicado para os demais usuários ou então num sistema de escala de notas (de 0 a 5), representado visualmente por ícones com "estrelas" concedidas ao material.

A tabela local_irepository_item_data pode manter uma série de registros para cada OA, que é referenciado através do campo itemid. Estes registros descrevem ações e eventos pertinentes ao OA no campo data e seu conteúdo dependerá do tipo de OA que está sendo monitorado. Seu formato interno pode ser registrado com texto não estruturado, ou de alguma forma organizada, com o emprego de notações em $X M L$, JSON ou ainda mais específicas, com o uso de vetores "serializados" do PHP. Cabe ao módulo responsável pelo seu armazenamento, a devida recuperação, tratamento e processamento destes dados.

\subsection{Casos práticos de uso do iRepositório integrado ao Moodle}

A seguir são apresentados alguns casos práticos de uso do repositório, bem como suas interações com o ambiente do Moodle. Através destes próximos exemplos práticos, pretende-se aperfeiçoar a compreensão do projeto e evidenciar as vantagens da integração do repositório e o uso do arcabouço daquele SGC. As próximas seções descrevem casos como o da autoria, visualização e busca de OA, importação e exportação de materiais em lote, bem como suas interações com módulos de atividades do Moodle, como o iTarefa.

\subsubsection{Autoria de novo OA}

O iRepositório oferece ao autor de conteúdo um procedimento para autoria de OA "genérico", que não esteja associado necessariamente a algum módulo do Moodle. Esta interface é baseada principalmente na biblioteca de gestão de formulários (Form API), disponível no arcabouço do SGC. A Figura 5.3 mostra o formulário correspondente a esta ação, cujos campos devem ser preenchidos pelo autor. A seguir, 3 dos seus blocos distintos de campos:

- Geral - cadastro de informações relativas ao OA, como rótulo, identificador, descrição e licença. Em termos técnicos, este bloco está vinculado à tabela local_irepository_item do banco de dados. É importante ressaltar que o campo da versão deste conteúdo (version) não é apresentado ao usuário, pois conforme constam nas regras de negócio do repositório, ele é calculado automaticamente, de acordo com o identificador informado pelo autor;

- Metadados - possibilita ao autor o cadastro dos metadados do OA, de acordo com o padrão de anotação ativo do iRepositório (determinado pelo usuário administrador do Moodle). Em termos técnicos, este bloco está vinculado diretamente à tabela local_irepository_md do banco de dados. Este cadastro não tem limitação quanto ao número de metadados a serem informados. Por padrão ele oferece 3 campos, mas caso seja necessário, o autor pode acionar o botão associado ao bloco, para acrescentar campos adicionais. Ressalta-se que o usuário também pode vincular ao OA múltiplas instâncias e valores para um mesmo metadado. Exemplo: um determinado OA pode conter diversos valores discriminados para o metadado "autor", do padrão Dublin Core;

- Arquivos complementares - utiliza a biblioteca disponível do Moodle (File API) para o carregamento de arquivos da máquina do usuário e definição de estrutura de diretórios (denominadas por "pastas" pelo Moodle). Estes serão vinculados, de forma automática pela própria biblioteca, à tabela files do seu banco de dados. Ela também é responsável pela escrita do seu arquivo físico correspondente, armazenado na estrutura nativa de arquivos do SGC. 


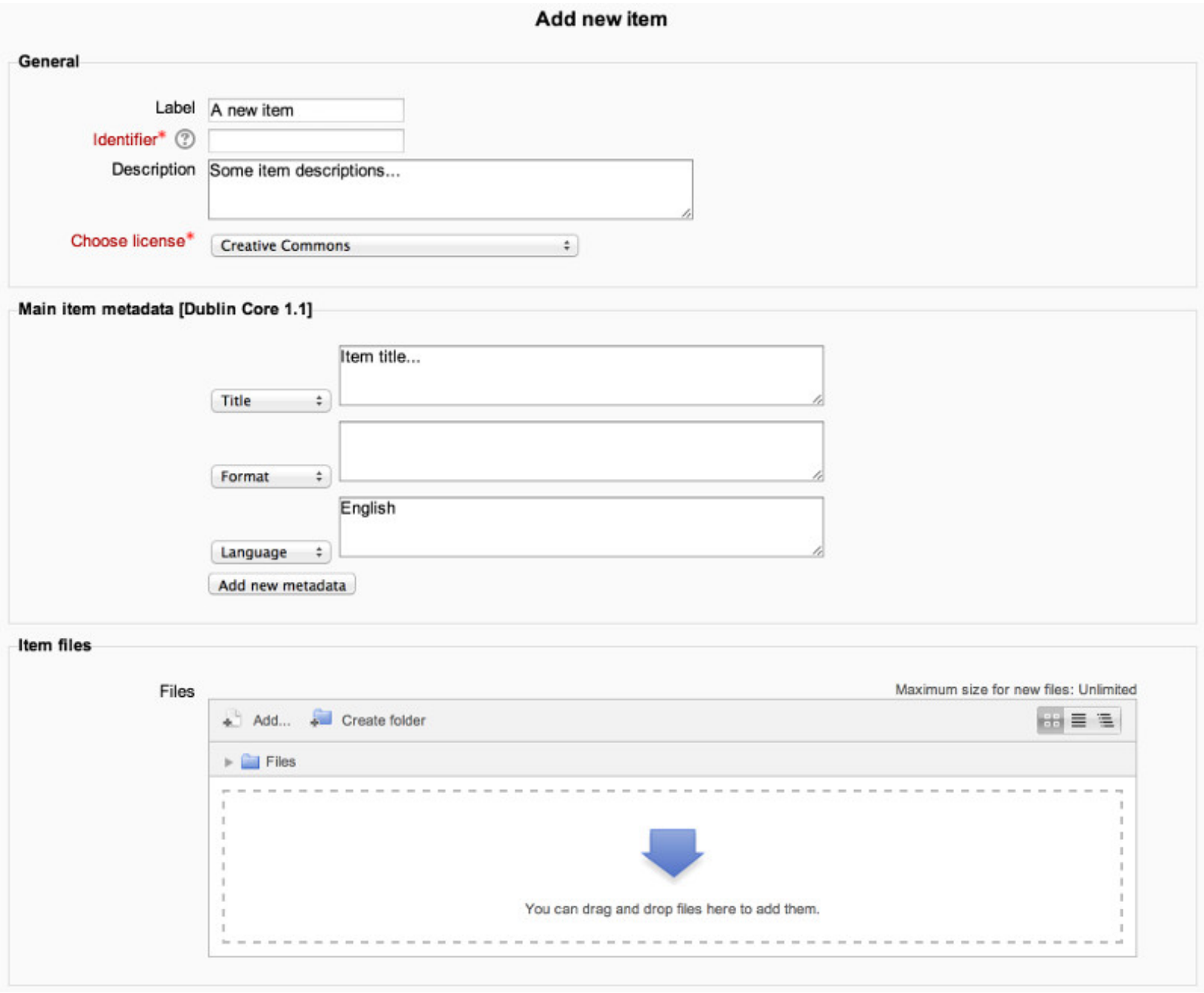

Figura 5.3: Formulário para autoria de novo OA no iRepositório. 


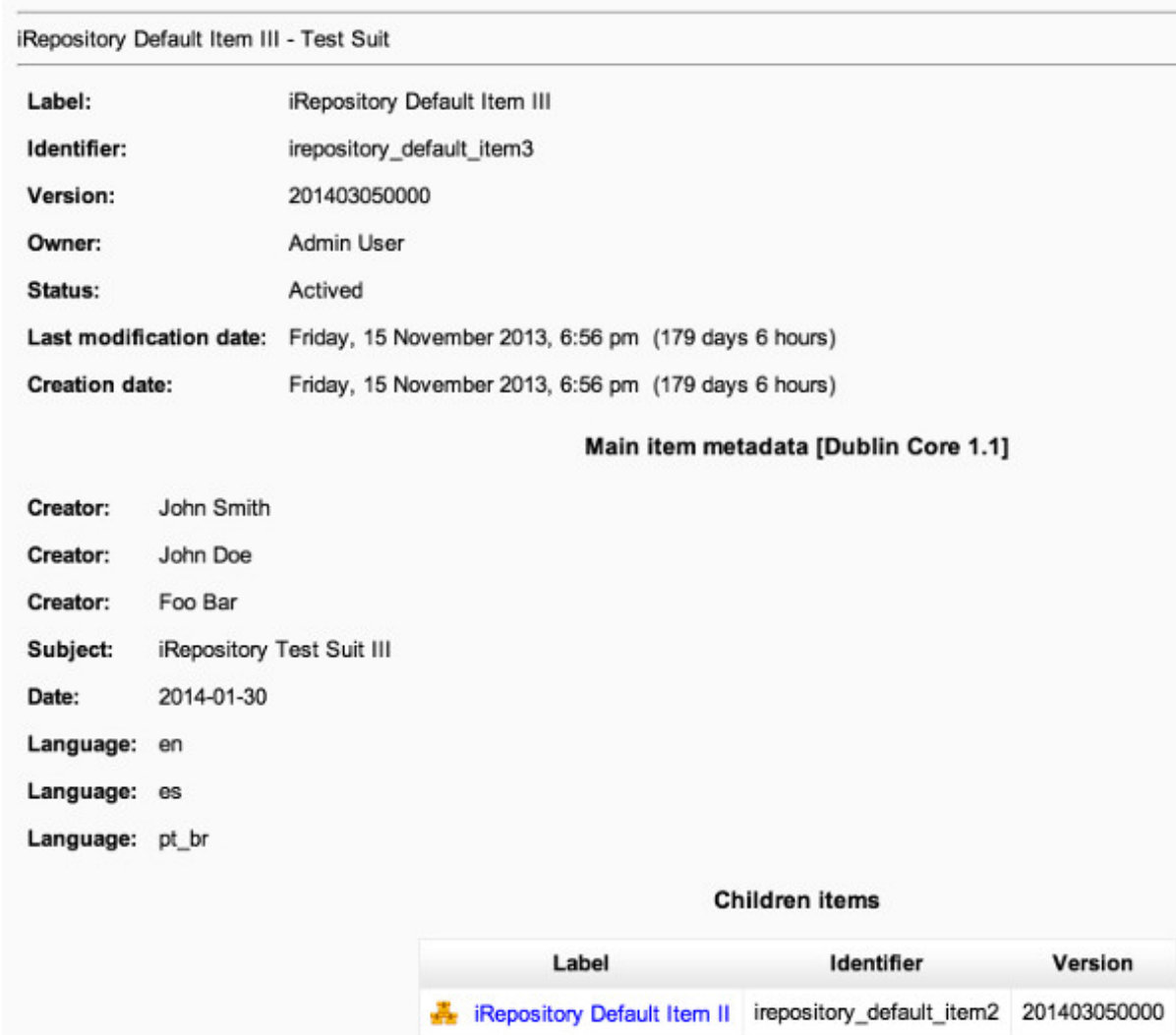

Figura 5.4: Visualização de detalhes de um OA do iRepositório.

\subsubsection{Visualização dos detalhes de um OA}

Um OA pode conter uma série de informações, metadados, arquivos referenciados e associações com outros materiais digitais. É necessário que o iRepositório disponha de uma tela propícia a esta visualização, ilustrada na Figura 5.4. Ela apresenta destacado no seu título principal, o par $<$ identificador $\rangle:\langle$ versã $o\rangle$, onde $<$ identificador $\rangle$ e $\langle$ versã $o\rangle$, correspondem aos valores respectivos dos campos de mesmo nome do OA. Logo abaixo, exibe sua descrição e os demais campos relativos ao OA. No bloco seguinte, são listados todos os metadados utilizados para sua classificação, em lista ordenada da sua chave (pode conter múltiplas chaves semelhantes) e seus respectivos valores. Se o material dispuser de associações de OA ("pais", "filhos" ou ambos), é exibida a relação de todas as suas referências. Em cada um destes itens, são descritos os dados do seu rótulo, identificador e versão. O usuário tem a disposição um apontador no rótulo de cada um destes OA, de modo que possa navegar livremente pelas telas correspondentes a estes demais materiais, ou então retornar a página do OA de origem.

\subsubsection{Busca e recuperação de OA armazenados no repositório}

Num cenário real, um repositório pode armazenar uma coleção relativamente abrangente de OA distintos. É esperado que esta ferramenta ofereça mecanismos facilitadores para localização dos seus conteúdos, de acordo com critérios fornecidos pelo usuário. A Figura 5.5 ilustra a tela do iRepositório responsável pela apresentação do formulário de busca, com campos para definição destes critérios. Este compreende: $i$ ) os principais campos determinantes dos OA, como por exemplo o seu rótulo, identificador, versão ou tipo de licença do material; ii) um verbo associado ("contém", "não contém", "inicia com", "termina com", etc); e geralmente iii) um campo associado lateralmente, que complemente a ação do verbo (exemplo: localizar OA que satisfaçam a regra "rótulo contém matemática"). 


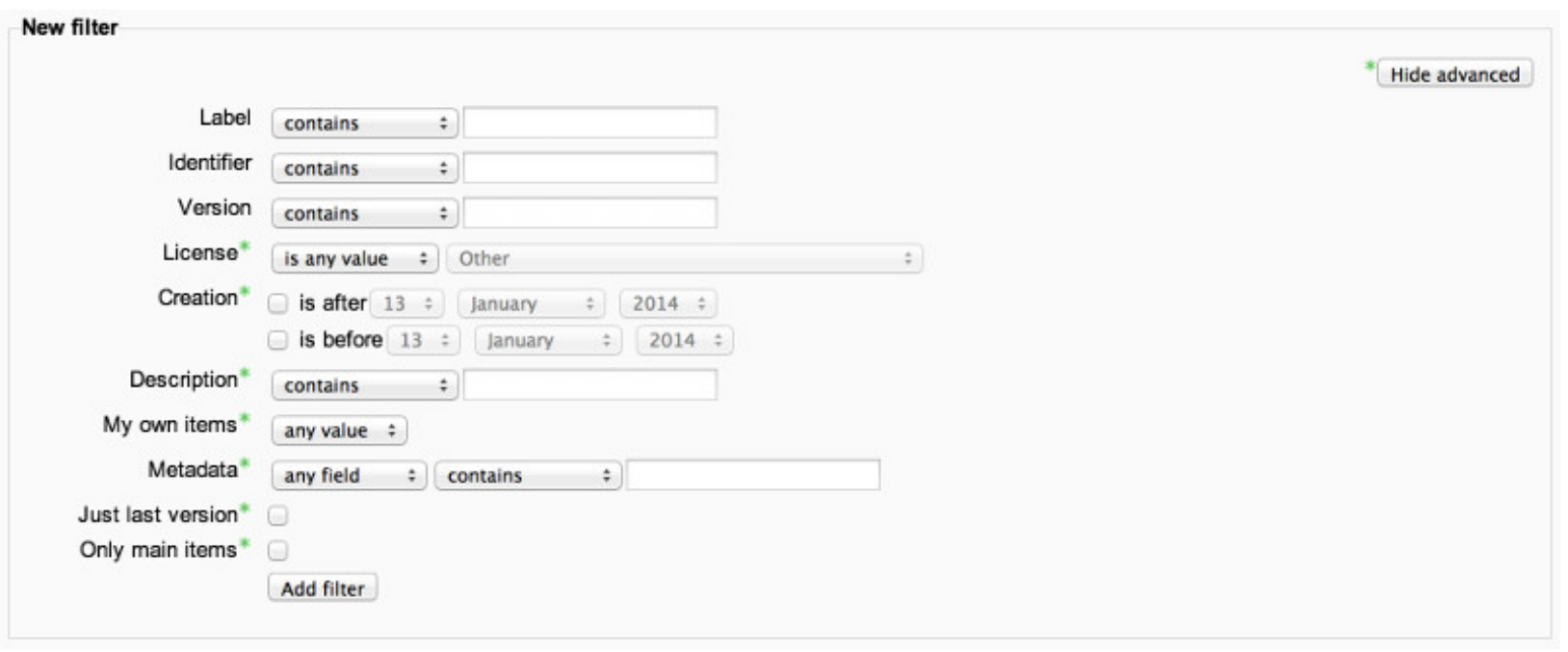

Figura 5.5: Formulário para localização de OA do iRepositório.

O resultado desta operação de busca está ilustado na Figura 5.6. Esta tela exibe: $i$ ) o total de objetos localizados, que satisfazem o critério de busca estipulado pelo usuário; ii) a relação completa deste itens, dispostos em linhas individuais numa tabela; iii) apontadores para navegação dos itens localizados entre múltiplas janelas de resultado (caso a pesquisa tenha extrapolado o limite de itens permitidos para a janela dos resultados) e $i v$ ) apontador para a tela de autoria de novo OA.

Cada OA exibido no resultado da busca contém um conjunto de ações e um informativo sobre o seu estado atual (Figura 5.7). As ações são as seguinte: $i$ ) editar direciona o usuário para o formulário semelhante ao exibido na Figura 5.3, porém com os dados pertinentes ao OA já preenchidos e preparados para possíveis alterações; ii) remover altera o estado atual do OA para "removido" - seu proprietário continua visualizando-o, porém este não está mais disponível ao público geral; iii) gerar cópia atualizada cria um novo OA, com todos os seus dados copiados a partir desta origem e com a versão atualizada - como consequência, o objeto de origem tem seu estado alterado para "obsoleto" e sua cópia recém-criada é marcada com "ativo"; iv) controle de associações direciona o usuário para outra tela, onde ele pode gerenciar as associações (vincular ou desvincular) dos materiais "filhos" e finalmente $v$ ) estado atual, representado por um caractere (no caso da Figura deste exemplo, este objeto está "bloqueado").

\subsubsection{Armazenamento de OA do iTarefa}

Este caso é baseado no diagrama representado na Figura 5.8 e ilustra dois casos de utilização do repositório, respectivamente para o depósito de um novo OA (utilizando um dos $i M A$ do grupo $L I n E$ existentes) e a criação de uma tarefa interativa. Estas ações podem ser tomadas de maneira isolada ou em conjunto - um OA recém inserido no repositório pode ser utilizado na etapa seguinte da definição da tarefa correspondente.

Primeiramente, o usuário (autor do conteúdo) deseja criar um novo exercício, como por exemplo, do tipo da classe $i G e o m$ dos $i M A$. Ele solicita ao Moodle uma instância daquela classe, que é então retornada para ele. Após ser parametrizado pelo autor, este novo exercício é submetido ao Moodle para que seja armazenado no iRepositório. O sistema responde ao autor, que pode, por sua vez, repetir estes passos para inserir novos exercícios adicionais.

Ao concluir esta etapa, todos os exercícios estarão disponíveis no repositório, na forma de OA. Desta maneira, estes poderão, por exemplo, serem referenciados no curso do professor em páginas HTML estáticas. Para isto, basta indicar no editor HTML do Moodle a referência ao OA desejado, através do mecanismo de busca embutido neste recurso. Internamente, a página do professor mantém o vínculo com o OA indicado através do seu identificador único.

A etapa da criação de uma tarefa interativa (neste caso utilizando o iTarefa) é análoga à criação de uma página HMTL estática. O autor solicita uma nova atividade e o Moodle apresenta o for- 
314 Items

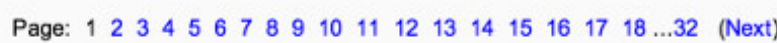

New filter

Label contains

Identifier contains $\quad$.

Version contains :

Add filter

\begin{tabular}{|c|c|c|c|c|c|c|}
\hline \multicolumn{7}{|c|}{ Add new item } \\
\hline Label & Identifier - & Version & License & Creation & & \\
\hline A new item & bla2 & 201404150000 & $\mathrm{cc}$ & 26 December 2013, 1:08 am & $4 \times \mp 0$ & [니] \\
\hline \pm A new item & bla4 & 201404150000 & $\mathrm{cc}$ & 26 December 2013, 1:10 am & $4 \times \square 0$ & [니] \\
\hline A new item & bla5 & 201404150000 & $\mathrm{cc}$ & 26 December 2013, 1:11 am & $* \times \mp ?$ & [D] \\
\hline I iRepository Default Item & irepository_default_item & 201403050000 & $\mathrm{cc}$ & 15 November $2013,6: 56$ pm & $* \times \mp \%$ & \\
\hline I iRepository Default Item II & irepository_default_item2 & 201403050000 & $\mathrm{cc}$ & 15 November $2013,6: 56 \mathrm{pm}$ & $* \times \oplus:$ & [I] \\
\hline I & irepository_default_item3 & 201403050000 & allrightsreserved & 15 November $2013,6: 56$ pm & क $\times 5$ & \\
\hline If iRepository Default Item III & irepository_default_item3 & 201404140000 & allrightsreserved & 26 December $2013,12: 13$ am & $* \times \oplus ?$ & [1] \\
\hline ․ㅗㄹ A new item & item1 & 201404140000 & $\mathrm{cc}$ & 25 December $2013,11: 58$ pm & $\neq \times \square 0$ & [l] \\
\hline \pm A new item & item1 & 201404140002 & $\mathrm{cc}$ & 26 December $2013,12: 00 \mathrm{am}$ & * $\times$ 田 & [l] \\
\hline A new item & item1 & 201404140003 & $c c$ & 26 December $2013,12: 00$ am & $* \times \mp ?$ & \\
\hline
\end{tabular}

Add new item

Page: $\begin{array}{llllllllllllllllllll}1 & 2 & 3 & 4 & 5 & 6 & 7 & 8 & 9 & 10 & 11 & 12 & 13 & 14 & 15 & 16 & 17 & 18 & \ldots 32 & \text { (Next) }\end{array}$

Figura 5.6: Resultado da busca de OA realizada no iRepositório.

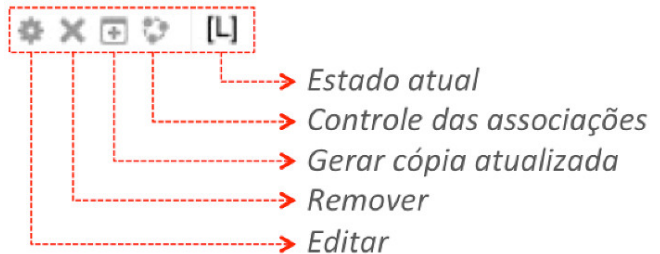

Figura 5.7: Detalhe das ações e informações associadas a um $O A$. 


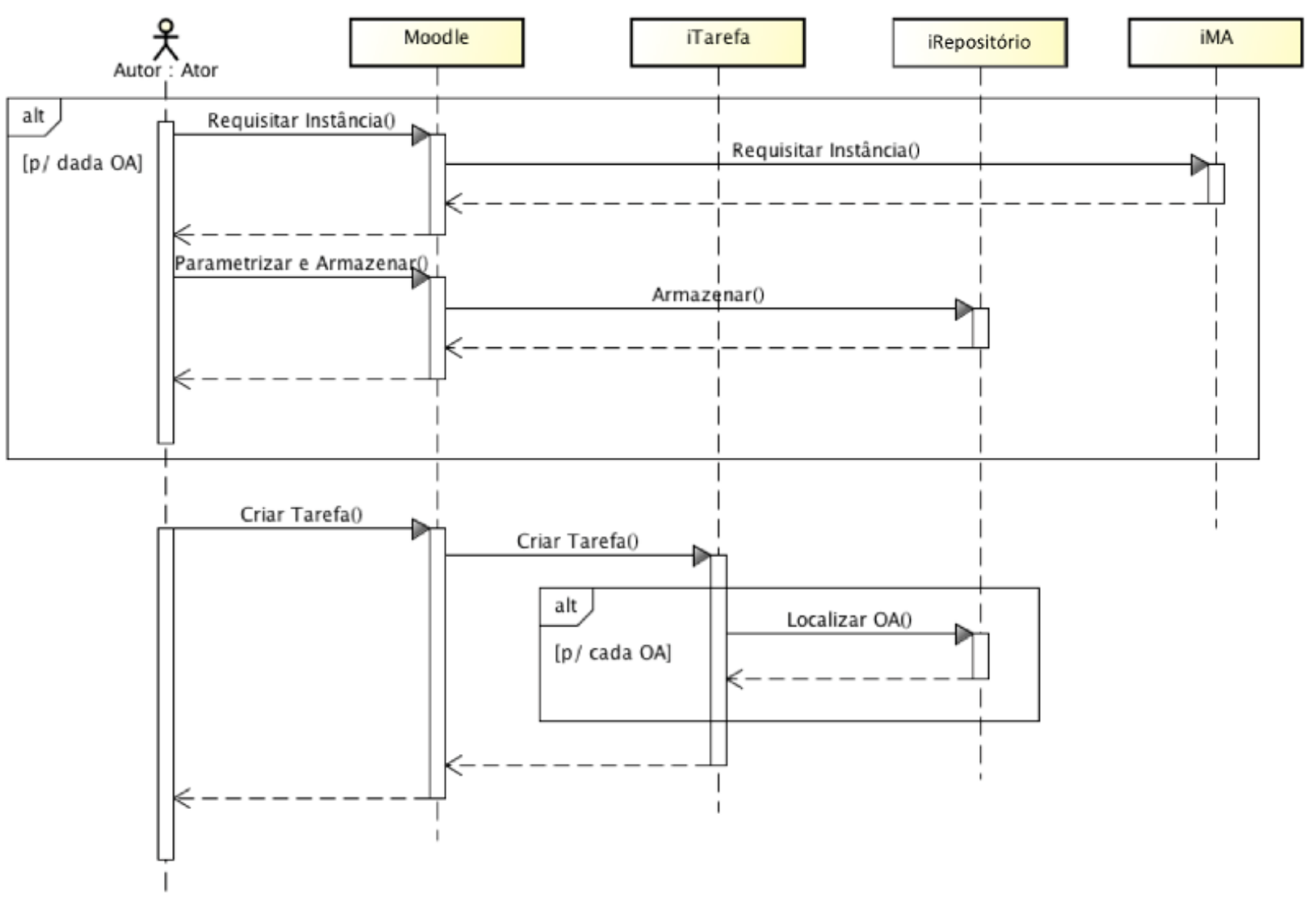

Figura 5.8: Diagrama de Sequência UML para o armazenamento de OA e definição de Tarefa Interativa.

mulário para o preenchimento dos seus dados e personalização. Em seguida ele tem a oportunidade de inserção dos objetos do repositório com o auxílio do seu mecanismo de busca, de acordo com critérios fornecidos pelo professor. Finalmente a tarefa é armazenada no ambiente e o Moodle responde ao professor. Da mesma maneira que as páginas HTML estáticas descritas, o módulo iTarefa armazena internamente nos seus descritores todos os OA referenciados do repositório através do seu identificador único.

É importante observar que em nenhum instante dos dois processos houve uma interação direta entre o ator do processo (o professor, autor do conteúdo) e o iRepositório. Este último agiu de forma transparente, através do Padrão de Projeto Fachada [Gamma et al. (1994)]. Ele respondeu a requisições feitas pelo Moodle ou a partir dos seus componentes internos, como o iTarefa, utilizado neste exemplo.

\subsubsection{Recuperação de OA a partir do iTarefa}

Este caso é baseado no diagrama representado na Figura 5.9 e ilustra um caso de utilização do repositório, em que uma atividade interativa (neste caso o iTarefa), que contém um ou mais OA é invocada pelo aluno. Ao finalizar a tarefa, o aluno submete ao Moodle suas respostas, que devem ser adequadamente registradas no ambiente.

Primeiramente o usuário (aluno) solicita ao Moodle a recuperação de uma tarefa interativa. Este por sua vez localiza seus registros correspondentes e recupera o seu conteúdo definido pelo professor. Caso esta atividade possua objetos armazenados no iRepositório, o iTarefa irá solicitar cada um deles ao repositório, utilizando seu identificador único. Caso o seu tipo seja uma classe $i M A$ (o iGeom, por exemplo), o iRepositório solicita por sua vez uma instância ao iMA correspondente. Este é então retornado ao repositório e em seguida a atividade interativa. Este processo é repetido até que todos os $\mathrm{OA}$ daquela atividade sejam requisitados ao repositório. Finalmente a tarefa interativa é devolvida ao aluno solicitante. 


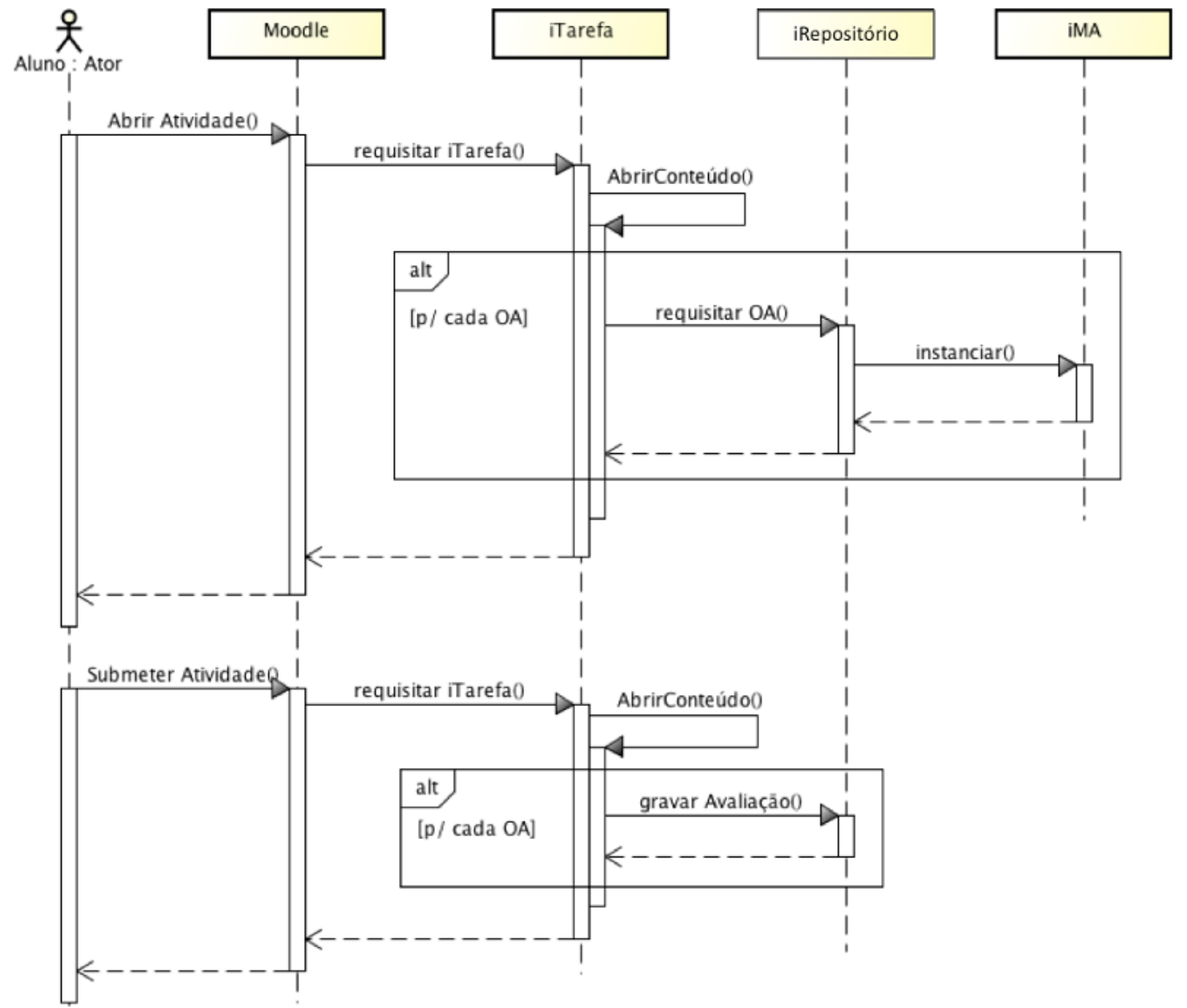

Figura 5.9: Diagrama de Sequência UML para a recuperação de OA e submissão de uma Tarefa Interativa. 


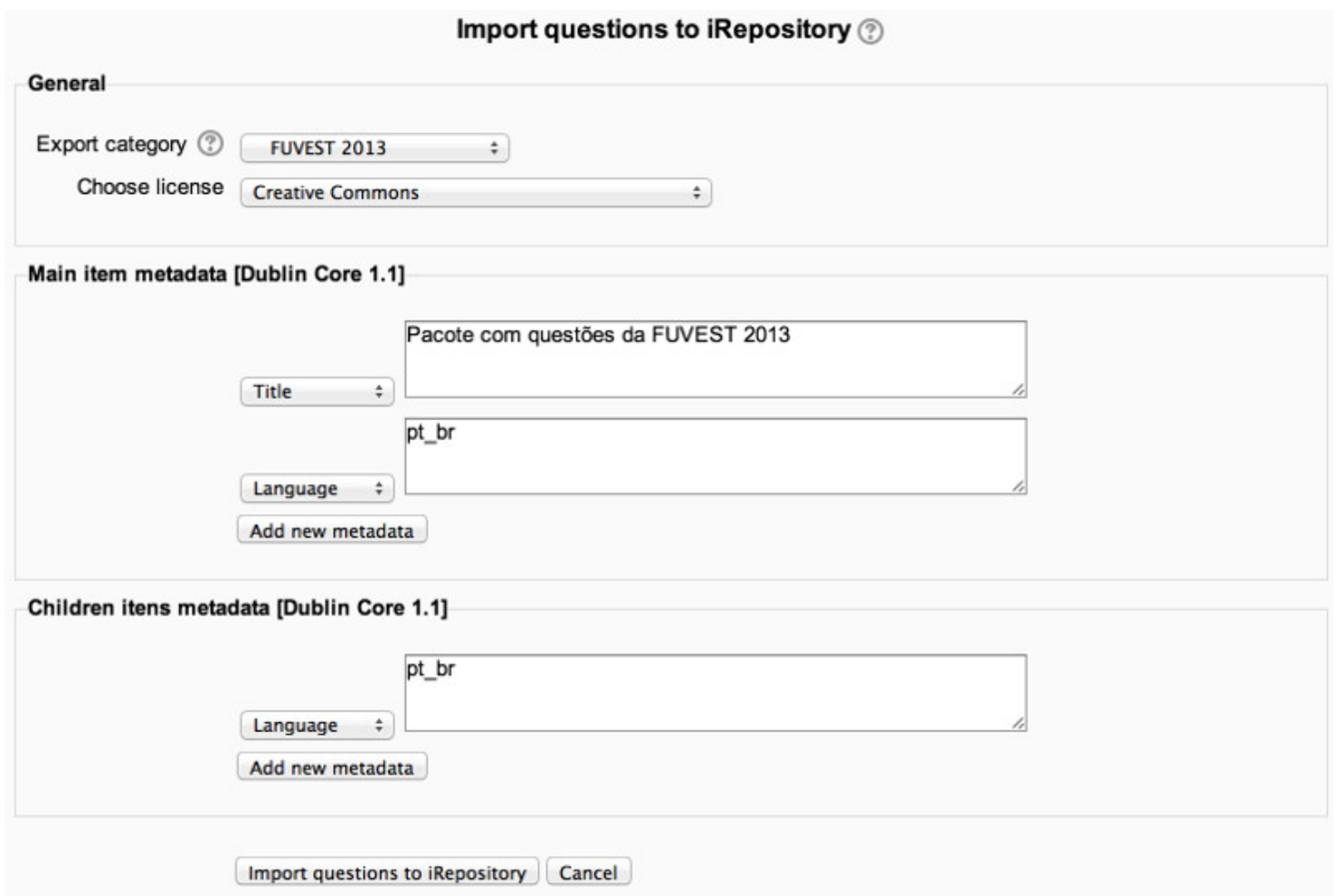

Figura 5.10: Interface para importação em lote de questões do banco para o repositório.

Num instante seguinte, após realizar as atividades exigidas pela tarefa interativa, o aluno deve submetê-las ao Moodle, na forma de um pacote contendo todos os seus dados. Estes são por sua vez enviados ao módulo iTarefa, que abre novamente o seu conteúdo correspondente e passa a processar a avaliação do aluno. Para cada um dos seus OA enviados pelo ator, o iTarefa armazena no repositório sua avaliação correspondente. Após o processamento de todas as respostas dos OA associados, um retorno é enviado ao aluno.

Nota-se que, assim como na seção anterior, o processo descrito aqui de recuperação de atividade interativa e submissão de avaliação do aluno, também não houve interação direta entre o ator (o aluno) e o iRepositório.

O pacote de dados enviado pelo aluno ao ambiente do SGC e que é internamente registrado no iRepositório é particularmente útil para uma série de análises deste serviço, como por exemplo a da mineração de dados do repositório e rastreamento das suas atividades e realizações.

\subsubsection{Importação e exportação de materiais em lote}

Conforme mencionado no início deste capítulo, o iRepositório possui o sub-diretório interface, localizado na raiz do seu código-fonte, onde é prevista a inclusão de bibliotecas de integração deste sistema com demais módulos do Moodle. Rotinas responsáveis por importação e exportação de materiais em lote também fazem parte do seu conteúdo, como é o caso, por exemplo, do importador de questões para o repositório, ilustrado na Figura 5.10.

O propósito dos importadores de conteúdo em lote é o de facilitar e otimizar o trabalho do autor, ao oferecer uma interface prática na qual ele recupere um conjunto de materiais do ambiente e compacte-os num único OA do repositório. De maneira análoga, também é esperada a função inversa: a partir de um OA, que contenha um pacote de materiais, é possível que ele seja aberto e que seus conteúdos possam ser extraídos e instalados de volta no SGC.

A interface ilustrada na Figura 5.10 mostra o processo de importação de materiais do Moodle (neste caso questões do banco de questões), para um único OA do repositório. Este importador oferece a árvore hierárquica de categorias definidas no ambiente do SGC para as questões. O autor pode selecionar um nível qualquer desta árvore. Todas as questões contidas nesta e nas suas sub- 
categorias serão consideradas para importação. Nos campos seguintes do formulário de importação, o autor indica a licença deste material, bem como um conjunto de metadados (do padrão ativo do iRepositório), tanto para o pacote unificado quanto para cada questão individual. Após acionar o botão de importação, o novo OA é gerado e publicado no repositório.

Internamente, este processo de importação gera ao todo $n+1 \mathrm{OA}$, considerando-se uma categoria do banco de questões com $n$ questões. Cada uma destas gera um OA e adicionalmente outro OA, "pai" de todas elas, também é criado. Ele é considerado o OA que detém o vínculo com todas as questões associadas, ou ainda, que é o responsável pela organização do "empacotamento". Para que esta hierarquia de objetos seja mantida de forma íntegra, o OA "empacotador" estabelece associações lógicas para cada um dos OA das questões.

Ressalta-se também o compromisso da não-duplicidade de conteúdo pelo repositório. Em outras palavras, caso o processo de importação identifique que alguma das questões a ser importada já possua um objeto equivalente no repositório, ele apenas fará a associação lógica desta com o OA empacotador. Não é necessário (nem desejável) re-criar ou duplicar o seu conteúdo no repositório, para objetos idênticos e redundantes.

Para processos de importação de materiais, o iRepositório solicita ao Moodle que este entregue o conteúdo de cada um deles em sua forma nativa de backup. Como este conteúdo é formado por uma cadeia de caracteres, ele pode ser armazenado como parte dos arquivos componentes do OA. De forma análoga, durante o processo de exportação dos objetos para materiais do Moodle, o repositório entrega o conteúdo deste arquivo ao SGC e solicita que este execute sua rotina nativa de restauração. Por delegar ambas as rotinas ao Moodle, o iRepositório pode tratar os processos de importação e exportação de conteúdo de forma genérica e independente da classe do material a ser tratado. Basta que ele estabeleça as rotinas adequadas de comunicação com a interface pública do módulo desejado.

\subsection{Resultados de experimentos}

\subsubsection{Avaliação do iRepositório por professores do Ensino Médio}

O iRepositório foi avaliado na prática, por um grupo composto por 15 professores do Ensino Médio, de diferentes áreas do conhecimento, durante o XLIII Programa de Verão IME-USP, realizado em Janeiro de 2014. Este programa ofereceu diversos cursos de extensão e aprimoramento profissional aos interessados, sendo que o "LEM 4 - Autoria de Atividades Interativas no Moodle com iTarefa e iGeom" foi o utilizado para este experimento. A razão por esta escolha foi devido ao seu enfoque direcionado às práticas e linha de pesquisa do grupo LInE, voltadas para autoria de módulos de atividades interativas, compartilhamento de OA e repositórios de conteúdos digitais.

Durante o curso, composto por aulas práticas em laboratório de informática, os participantes foram instruídos para o uso do $i M A$ para Geometria Interativa (iGeom), num ambiente Moodle disponibilizado especialmente para este propósito. Em seguida, eles avançaram para o módulo iTarefa, para autoria de atividades interativas através da inserção de exercícios daquele $i M A$.

Finalizadas as etapas anteriores, foi apresentado o iRepositório. Suas vantagens foram evidenciadas ao grupo participante, em relação a autoria, busca, classificação e compartilhamento de OA e comparadas às formas convencionais de gestão deste tipo de conteúdo em meios digitais. Em seguida, os participantes foram convidados a interagir com as principais funcionalidades do repositório. Foram avaliadas na prática a autoria de OA a partir de exercícios de $i M A$, compartilhamento destes materiais entre os presentes e buscas por determinados conteúdos a partir de critérios estabelecidos de busca.

Antes do encerramento do curso, foi solicitado que os professores participassem de uma pesquisa de avaliação, a respeito de todo o material apresentado e praticado durante as aulas, incluindo o uso do iRepositório. Esta pesquisa foi composta tanto por questões de escolha simples quanto dissertativas. Seus enunciados, opções das alternativas, bem como as respostas concedidas pelos participantes, são relatados no Apêndice C. 
O plugin do iRepositório que foi disponibilizado aos participantes durante a realização do curso, contava apenas com uma versão simplificada, com funcionalidades restritas e ainda não possuía recursos para associações entre OA ou importação de conteúdos em lote. Apesar disto, foi evidenciado êxito no seu uso pelos professores, de acordo tanto com o desenvolvimento das atividades em sala de aula pelos professores, quanto pela leitura e análise das respostas concedidas no questionário de avaliação. Foram verificadas algumas exceções pontuais, de professores que declararam possuir dificuldade no manuseio do computador e interações com ferramentas digitais de maneira geral. Entretanto, a maioria dos presentes, conseguiu trabalhar com o iRepositório de maneira satisfatória, ao gerar e armazenar conteúdos digitais, realizar buscas por conteúdos a partir de alguns critérios de busca e compartilhar materiais entre seus pares. 


\section{Capítulo 6}

\section{Conclusões}

O presente projeto apresentou um modelo conceitual para um ROA inovador, o iRepositório. O conjunto dos seus requisitos funcionais fundamentais foi avaliado a partir de uma revisão bibliográfica dos ROA existentes. Isto garantiu ao modelo as funções de base previstas nesta classe de sistema como a autoria, publicação, classificação e busca de materiais digitais armazenados nos seus registros.

Por estar integrado ao SGC Moodle, o iRepositório pode compartilhar e usufruir da sua infraestrutura, como o arcabouço, bibliotecas de funções, interfaces públicas e seu banco de dados. Isso trouxe uma série de benefícios diretos, como a redução de tempo necessário para sua implementação e reutilização dos recursos pré-existentes do SGC. Entretanto, os maiores diferenciais que de fato puderam ser obtidos a partir desta estratégia, em relação aos repositórios convencionais, foi o intercâmbio constante de dados entre os dois sistemas, durante determinados eventos monitorados por ambos. Uma vez trabalhando em conjunto e integrado ao Moodle, o iRepositório pode atuar como um mediador entre o SGC e seus materiais digitais. Módulos como o iTarefa e Questionário, por exemplo, passaram a requisitar seus conteúdos a partir deste repositório, ao invés de precisarem mantê-los pela sua própria gestão. Em contrapartida, estes módulos retro-alimentam o repositório com dados pertinentes às avaliações obtidas pelos alunos em cada um dos seus objetos. Além disso, o iRepositório oferece aos professores a possibilidade de qualificar os seus OA e respectivos autores, através de um módulo de avaliações. Tal registro da eficácia educacional do OA garante que bons materiais sejam priorizados nos resultados de buscas realizadas pelos usuários. Ainda nas funções de autoria e compartilhamento de materiais digitais, o iRepositório conta com interfaces especializadas para a importação em lote de materiais de atividades pedagógicas do Moodle na forma de OA e o processo análogo, de restauração destes para o formato nativo do SGC.

Um protótipo funcional do sistema com funções simplificadas, foi testado e avaliado na prática, através de laboratório com uma classe composta por 15 professores, de modo que estes pudessem interagir com ele para autoria, busca e compartilhamento de OA. A avaliação recebida ao final do evento foi de maneira geral satisfatória e positiva. Além disso, contribuiu de forma significativa para sinalizar e comprovar os benefícios previstos originalmente para este repositório.

Visando contribuir com a grande comunidade, tanto dos usuários do Moodle quanto por professores e autores de conteúdos deste SGC, o plugin do iRepositório será disponibilizado publicamente, de forma livre e gratuíta, sob a licença $G N U$ GPL. Ele já conta com pacotes nos idiomas inglês e português, sendo que outros poderão ser agregados futuramente, conforme a necessidade e demanda de uso.

\subsection{Sugestões para pesquisas futuras}

As próximas seções descrevem algumas sugestões para pesquisas futuras. Todos os tópicos relacionados abaixo possuem pontos de intersecção e estão de certa forma alinhados com a área de Informática na Educação, em particular para temas relacionados a autoria e produção de OA, reputação de OA e dos seus autores e compartilhamento destes recursos. Os leitores e pesquisadores em 
geral interessados, poderão tomar como base o projeto do iRepositório e extendê-lo e aprimorá-lo para estas áreas.

Tais assuntos foram abordados de maneira breve e sucinta ao longo desta dissertação. Isto foi necessário devido a extensão que estes tomariam, em termos de esforço, tempo e recursos necessários para revisões bibliográficas adicionais, re-validação do escopo do projeto de pesquisa e consequentemente re-adequação do protótipo proposto para o iRepositório.

A ideia da incorporação (ou retirada) dos assuntos pertinentes a esta pesquisa foi sendo amadurecida e esclarecida através das reuniões periódicas realizadas pelo grupo de pesquisa LInE, desde o início deste projeto e foi concluída após as valiosas sugestões e críticas debatidas com a banca de professores da qualificação desta pesquisa.

\subsubsection{Mineração de dados no repositório}

De maneira geral, a Mineração de Dados é uma área de pesquisa e desenvolvimento interdisciplinar, que lida com o apoio da Computação e da Estatística, com o processamento massivo de dados provenientes de um repositório de dados ${ }^{1}$. Suas principais finalidades são a identificação de padrões, descobertas de novas informações, regras de associações ou ainda sequências temporais. O auxílio da Computação é vital para este tipo de trabalho, pois o seu poder de processamento garante uma análise eficiente e sistemática dos dados de entrada [Fayyad et al. (1996)].

Um ramo de pesquisa da Mineração de Dados que tem recebido destaque nos últimos anos é a voltada ao contexto do Ensino, denominada por Mineração de Dados Educacionais - MDE. O advento dos cursos de EaD, em particular os denominados Massive Open Online Course (MOOC), em conjunto com a adoção crescente de SGC que os apóiam, tem gerado uma quantidade de dados, a partir do seu uso pelos professores e alunos, suficiente para a abordagem deste processo. Romero e Ventura (2010) realizaram uma abrangente revisão da litetura desta área onde destacam estudos em diferentes contextos do ensino, como por exemplo: $i$ ) a descoberta de novos conhecimentos baseados na utilização do SGC pelos alunos, a fim de aprimorar suas experiências neste ambiente; ii) descoberta de conhecimentos para auxiliar professores a gerirem suas turmas de maneira eficaz e compreenderem mais precisamente o processo de aprendizado do aluno, de modo que ofereçam retroação ágil para eles e iii) aprimoramento do contexto pedagógico de um curso.

O repositório de OA pode tomar como base estes conceitos e práticas utilizadas, a fim de adotar um conjunto dessas análises, para que possa aprimorar os processos de ensino e de aprendizagem, além da promoção de OA determinados como de boa qualidade.

\subsubsection{Teoria da Resposta ao Item}

A proposta da Teoria da Resposta ao Item (TRI) foi introduzida a partir dos anos 1950, sendo apresentada como uma evolução da Teoria Clássica dos Testes. Ela tem sido revisitada e adotada por pesquisadores da área da Educação nestas últimas duas décadas, com o advento dos sistemas computacionais que facilitam o armazenamento, classificação e elaboração de testes. O seu propósito é o de prover um modelo estatístico que possa mensurar a qualidade de um material de avaliação, bem como um item individual (ou questão) comporta-se neste exame.

Em sua obra "Teoria da Resposta ao Item: Conceitos e Aplicações", frequentemente referenciada no meio, de Andrade et al. (2000) afirma que a TRI pode ser utilizada para o refinamento de questionários ao longo do tempo, com o uso de grandes bancos de questões e a equalização do seu grau de dificuldade em sucessivas versões de um exame. Ainda segundo estes autores, "o que esta teoria sugere são formas de representar a relação entre a probabilidade de um indivíduo dar uma certa resposta a um item e suas habilidades na área de conhecimento avaliada". Em termos práticos, a teoria garante semelhança de dificuldade entre duas avaliações aplicadas, em momentos distintos e com questões diferentes entre elas.

\footnotetext{
${ }^{1}$ Normalmente um Banco de Dados, ou mais especificamente, um Armazém de Dados, que agrega num local centralizado os dados pertinentes a estes sistemas, originados a partir de uma ou mais fontes.
} 
Um caso de referência de uso da TRI desde 2009 no Brasil é o Exame Nacional do Ensino Médio (Enem), promovido pelo Inep e pelo Ministério da Educação (MEC). Estes institutos mantêm um grande banco de itens, denominado por "Banco Nacional de Item". Itens são pré-avaliados, reformulados e incorporados a este repositório ao longo do tempo.

O repositório pode servir como base para o fornecimento e acompanhamento das avaliações dos seus materiais para a TRI, para a melhoria contínua desses e consequentemente a uma avaliação mais adequada e consistente para o aluno.

\subsubsection{Aperfeiçoamento dos algoritmos e sistemas de buscas dos OA}

O projeto atual do iRepositório conta com um conjunto relativamente abrangente de critérios disponíveis para busca de OA. Como parte da estratégia adotada de compartilhamento de recursos do Moodle, ele usufrui dos seus mecanismos internos de localização de registros do seu banco de dados. A partir da requisição de uma busca pelo usuário, o repositório constrói, com o auxílio das bibliotecas do SGC, uma consulta do tipo $S Q L$, que é enviada ao banco para recuperação de possíveis registros. O seu resultado é retornado ao repositório, que o exibe ao usuário, na forma de dados distribuídos entre janelas visuais de paginação.

Apesar de funcional, esta estratégia apresenta algumas deficiências. As bibliotecas oferecidas atualmente pelo Moodle apresentam dificuldades na prática em lidar com consultas complexas, que envolvam retorno de milhares de registros. Além disso, ele não tem a capacidade de sugerir alternativas aos dados solicitados pelo usuário, caso não os localize na forma exata como foram solicitados.

Existem áreas de pesquisa atualmente na Computação especializadas no armazenamento, processamento e localização de quantidade massiva de dados, distribuídos muitas vezes de maneira dispersa em clusters entre múltiplos servidores. Concomitantemente, sistemas computacionais têm sido promovidos para este propósito, como é o caso do projeto Apache Hadoop ${ }^{2}$.

O repositório poderia ser integrado com uma ferramenta deste propósito, para que pudesse contar com um incremento na sua capacidade de processamento e busca de materiais armazenados, em ambientes de larga escala.

\footnotetext{
${ }^{2}$ Disponível em http://hadoop.apache.org/.
} 
CONCLUSÕES 


\section{Apêndice A}

\section{Ambiente $\boldsymbol{A} M \boldsymbol{M}$ e possíveis configurações}

Este Apêndice apresenta a infra-estrutura computacional de apoio necessária ao Moodle e ao iRepositório, em termos conceituais e práticos. Um leitor interessado poderá utilizar e praticar as técnicas aqui descritas para a instalação e configuração de ambientes $A M P$ completos.

O nome $A M P$ é um acrônimo dos seus componentes de base, que formam uma "pilha de serviços" ou um "pacote", comumente utilizados em sistemas apoiados na Web. De forma geral, ele é composto por 3 classes de aplicativos: $i$ ) Servidor Web Apache; ii) gerenciador de Banco de Dados $M y S Q L$, MariaDB ou MongoDB e iii) um conjunto de um ou mais interpretadores das linguagens de programação PHP, Python ou Pearl. Dentre suas caracterísicas, destacam-se o fato de ser um pacote composto por componentes com licenças gratuítas, código-fonte aberto e independente da plataforma do Sistema Operacional [Melo e Nascimento (2007)]. Dentro do contexto particular deste projeto, a segunda e terceira letras do acrônimo $A M P$ são referenciadas, respectivamente, pelo banco de dados $M y S Q L$ e pela linguagem de programação $P H P$.

A Figura A.1 exibe a estrutura básica deste pacote (destacada em fundo cinza) e suas interações com outros componentes relacionados (Sistema Operacional, seu sistema de arquivos e navegador Web). As flexas indicam as possíveis interações entre os componentes (internas e externas) ao $A M P$. Um caminho frequentemente percorrido, dentro destas interações é: $i$ ) o usuário faz uma requisição HTTP no seu navegador Web ao serviço; ii) o Servidor Web Apache recebe todas as requisições externas e faz o seu devido tratamento e roteamento; iii) se a requisição for para recuperação de um arquivo estático do servidor (imagem, folha de estilo, código Javascript) ele localiza seu armazenamento e entrega seu conteúdo de volta ao navegador Web; iv) caso contrário, se a requisição for para um script PHP, ele delega sua execução para este interpretador; $v$ ) o PHP pode, por sua vez interagir com o gerenciador do Banco de Dados (consulta de dado, registro de nova informação) ou ainda consultar arquivos do sistema operacional; vi) encerrada a execução do script, seu resultado final é retornado ao Servidor Web Apache, que por sua vez é devolvido ao navegador Web. Como "pano de fundo" destas operações, o Sistema Operacional destes serviços atua com apoio ao sistema de arquivos local, bibliotecas, extensões e outros componentes necessários a pilha $A M P$.

Algumas extensões deste acrônimo também são comumente citadas na litetura e possuem um caractere que prefixa o acrônimo $A M P$. Este varia de acordo com a família do seu Sistema Operacional de apoio. Algumas delas são: i) LAMP para os que utilizam alguma das distribuições Linux; ii) $M A M P$ para o Mac OS e iii) WAMP para o Windows.

As seções seguintes exemplificam sua instalação e configuração em termos práticos em alguns Sistemas Operacionais. Inicialmente são apresentados alguns pacotes pré-configurados para sua utilização, voltados principalmente para configuração ágil de ambientes ou ainda para usuários iniciantes e que não tenham familiaridade com instalação de aplicativos em um servidor Web. Em seguida são descritos exemplos de instalação através de pacotes integrados e pré-compilados, para os sistemas Linux e Mac $O S X$. Finalmente é descrita a instalação do PHP via compilação do seu código-fonte, feito diretamente no servidor Web. 


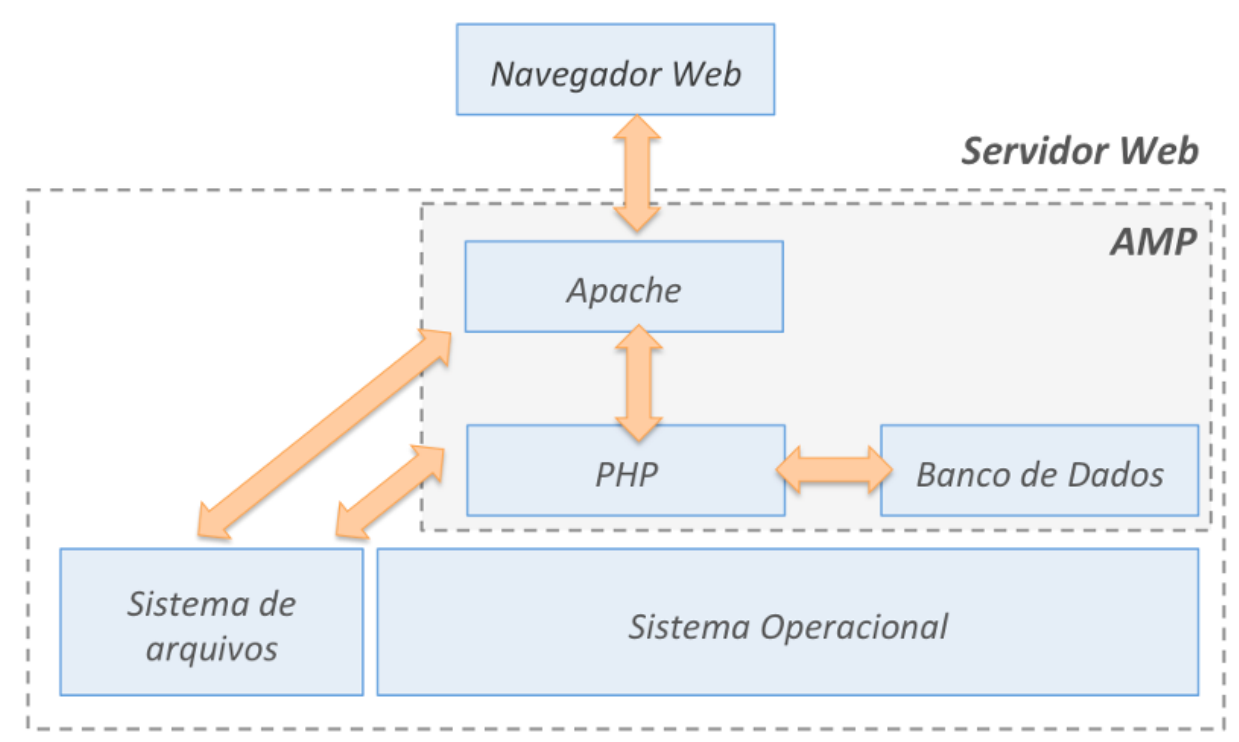

Figura A.1: Estrutura básica do pacote AMP e suas interações com os demais serviços. Adaptado de Melo e Nascimento (2007)

\section{A.1 Pacotes $A M P$ pré-configurados e parametrizados}

Algumas vantagens do uso de pacotes pré-configurados e parametrizados são a agilidade e facilidade para sua instalação e uso. São ideais para usuários interessados que não possuam conhecimento técnico neste tipo de ambiente, ou ainda para montagem de ambientes pessoais de desenvolvimento ou de pequenos testes para aplicações Web.

Geralmente dispostos em um único arquivo de instalação, podem ser descarregados do seus respectivos sítios e instalados no servidor através de assistente. Com frequência, possuem gerenciadores em ambientes gráficos. Estes ocultam detalhes internos de cada um dos seus aplicativos e exibem suas informações e parametrizações mais relevantes em interfaces integradas e de utilização facilitada e assistida aos usuários. Desta maneira, não há necessidade do conhecimento técnico de comandos ou interfaces particulares utilizadas por cada um dos componentes.

Outro fato interessante, é que com frequência, estes pacotes trazem consigo sistemas e ferramentas adicionais a pilha essencial do $A M P$. Interfaces gráficas para manipulação do banco de dados (ex: phpMyAdmin), aceleradores de desempenho (ex: Zend Optimizer), depuradores (ex: XDebug) ou ainda sistemas Web (ex: Moodle, Wordpress, Joomla) podem ser encontrados prontos para utilização em alguns destes projetos.

Apesar das vantagens mencionadas, não recomenda-se, entretanto, a utilização destes pacotes pré-configurados em ambientes servidores de produção ou ainda que exijam o processamento de grande volume de dados. Neste caso, sugere-se ambientes ajustados de forma mais precisa e individual as necessidades dos seus sistemas. Este cenário é descrito na próxima seção.

\section{A.1.1 Windows}

Este Sistema Operacional tem uma oferta considerável de pacotes pré-configurados, em que destacam-se: WampServer ${ }^{1}$, EasyPHP ${ }^{2}, X A M P P^{3}$ e VertrigoServ $^{4}$.

O exemplo a seguir trata a respeito do pacote VertrigoServ, na plataforma Windows Server 2012. Basta descarregar o pacote a partir do seu sítio oficial e instalar através do assistente (Figura A.2 a). O Painel Gerenciador (Figura A.2 b) será exibido a partir de um ícone na bandeja do

\footnotetext{
${ }^{1}$ Disponível em http://www.wampserver.com/.

${ }^{2}$ Disponível em http://www.easyphp.org/.

${ }^{3}$ Disponível em http://www.apachefriends.org/en/xampp-windows.html.

${ }^{4}$ Disponível em http://vertrigo.sourceforge.net/.
} 


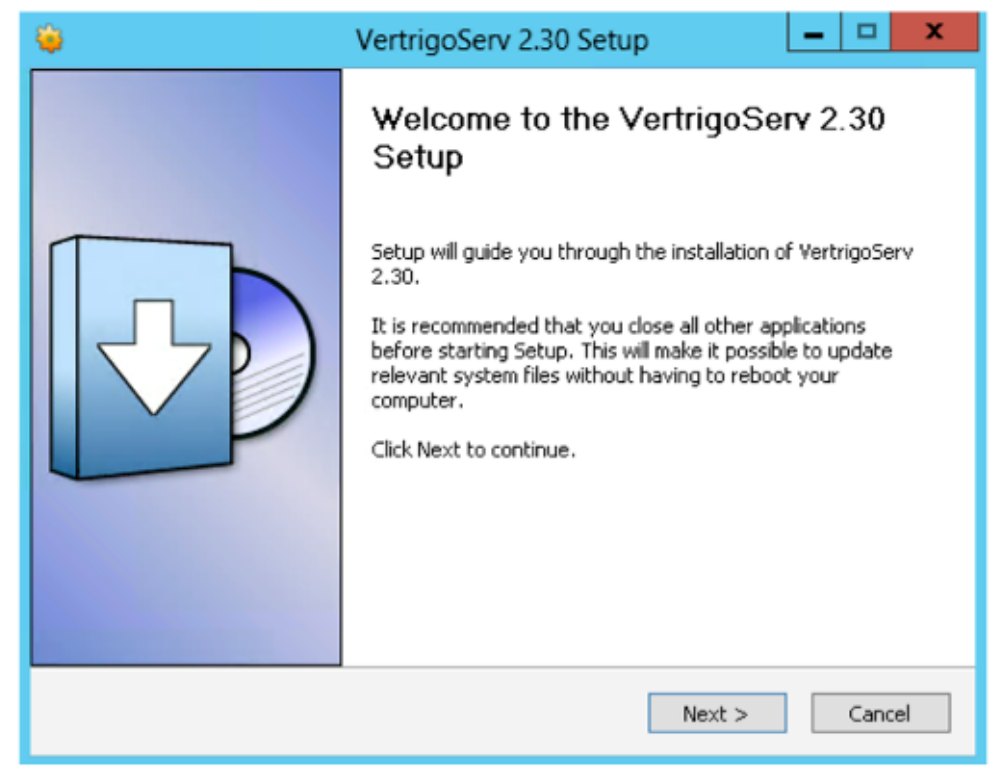

(a)

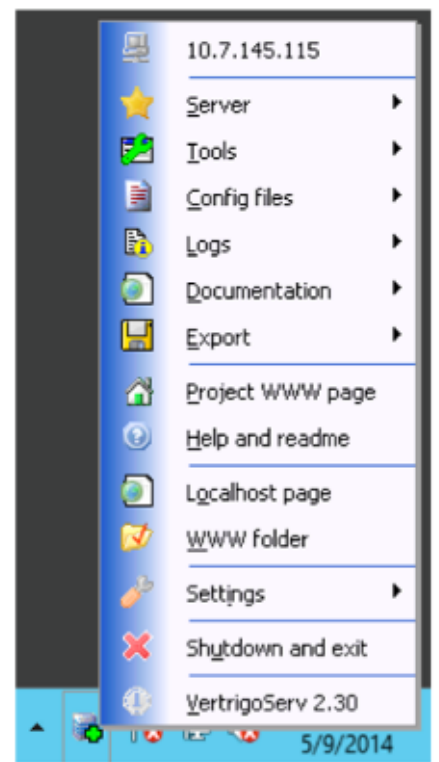

(b)

Figura A.2: VertrigoServ no Windows: a) uma das telas do assistente de instalação; b) detalhe do seu Painel Gerenciador gráfico.

sistema. Uma série de opções estão disponíveis como: parametrizações do Servidor Web Apache, registros de logs, página inicial do sistema, etc.

\section{A.1.2 Mac OS X}

O pacote $M A M P^{5}$ é frequentemente referenciado para este Sistema Operacional. Sua instalação é semelhante a descrita anteriormente para o VertrigoServ no sistema Windows. A instalação básica compreende o banco de dados $M y S Q L$, as linguagens de programação PHP, Perl e Python e Servidor Web Apache.

\section{A.2 Configuração manual do AMP a partir de gerenciadores de pacotes pré-compilados}

Uma proposta alternativa a apresentada na seção anterior, é a configuração de um ambiente $A M P$ a partir da instalação individual de cada um dos seus componentes e posterior integração entre eles. Uma das maiores vantagens deste método é o do domínio das parametrizações particulares de cada componente, uma vez que não existe, neste caso, um "assistente gerenciador" do $A M P$, que venha a ocultar seus detalhes e parâmetros internos.

Por permitir ajustes finos e individuais em cada um dos seus componentes, é considerada uma maneira recomendada para configuração de servidor Web, inclusive para sistemas em produção. Por outro lado, exige maior tempo de instalação em relação ao pacote integrado e um conhecimento técnico mais apurado por parte do seu usuário administrador responsável.

\section{A.2.1 Via utilitário $A P T$ do Linux}

Os componentes do pacote $A M P$ podem ser descarregados e instalados diretamente na linha de comando do console, com uma conta de "super-usuário", a partir dos utilitários da família APT (Advanced Packaging Tool) de gerenciamento de pacotes, disponíveis para as distribuições Ubuntu, Debian dentre outras do Linux. São eles:

\# apt-get install mysql-server

\footnotetext{
${ }^{5}$ Disponível em http://www.mamp.info/.
} 


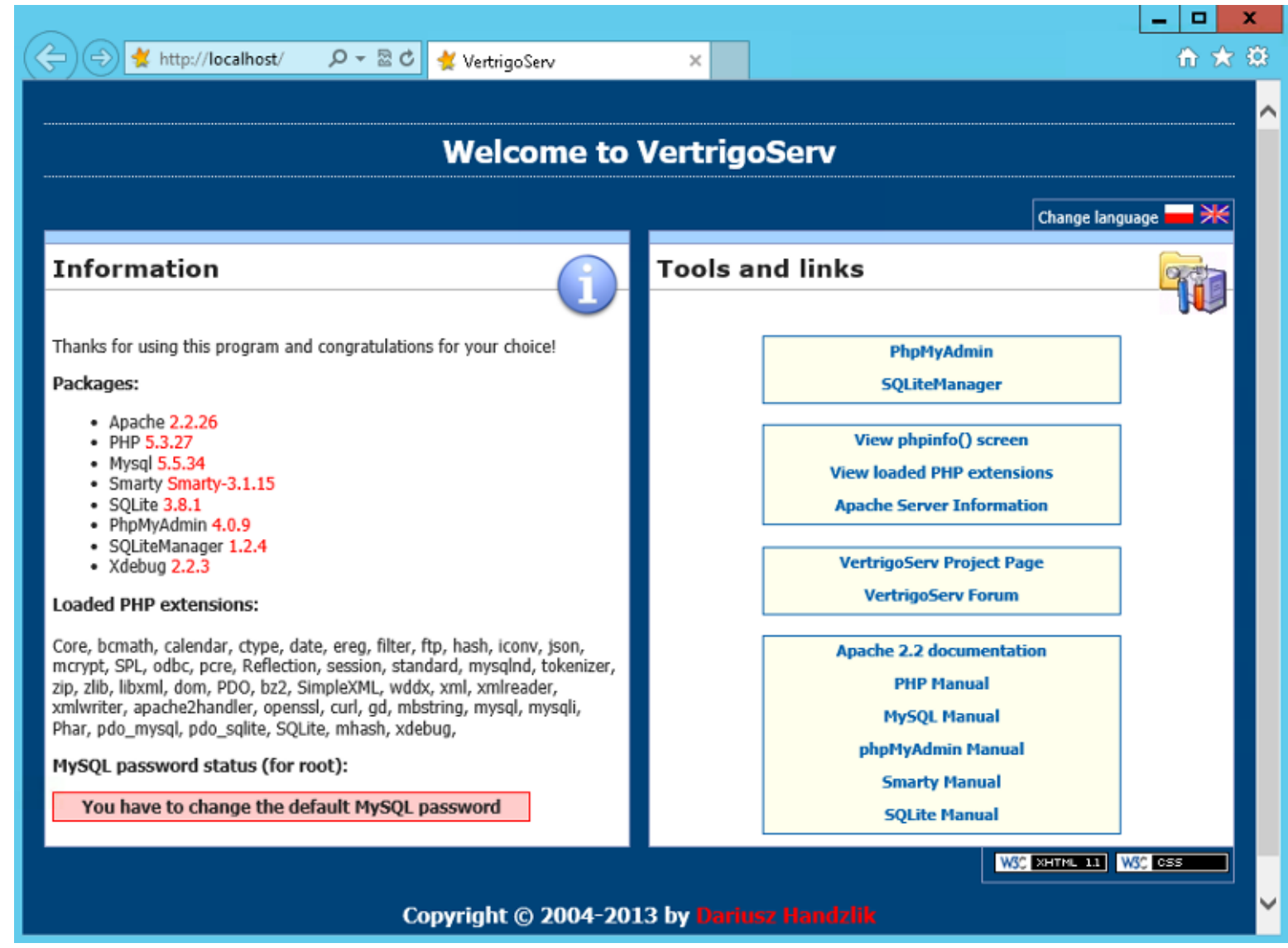

Figura A.3: Tela inicial do navegador Web, a partir do VertrigoServ.

\# apt-get install php5

\# apt-get install php5-mysql php5-curl php5-xmlrpc php5-gd php5-intl

Os dois primeiros comandos são suficientes para uma instalação básica do ambiente $A M P$. Eles instalam, respectivamente, o gerenciador de banco de dados $M y S Q L$ e PHP. Outros módulos adicionais são também descarregados e instalados automaticamente no segundo comando, entre eles o servidor Web Apache. Adicionalmente, o terceiro comando pode ser executado para instalação de módulos complementares ao PHP e que serão úteis posteriormente ao Moodle.

Estes comandos criam um local padrão no disco $(/ \mathrm{var} / \mathrm{www} / \mathrm{html})$ para o armazenamento de páginas estáticas, scripts e demais recursos (imagens, folhas de estilos, Javascript, etc), que servirão às requisições recebidas pelo Servidor Web Apache. Um script de avaliação dos módulos instalados e parâmetros gerais do PHP pode ser criado neste local através do comando:

\# echo "<?php phpinfo();" > /var/www/html/phpinfo.php

Após a criação do arquivo, requisitar a URL deste recurso a partir de navegador Web. Ela tem o padrão http: //<servidor > phpinfo.php, onde <servidor > deve ser substituído pela identificação da máquina (nome ou IP) onde o ambiente $A M P$ foi preparado. A Figura A.4 exibe o trecho inicial da página resultante da execução deste script.

Para parametrizações mais finas do ambiente, os seguintes arquivos estão disponíveis para edição:

- Servidor Web Apache - arquivos com extensão "conf" contidos em diretórios e sub-diretórios do caminho /etc/apache2;

- Banco de Dados MySQL - arquivos com extensão "cnf" contidos em diretórios e sub-diretórios do caminho /etc/mysql;

- PHP - arquivos com extensão "ini" contidos em diretórios e sub-diretórios do caminho /etc/php5. 


\section{PHP Version 5.5.9-1ubuntu4}

\begin{tabular}{|c|c|}
\hline System & $\begin{array}{l}\text { Linux ip-10-138-47-12 3.13.0-24-generic \#46-Ubuntu SMP Thu Apr } 10 \text { 19:11:08 } \\
\text { UTC } 2014 \text { x86_64 }\end{array}$ \\
\hline Build Date & Apr 92014 17:08:00 \\
\hline Server API & Apache 2.0 Handler \\
\hline $\begin{array}{l}\text { Virtual Directory } \\
\text { Support }\end{array}$ & disabled \\
\hline $\begin{array}{l}\text { Configuration File } \\
\text { (php.ini) Path }\end{array}$ & /etc/php5/apache2 \\
\hline $\begin{array}{l}\text { Loaded Configuration } \\
\text { File }\end{array}$ & /etc/php5/apache2/php.ini \\
\hline $\begin{array}{l}\text { Scan this dir for } \\
\text { additional .ini files }\end{array}$ & /etc/php5/apache2/conf.d \\
\hline $\begin{array}{l}\text { Additional .ini files } \\
\text { parsed }\end{array}$ & $\begin{array}{l}\text { /etc/php5/apache2/conf.d/05-opcache.ini, /etc/php5/apache2/conf.d/10-pdo.ini, } \\
\text { /etc/php5/apache2/conf.d/20-json.ini, /etc/php5/apache2/conf.d/20-readline.ini }\end{array}$ \\
\hline PHP API & 20121113 \\
\hline PHP Extension & 20121212 \\
\hline Zend Extension & 220121212 \\
\hline Zend Extension Build & API220121212,NTS \\
\hline PHP Extension Build & API20121212,NTS \\
\hline Debug Build & no \\
\hline Thread Safety & disabled \\
\hline Zend Signal Handling & disabled \\
\hline Zend Memory Manager & enabled \\
\hline Zend Multibyte Support & provided by mbstring \\
\hline IPv6 Support & enabled \\
\hline DTrace Support & enabled \\
\hline Registered PHP Streams & https, ftps, compress.zlib, compress.bzip2, php, file, glob, data, http, ftp, phar, zip \\
\hline $\begin{array}{l}\text { Registered Stream } \\
\text { Socket Transports }\end{array}$ & tcp, udp, unix, udg, ssl, sslv3, tls \\
\hline $\begin{array}{l}\text { Registered Stream } \\
\text { Filters }\end{array}$ & $\begin{array}{l}\text { zlib. }{ }^{\star}, \text { bzip2.* , convert.iconv.*, string.rot13, string.toupper, string.tolower, } \\
\text { string.strip_tags, convert. }{ }^{*} \text {, consumed, dechunk }\end{array}$ \\
\hline
\end{tabular}

Figura A.4: Resultado parcial do comando phpinfo no servidor LAMP baseado no Ubuntu. 


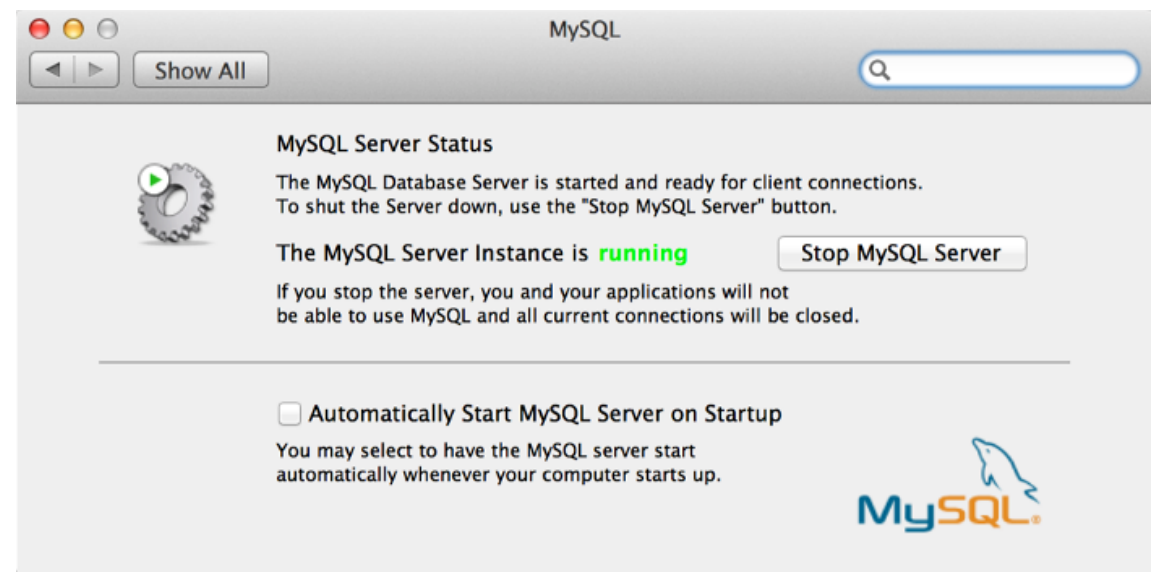

Figura A.5: Painel de administração do MySQL no Mac OS X.

\section{A.2.2 Via utilitário $Y U M$ do Linux}

Outro forma alternativa de instalação do pacote $A M P$, para distribuições RedHat, CentOS dentre outras do Linux, é com a utilização do comando YUM (Yellowdog Updater Modified), baseado no gerenciador de pacotes RPM. Também é necessária a utilização de uma conta de "super-usuário" diretamente num console do sistema. Os comandos são:

\# yum install mysql-server

\# /etc/init.d/mysqld start

\# yum install php

\# yum install php-mysql php-curl php-xmlrpc php-gd php-intl

\# /etc/init.d/httpd start

Os dois primeiros instalam e instanciam, respectivamente, o servidor de banco de dados $M y S Q L^{6}$. Os 2 seguintes são responsáveis pela instalação do $P H P$, bibliotecas necessárias ao Moodle e servidor Web Apache. O último instancia o servidor Web.

Estes comandos criam um local semelhante no disco $(/ \mathrm{var} / \mathrm{www} / \mathrm{html})$ para o armazenamento de páginas estáticas, scripts e demais recursos que poderão ser requisitados pelo navegador Web. $\mathrm{O}$ exemplo da seção anterior do arquivo $/ \mathrm{var} / \mathrm{www} / \mathrm{html} /$ phpinfo.php pode ser utilizado neste caso para avaliação do ambiente preparado.

\section{A.2.3 Mac OS X}

Versões mais recentes deste Sistema Operacional (desde a sua versão 10.0) já contam com o Servidor Web Apache e linguagem de Programação PHP embutidos por padrão. É preciso apenas habilitá-los através de arquivos de configuração. Basta editar o arquivo /private/etc/apache2/httpd.conf e retirar o comentário das linhas indicadas abaixo, para garantir que o módulo do PHP seja carregado durante a próxima instanciação do servidor Web.

LoadModule php5_module libexec/httpd/libphp5.so

AddModule mod_php5.c

Já o banco de dados $M y S Q L$ necessita ser descarregado a partir do seu sítio ofical ${ }^{7}$ e instalado manualmente. Ele conta com um Painel de Administração (Figura A.5), acessível a partir das Preferências do Sistema, onde é possível controlar o início ou término do seu serviço de maneira facilitada.

\footnotetext{
${ }^{6} \mathrm{~A}$ instalação do $M y S Q L$ cria automaticamente a conta do super-usuário root, com senha vazia. Para efeito de segurança, recomenda-se sua alteração o mais breve possível.

${ }^{7}$ Disponível em http://www.mysql.com/.
} 


\section{A.3 Compilação manual do $P H P$ a partir do seu código-fonte}

Assim como descrito na seção anterior, também é um método altamente recomendado para ambientes de produção. A diferença é que sua instalação é feita a partir da compilação do códigofonte do PHP diretamente no Sistema Operacional do servidor Web. Além disso, os pacotes devem ser integrados entre si de forma manual. Uma das vantagens desta instalação é a de possibilitar a definição de parâmetros para a compilação do $P H P$ de forma mais específica, controlar a versão desejada para cada componente, indicar as bibliotecas que deverão ser incluídas ou removidos do ambiente, dentre outras opções mais avançadas.

Para efeito de simplificação, serão descritos os passos para a compilação do $P H P$ na distribuição Linux Ubuntu. Os demais componentes do $A M P$, neste caso, serão instalados via gereciador de pacote. Pressupõe-se também que o gerenciador de Banco de Dados MySQL já tenha sido instalado, conforme descrito nas seções anteriores.

Assim como nas demais instalações exibidas, é necessário a utilização de uma conta de "superusuário", num console de linha de comando. Primeiramente os pacotes do Servidor Web Apache 8 e de bibliotecas auxiliares a compilação do PHP devem ser instalados. Os dois comandos abaixo são responsáveis por isso:

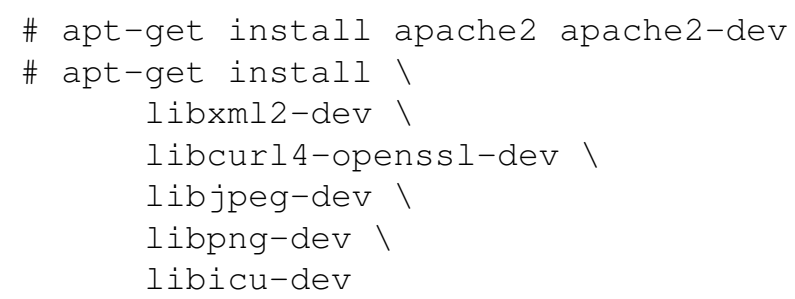

O código-fonte do PHP deve ser descarregado a partir do seu sítio oficial e descompactado. Os comandos abaixo pressupõe a versão utilizada 5.5.7 do $P H P^{9}$, mas poderiam ser alterados para refletir uma mais recente, caso necessário.

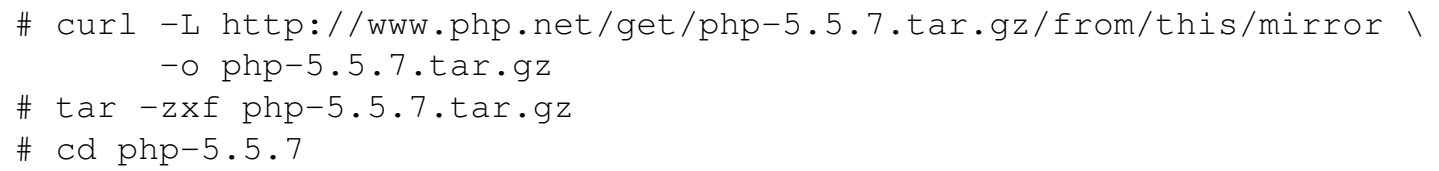

Em seguida, dá-se início a etapa propriamente dita de compilação do código-fonte do PHP. Os comandos a seguir realizam respectivamente, sua parametrização com as bibliotecas necessárias ao Moodle, compilação e montagem do binário.

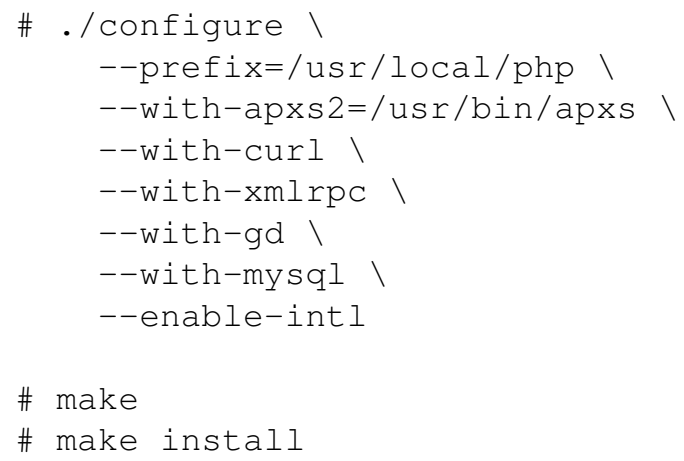

Após a compilação, é necessário configurar o arquivo php.ini do PHP e depois integrá-lo ao Servidor Web Apache.

\footnotetext{
${ }^{8} \mathrm{O}$ pacote "apache2-dev", apesar de não ser utilizado diretamente pelo servidor Web, é necessário a futura compilação do código-fonte do $P H P$.

${ }^{9}$ Este guia utilizou a versão mais recente da linha 5.5 do PHP, disponibilizada no período da sua escrita.
} 
\# cp -a php.ini-production /usr/local/lib/php.ini

\# In -s /usr/local/lib/php.ini /etc/

Editar o arquivo/etc/apache2/mods-enabled/php5.load de configuração do Servidor Web Apache e certificar que as linhas abaixo constam no mesmo. Caso não estiverem, deverão ser incluídas.

LoadModule php5_module modules/libphp5.so

AddType application/x-http-php .php

Editar o arquivo /etc/apache2/mods-enabled/dir.conf de configuração do Servidor Web Apache e certificar que o valor "index.php" esteja contido dentre as opções disponíveis da diretiva "DirectoryIndex". Caso não esteja, deverá ser incluída.

DirectoryIndex index.php index.html index.cgi index.pl index.xhtml index.htm

Finalmente, basta reiniciar o Servidor Web Apache para que as configurações anteriores tenham efeito.

\#/etc/init.d/apache2 restart

O diretório /var/www/html é configurado durante a instalação como sendo o raiz do servidor. O script de teste phpinfo.php pode ser utilizado neste local para avaliação do ambiente preparado. 


\section{Apêndice B}

\section{Instalação do ambiente Moodle}

Este Apêndice apresenta a um guia para instalação padrão do SGC Moodle a partir de um pacote do seu sítio oficial. Qualquer um dos ambientes $A M P$ preparados no Apêndice A pode ser utilizado como apoio. Para ilustração de um caso prático, será utilizada a distribuição Ubuntu do Linux. De qualquer forma, a sequência e os comandos a seguir variam pouco de um sistema para outro, uma vez que este SGC não apresenta dependência explícita de um ambiente específico.

Primeiramente será criado um novo banco de dados no servidor local do MySQL para o SGC. Acessar a sua interface, via console em linha de comando, com o usuário "root" criado durante a configuração do ambiente $A M P$. Informar a sua senha, também definida durante aquele processo.

\# mysql -uroot $-\mathrm{p}$

Uma vez na inteface do banco, entrar com os seguintes comandos. Eles irão definir um novo banco de dados chamado "moodle_tutorial" e conceder acesso irrestrito a um usuário chamado "usuario", com a senha definida por "senha". O último comando desta lista retorna ao console do sistema.

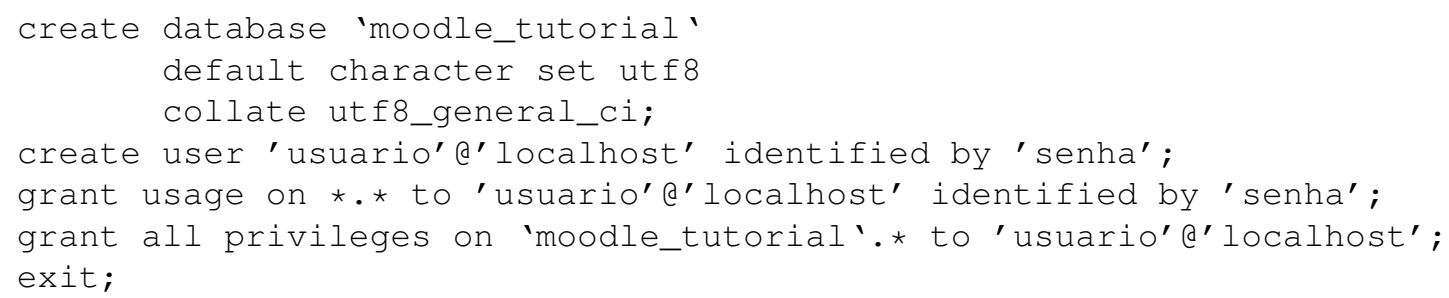

O código-fonte do Moodle deve ser descarregado a partir do seu sítio oficial e descompactado. Os comandos abaixo pressupõe a versão utilizada $2.6+{ }^{1}$, mas poderiam ser alterados para refletir uma mais recente, caso necessário.

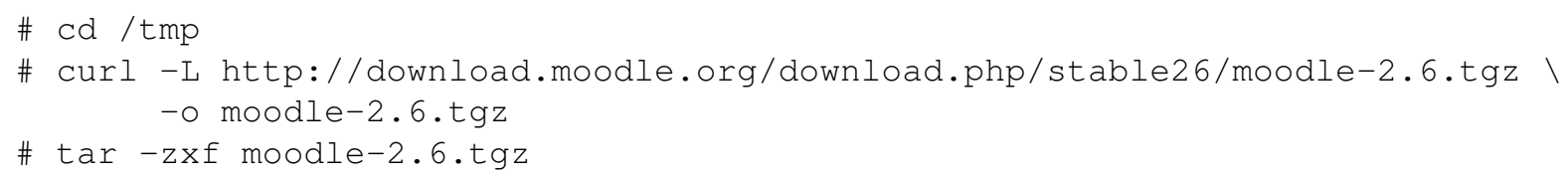

Após descompactá-lo, seus arquivos deverão ser movidos para a raiz do servidor Web. Outro diretório auxiliar, que não está mapeado no Servidor Web Apache, deverá também ser criado. Ele é o de dados, gerido internamente pelo ambiente e armazena tanto arquivos temporários (caches, scripts pré-compilados, etc), quanto permanentes (arquivos de usuários, backups de cursos, etc). O acesso a este recurso deverá ser concedido ao mesmo usuário e grupo do Apache.

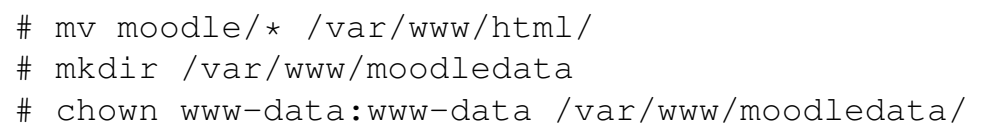

${ }^{1}$ Este guia utilizou a versão mais recente da linha 2.6 do Moodle, disponibilizada no período da sua escrita. 


\section{Installation}

\section{Language \\ Choose a language}

Please choose a language for the installation. This language will also be used as the default language for the site, though it may be changed later.

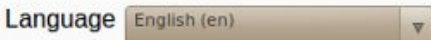

\section{Troodle}

Figura B.1: Assistente de instalação do Moodle.

Ao final destes passos, a estrutura de diretórios a partir de /var/www/ deverá apresentar o padrão semelhante ao abaixo.

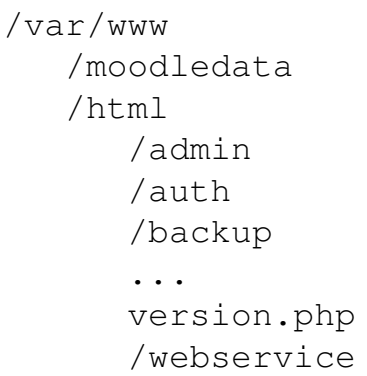

Requisitar a URL http://<servidor $>$ / a partir de um Navegador Web, onde < servidor $>$ deve ser substituído pela identificação da máquina (nome ou IP) onde o ambiente do Moodle está sendo preparado. Esta ação irá iniciar o processo do assistente de instalação do SGC, conforme a Figura B.1.

A próxima tela solicita os caminhos utilizados pelo ambiente (Web address, Moodle directory e Data directory). Os primeiros dois são auto-detectados. O último corresponde ao diretório recémcriado. Informar / var/www/moodledata para este campo. Na sequência é solicitado o tipo de conexão ao banco, sendo a nativa mysqli do PHP a padrão. Permanecer com esta escolha e seguir adiante, para as configurações de acesso ao banco de dados, conforme a Figura B.2. Fornecer os valores utilizados durante a criação do banco:

- Database name: moodle_tutorial;

- Database user: usuario;

- Database password: senha;

- Os demais valores sugeridos podem permanecer como tal.

Caso o Servidor Web Apache não tenha permissão de escrita no diretório /var/www/html, será solicitado que o conteúdo apresentado na tela seja escrito no arquivo /var/www/html/config.php. A tela seguinte (Figura B.3) confirma se todos as dependências de bibliotecas do PHP são cumpridas, para que a instalação possa seguir adiante. Caso alguma biblioteca obrigatória não seja localizada, 


\section{Improved MySQL (native/mysqli)}

Now you need to configure the database where most Moodle data will be stored. Database may be created if database user has needed permissions, username and password must already exist. Table prefix is optional.

Database host localhost
Database name moodle_tutorial
Database user usuario
Database password senha
Tables prefix mdl_
Database port
Unix socket

\section{ifnoodle}

Figura B.2: Parametrização para acesso ao banco de dados do Moodle.

Moodle 2.6+ (Build: 20131213)

For information about this version of Moodle, please see the online Release Notes

Server checks
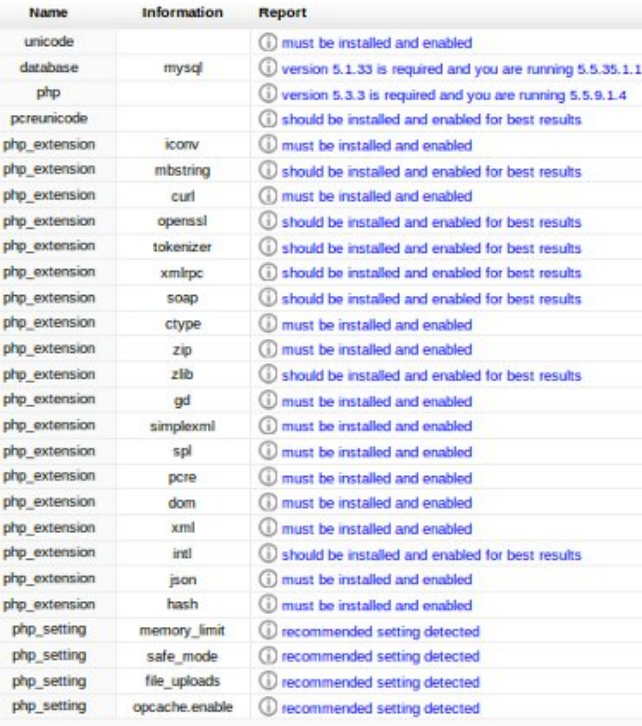

Your sevver environment meets all minimum requirements

Figura B.3: Avaliação das dependências do Moodle com as bibliotecas do PHP. 


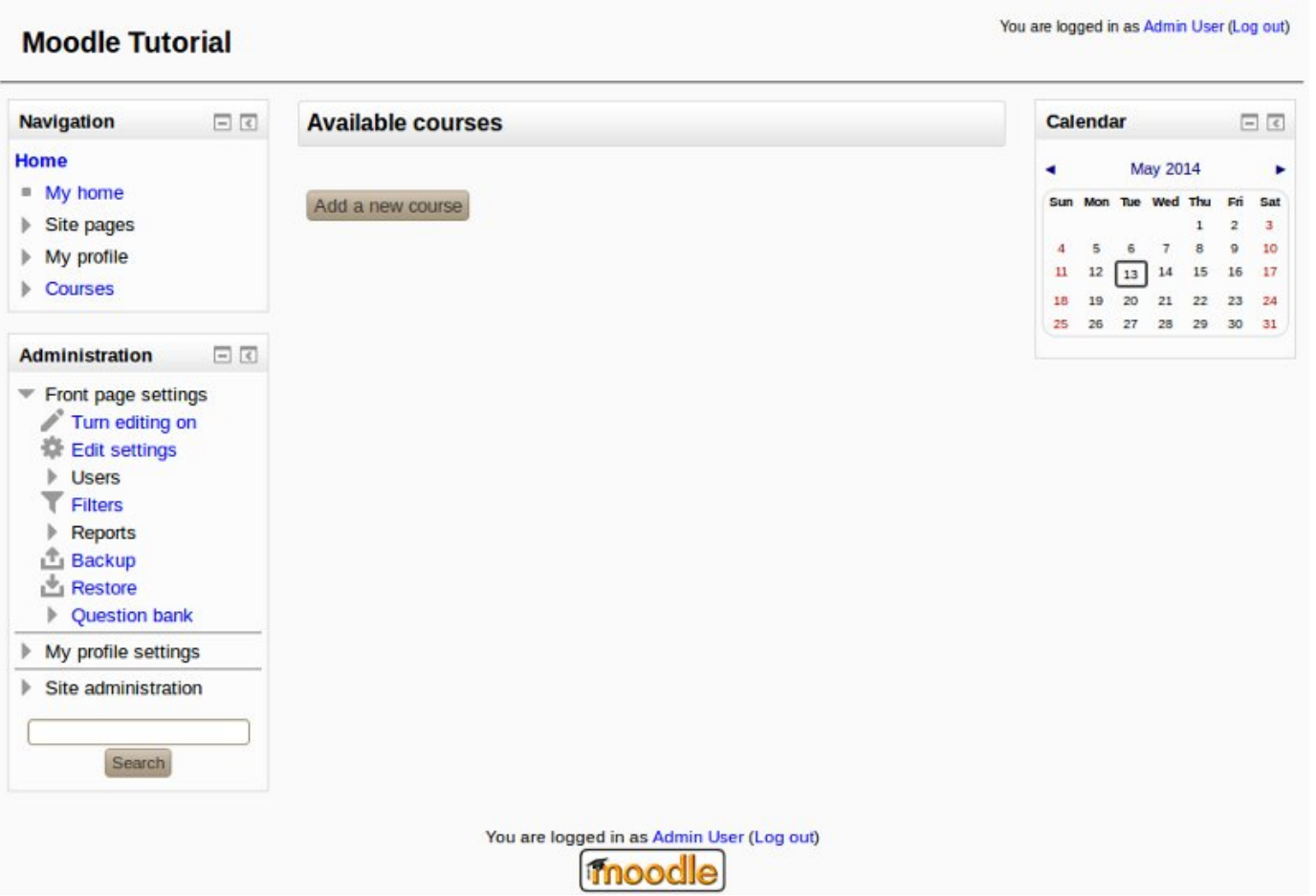

Figura B.4: Tela principal do ambiente Moodle recém-criado.

será necessário rever os passos anteriores de preparação do ambiente $A M P$. A tela seguinte serão apresentados de forma contínua os passos da instalação do ambiente e preparação do modelo necessário ao banco de dados.

Se tudo ocorreu conforme o esperado, a próxima tela solicita os dados da conta primária administrativa do ambiente. O nome "admin" é sugerido. Confirmar os valores dos demais campos e seguir adiante para a indicação dos dados gerais de parametrização do ambiente (nome do ambiente, etc). Após estes dois últimos passos, a tela principal do ambiente Moodle recém-criado deve ser exibida, conforme a Figura B.4. 


\section{Apêndice C}

\section{Pesquisa de avaliação do iRepositório}

Conforme descrito na seção Avaliação do iRepositório por professores do Ensino Médio, no final do Capítulo 5, este Apêndice apresenta tanto a avaliação aplicada quanto as respostas concedidas pelos participantes. Sua realização ocorreu ao final do curso de Extensão "LEM 4 - Autoria de Atividades Interativas no Moodle com iTarefa e iGeom", oferecido durante o XLIII Programa de Verão IME-USP.

As questões de escolha simples estão representadas na relação abaixo. Cada um dos itens contém o seu enunciado, seguido das alternativas propostas e total de respostas indicadas em cada uma entre parênteses, de forma percentual ao total dos participantes. As questões dissertativas estão representadas na relação seguinte. Cada um dos itens contém o seu enunciado, seguido de algumas respostas redigidas.

Como avalia a facilidade de uso?

Fácil (36\%); Regular (50\%); Difícil (14\%);

\section{Interface da ferramenta}

Excelente (7\%); Muito bom (21\%); Bom (50\%); Razoável (21\%);

\section{Recursos disponíveis}

Excelente (14\%); Muito bom (36\%); Bom (43\%); Razoável (7\%);

\section{Descrição dos metadados}

Excelente (14\%); Muito bom (21\%); Bom (36\%); Razoável (29\%);

Otimização de tempo utilizando esta ferramenta

Excelente (14\%); Muito bom (36\%); Bom (36\%); Razoável (14\%);

Como classifica sua motivação para usar o iRepositório em sua prática pedagógica?

Muito motivado (21\%); Motivado (57\%); Desmotivado (21\%);

Você considera este plugin para o Moodle

Excelente (36\%); Bom (50\%); Regular (14\%);

Por favor, explique sua opção quanto à motivação de usar o iRepositório.

Fundamentalmente, favorece a comunicação entre os desenvolvedores de conteúdo, proporcionando um intercâmbio de informações e acesso aos objetos.

Reutilizar e compartilhar material é sempre bom!

Gostei muito do iRepositório, pois me possibilita trocar/adquirir informações, exercícios e práticas com os colegas de trabalho.

Minha resposta está diretamente ligada a possibilidade de interação com outros professores, multiplicando meu conjunto de objetos de aprendizagem. 
É motivador pois não corro o risco de perder as atividades que eu crio e tenho acesso a materiais de outros professores me possibilitando conhecer experiências e aplicações de outro profissional.

Facilidade em achar atividades montadas para compor as atividades avaliativas das disciplinas que ministro.

\section{Como imagina que o iRepositório poderia lhe ajudar em seu dia-a-dia na escola?}

Favorece o armazenamento de conteúdos, tornando mais prático o seu reúso.

Evitar "retrabalho"!

Facilitação de acessos organizados aos dados.

Na redução do tempo de pesquisa e em contrapartida a redução para os colegas também.

Na busca de materiais para trabalhar na aula ou ajudar na elaboração de materiais para aula.

\section{Quais são as principais vantagens proporcionadas pelo iRepositório?}

O professor alcança uma maior gama de conteúdos e formas, além daqueles que ele próprio criaria.

Acessar facilmente arquivos de todos os assuntos que tenho interesse.

Redução no tempo para pesquisa.

Guardar atividades que poderão ser utilizadas posteriormente e compartilhar trabalhos.

Vejo muita vantagem na questão de gravar arquivos e informações de uma maneira compacta, na qual me possibilita ter acesso fácil e rápido, e me desprende de ficar presa a recursos/mídias, como e-mail, pen drive, CD e outros.

Ganho de tempo, ganho de conhecimento de outras soluções apresentadas, aquisição da cultura colaborativa em rede.

\section{Quais são as principais dificuldade encontradas no iRepositório?}

Os metadados.

O manuseio da ferramenta inicialmente não é fácil, embora seja muito útil. Mas acredito que é devido a pouco experiência. Sendo assim a frequência na utilização tende a diminuição das dificuldades.

Tive dificuldade em preencher os metadados por não dominar muito a parte técnica/sistema.

Embora seja muito cedo para essa avaliação, minha primeira impressão é que não terei dificuldades na utilização desse plugin.

É pouco intuitivo e creio que precise de funcionalidades que ajudem a dar vazão às produções colaborativas. 


\section{Referências Bibliográficas}

Alves e Gomes (2007) Ana Paula Alves e Maria João Gomes. O ambiente Moodle no apoio a situações de formação não presencial. Em V Conferência Internacional de Tecnologias de Informação e Comunicação na Educação, páginas 337-349. Centro de Competência da Universidade do Minho. ISBN 978-972-8746-52-0. URL http://hdl.handle.net/1822/7048. Citado na pág. 2, 9

Arimoto e Barbosa (2013) Mauricio Massaru Arimoto e Ellen Francine Barbosa. Towards the establishment of an agile method for OERs development and delivery. Em Proceedings of the 43th Frontiers in Education - FIE, páginas 541-547. Citado na pág. 1, 11

Aschenbrenner et al. (2010) Andreas Aschenbrenner, Tobias Blanke, Marc Küster e Wolfgang Pempe. Towards an open repository environment. Journal of Digital Information, 11(1). ISSN 1368-7506. URL http://journals.tdl.org/jodi/article/view/758/646. Citado na pág. 28

Barbosa et al. (2012) Ellen Francine Barbosa, Itana M. S. Gimenes e Leonor Barroca. Towards the development of open educational resources: Challenges and issues. Em Anais dos Workshops do Congresso Brasileiro de Informática na Educação. URL http://www.br-ie.org/pub/index. php/wcbie/article/view/1889/1652. Citado na pág. 1

Blat et al. (2006) Josep Blat, David Griffiths, Toni Navarrete, José Luis Santos, Pedro García e Jordi Pujol. Planetdr, a scalable architecture for federated repositories supporting IMS Learning Design. Em IST/Technology Enhanced Learning. Citado na pág. 2, 38

Cole e Foster (2007) Jason Cole e Helen Foster. Using Moodle - Teaching with the popular open source course management system. O'Reilly, 2 ed. Citado na pág. 9

Cruz et al. (2008) Claudia C. P. Cruz, Claudia L. R. Motta, Flavia Maria Santoro e Marcos Elia. Um estudo sobre reputação baseado no grau de concordância entre os membros de comunidades de prática. Em XIX Simpósio Brasileiro de Informática na Educação - SBIE. Citado na pág. 39

Dalmon (2012) Danilo Leite Dalmon. Uma linha de produto de software para Módulos de Aprendizagem Interativa. Dissertação de Mestrado, Instituto de Matemática e Estatística - USP, São Paulo. Citado na pág. 14, 15

Dalmon e Brandão (2013) Danilo Leite Dalmon e Leônidas Brandão. Sobre o desenvolvimento de software educacional: proposta de uma Linha de Produto de Software para Módulos de Aprendizagem Interativa. Revista Brasileira de Informática na Educação, 21(03):113-130. doi: 10.5753/ RBIE.2013.21.03.113. URL http://www.br-ie.org/pub/index.php/rbie/article/view/2403. Citado na pág. 15

Dalmon et al. (2011) Danilo Leite Dalmon, Maria José Tanbellini, Alexandre Eisenmann, Mauricio Garcia Nascimento, Patrícia Alves Rodrigues, Seiji Isotani, Anarosa Alves Brandão e Leônidas Brandão. Interactive Learning Modules in Engineering education as a motivational tool for middle and high school students. Em International Symposium on Engineering Education - IGIP. Citado na pág. 14

DCMI (2012) DCMI. DCMI metadata terms. Dublin Core Metadata Initiative. URL http: //dublincore.org/documents/dcmi-terms/. Último acesso em 20/10/2012. Citado na pág. 8 
de Andrade et al. (2000) Dalton Francisco de Andrade, Heliton Ribeiro Tavares e Raquel da Cunha Valle. Teoria da Resposta ao Item: conceitos e aplicações. Associação Brasileira de Estatística - ABE, São Paulo. Citado na pág. 62

de Santiago e Raabe (2011) Rafael de Santiago e André Luís Alice Raabe. Arquitetura para compartilhamento de objetos de aprendizagem entre instituições de ensino. Revista Brasileira de Informática na Educação, 19(1). URL http://www.br-ie.org/pub/index.php/rbie/article/view/ 1291. Citado na pág. 38

do Prado (2008) Reginaldo do Prado. iGraf: Uma proposta de sistema para ensino de função via web. Dissertação de Mestrado, Instituto de Matemática e Estatística - USP, São Paulo. Citado na pág. 15

Duval (2001) Erik Duval. Metadata standards: What, who \& why. Journal of Universal Computer Science, 7(7):591-601. doi: 10.3217/jucs-007-07-0591. URL http://dx.doi.org/10.3217/ jucs-007-07-0591. Citado na pág. 38

Eisenmann (2009) Alexandre Luís Kundrát Eisenmann. iComb: Um sistema para o ensino e aprendizagem de combinatória em ambiente web. Dissertação de Mestrado, Instituto de Matemática e Estatística - USP, São Paulo. Citado na pág. 15

Eliasquevici et al. (2008) Eliasquevici, Marianne Kogut, Prado Junior e Arnaldo Corrêa. O papel da incerteza no planejamento de sistemas de educação a distância. Educação e Pesquisa, 34:309 - 325. ISSN 1517-9702. URL http://www.scielo.br/scielo.php?script=sci_arttext\&pid= S1517-97022008000200007\&nrm=iso. Citado na pág. 2

Fayyad et al. (1996) Usama Fayyad, Gregory Piatetsky-Shapiro e Padhraic Smyth. From data mining to knowledge discovery in databases. American Association for Artificial Intelligence, páginas 37-54. URL http://www.kdnuggets.com/gpspubs/aimag-kdd-overview-1996-Fayyad.pdf. Citado na pág. 62

Fernandes e Ferreira (2011) Geraldo Wellington Rocha Fernandes e Carlos Alberto Rosa Ferreira. Dificuldades e soluções durante a produção de e-conteúdos para formação em ciência e tecnologia em Portugal. Revista Brasileira de Informática na Educação, 19(3). URL http://www.br-ie.org/pub/index.php/rbie/article/view/1278. Citado na pág. 1, 10

Gamma et al. (1994) Erich Gamma, Richard Helm, Ralph Johnson e John Vlissides. Design Patterns: Elements of Reusable Object-Oriented Software. Addison-Wesley Professional. Citado na pág. 55

Gerard (1967) Gerard. Shaping the mind: computers in education. Applied Science and Technological Progress, página 222. Citado na pág. 5

Haguenauer et al. (2009) Cristina Jasbinschek Haguenauer, Marcus Vinicius Freitas Mussi e Francisco Cordeiro Filho. Ambientes virtuais de aprendizagem: Definições e singularidades. Revista EducaOnline, 3(2). ISSN 1983-2664. Citado na pág. 2

Hodgins (2002) Wayne Hodgins. The future of learning objects. Em e-Technologies in Engineering Education: Learning Outcomes Providing Future Possibilities, páginas 76-82. URL http://dc. engconfintl.org/etechnologies/11. Citado na pág. 6, 7, 10

IEEE (2002) IEEE. IEEE Standard for Learning Object Metadata. IEEE Std 1484.12.1-2002, páginas i -32. doi: 10.1109/IEEESTD.2002.94128. Citado na pág. 6, 8

IMS (2006) IMS. Learning resource meta-data specification. IMS Global Learning Consortium. URL http://www.imsglobal.org/metadata/. Último acesso em 20/10/2012. Citado na pág. 8 
IMS (2007) IMS. IMS GLC learning technology satisfaction and trends: North american higher education. IMS Global Learning Consortium. URL http://www.imsglobal.org/ltst/getpdf.cfm? DocName=IMS\%20LTTrends\%20Feb07-public.pdf. Último acesso em 13/01/2012. Citado na pág. 9

Inep (2011) Inep. Resumo técnico: Censo da educação superior 2010, 2011. URL http://www. inep.gov.br/superior/censosuperior. Último acesso em 05/08/2012. Citado na pág. 1

Isotani (2005) Seiji Isotani. Desenvolvimento de ferramentas no iGeom: utilizando a geometria dinâmica no ensino presencial e a distância. Dissertação de Mestrado, Instituto de Matemática e Estatística - USP, São Paulo. Citado na pág. 15

Isotani e Brandão (2003) Seiji Isotani e Leônidas Brandão. Uma ferramenta para ensino de geometria dinâmica na internet: iGeom. Em Anais do IX Workshop de Informática na Educação. Citado na pág. 14

JISC (2012) JISC. About JISC, 2012. URL http://www.jisc.ac.uk/aboutus.aspx. Último acesso em 01/06/2012. Citado na pág. 21

Kamiya (2010) Reginaldo Rideaki Kamiya. iVProg: um sistema visual para ensino-aprendizagem de programação via web. Dissertação de Mestrado, Instituto de Matemática e Estatística - USP, São Paulo. Citado na pág. 15

Lam e Chan (2007) Ki-Tat Lam e Diana L. H. Chan. Building an institutional repository: sharing experiences at the HKUST Library. Hong Kong University of Science and Technology Institutional Repository, 23(3):310-323. URL http://hdl.handle.net/1783.1/2948. Citado na pág. 29

Lewis et al. (2012) Stuart Lewis, Kim Shepherd, Yin Yin Latt, Andrea Schweer e Adam Field. Repository as a Service (RaaS). Journal of Digital Information, 13(1). ISSN 1368-7506. URL http://journals.tdl.org/jodi/article/view/5872/5884. Citado na pág. 13

LInE (2012) LInE. LInE - Laboratório de Informática na Educação, 2012. URL http://line.ime. usp.br/. Último acesso em 20/11/2012. Citado na pág. 13

Lynch (2003) Clifford A. Lynch. Institutional Repositories: Essential infrastructure for scholarship in the digital age, Fevereiro 2003. URL http://www.arl.org/resources/pubs/br/br226/br226ir. shtml. Último acesso em 05/06/2012. Citado na pág. 12

McGreal (2004) Rory McGreal. Learning objects: A practical definition. International Journal of Instructional Technology and Distance Learning, 1(9). ISSN 1550-6908. Citado na pág. 5, 6, 7

McGreal (2007) Rory McGreal. A typology of learning object repositories, sep 2007. URL http://hdl.handle.net/2149/1078. Último acesso em 01/10/2012. Citado na pág. 12, 20

Melo e Nascimento (2007) Alexandre Altair Melo e Mauricio Garcia Nascimento. PHP Profissional. Novatec. ISBN 978-85-7522-141-9. URL http://www.novatec.com.br/livros/phppro/. Citado na pág. 10, 65, 66

Merrill (2000) David Merrill. Knowledge objects and mental models. Em International Workshop on Advanced Learning Technologies - IWALT, páginas 244 -246. doi: 10.1109/IWALT.2000. 890621. Citado na pág. 5, 6

Mikhail et al. (2012) Youssef Mikhail, Noha Adly e Magdy Nagi. Dar: A modern institutional repository with a scalability twist. Journal of Digital Information, 13(1). ISSN 1368-7506. URL http://journals.tdl.org/jodi/article/view/5396/5885. Citado na pág. 28

Moodle (2012) Moodle. Moodle statistics, 2012. URL https://moodle.org/stats. Último acesso em 18/11/2012. Citado na pág. 2, 10 
Moodle (2014a) Moodle. Moodle local plugins, 2014a. URL http://docs.moodle.org/dev/Local_ plugins. Último acesso em 10/01/2014. Citado na pág. 45

Moodle (2014b) Moodle. Moodle architecture, 2014b. URL http://docs.moodle.org/dev/ Moodle_architecture. Último acesso em 10/01/2014. Citado na pág. 44

Moran (2000) José Manuel Moran. Ensino e aprendizagem inovadores com tecnologias. Informática na Educação: Teoria e Prática, páginas 137-144. Citado na pág. 1

Nascimento et al. (2013) Mauricio G. F. Nascimento, Anarosa A. F. Brandão e Leônidas O. Brandão. A model to support a learning object repository for web-based courses. Em Proceedings of the 43th Frontiers in Education - FIE, páginas 548 - 552. Citado na pág. 17

Neven e Duval (2002) Filip Neven e Erik Duval. Reusable learning objects: a survey of lom-based repositories. Em In Proceedings of ACM Multimedia. ACM, Dec 2002. Accepted http://mm02.eurecom.fr, páginas 291-294. ACM Press. Citado na pág. 2, 19

Nibon (2008) Rogério Trévia Nibon. Identificação de aspectos positivos no desenvolvimento de objetos de aprendizagem em empresas nacionais. Dissertação de Mestrado, Universidade Federal de Pernambuco. Citado na pág. 10

Ochoa e Duval (2009) Xavier Ochoa e Erik Duval. Quantitative analysis of learning object repositories. Learning Technologies, IEEE Transactions on, 2(3):226-238. ISSN 1939-1382. doi: 10.1109/TLT.2009.28. Citado na pág. 2, 20

PMI (2012) PMI. PMBOK - Guia do conhecimento em gerenciamento de projetos. Project Management Institute. Citado na pág.

Polsani (2006) Pithamber Polsani. Use and abuse of reusable learning objects. Journal of Digital Information, 3(4). ISSN 1368-7506. URL http://journals.tdl.org/jodi/article/view/89/88. Citado na pág. 6

Retalis (2004) S. Retalis. Usable and interoperable e-learning resources repositories, 2004. Último acesso em 15/09/2012. Citado na pág. 11, 38

Rocha et al. (2011) Farley L. Rocha, Henrich N. de Moraes, Luciana B. W. Fabri, Tárik de J. Oliveira, Adriana C. R. Costa, Cristiane M. Netto, Helder R. da Costa e Rossana C. R. Morais. Repositórios de objetos de aprendizagem - um estudo exploratório. Em XXII Simpósio Brasileiro de Informática na Educação - SBIE, páginas 304-312. Citado na pág. 2, 20

Rodrigues (2011) Patrícia Alves Rodrigues. iTarefa: components Moodle para incorporar Módulos de Aprendizagem Interativa em cursos web. Dissertação de Mestrado, Instituto de Matemática e Estatística - USP, São Paulo. Citado na pág. 2, 15, 16

Rodrigues et al. (2010) Patrícia Alves Rodrigues, Anarosa Alves Brandão e Leônidas Brandão. Interactive Assignment: a Moodle component to enrich the learning process. Em Proceedings of the 40th Frontiers in Education - FIE. Citado na pág. 15

Romero e Ventura (2010) Cristóbal Romero e Sebastián Ventura. Educational data mining: A review of the state of the art. Systems, Man, and Cybernetics, Part C: Applications and Reviews, IEEE Transactions on, 40(6):601-618. ISSN 1094-6977. doi: 10.1109/TSMCC.2010.2053532. Citado na pág. 37, 62

Rosa e Brandão (2011) Eliane Marion Santa Rosa e Leônidas Brandão. Repositório para recursos digitais interativos, integrado ao ambiente Moodle. Em XXII Simpósio Brasileiro de Informática na Educação - SBIE, páginas 792-799. Citado na pág. 2, 17, 18, 44 
Sartori et al. (2009) Adriel Fernandes Sartori, Ewout ter Haar e Eugenio Maria de França Ramos. Uma análise exploratória de repositórios educacionais enquanto ambientes virtuais de aprendizagem na web moderna: o Portal do Professor. Em XVIII Simpósio Nacional de Ensino de Física - SNEF. URL http://www.sbf1.sbfisica.org.br/eventos/snef/xviii/. Citado na pág. 2

SHERPA (2006) SHERPA. SHERPA wins sparc europe award, 2006. URL http://www.sherpa. ac.uk/news/award.html. Último acesso em 01/06/2012. Citado na pág. 20

South e Monson (2000) Joseph South e David Monson. A university-wide system for creating, capturing, and delivering learning objects, 2000. URL http://reusability.org/read/chapters/ south.doc. Último acesso em 09/09/2012. Citado na pág. 11

Souza (1996) Paulo Renato Souza. Presidência da república - lei de diretrizes e bases da educação nacional (lei n. 9.394, de 20/12/1996), 1996. URL http://www.planalto.gov.br/ccivil_03/Leis/ L9394.htm. Último acesso em 05/08/2012. Citado na pág. 1

TIOBE (2012) TIOBE. TIOBE Programming Community Index for November 2012, 2012. URL http://www.tiobe.com/index.php/content/paperinfo/tpci/index.html. Último acesso em 15/11/2012. Citado na pág. 10

Welling e Thomson (2008) Luke Welling e Laura Thomson. PHP and MySQL Web Development. Addison-Wesley Professional, 4 ed. ISBN 978-0672329166. Citado na pág. 10

Wiley (2000) David Wiley. Connecting learning objects to instructional design theory: A definition, a metaphor, and a taxonomy, 2000. URL http://reusability.org/read/chapters/wiley.doc. Último acesso em 09/09/2012. Citado na pág. 5, 6 